\title{
Singlet-Oxygen-Mediated Inactivation of Acetylcholinesterase: A Comparison of Purified Enzyme in Solution and Enzyme Bound to K562 Leukemia Cells
}

Gail D. Deadwyler

Loyola University Chicago

Follow this and additional works at: https://ecommons.luc.edu/luc_diss

Part of the Biochemistry Commons

\section{Recommended Citation}

Deadwyler, Gail D., "Singlet-Oxygen-Mediated Inactivation of Acetylcholinesterase: A Comparison of Purified Enzyme in Solution and Enzyme Bound to K562 Leukemia Cells" (1997). Dissertations. 3424.

https://ecommons.luc.edu/luc_diss/3424

This Dissertation is brought to you for free and open access by the Theses and Dissertations at Loyola eCommons. It has been accepted for inclusion in Dissertations by an authorized administrator of Loyola eCommons. For more information, please contact ecommons@luc.edu. (c) $($ ) $\Theta \Theta$

This work is licensed under a Creative Commons Attribution-Noncommercial-No Derivative Works 3.0 License. Copyright @ 1997 Gail D. Deadwyler 
MEDICAL CENTER

LOYOLA UNIVERSITY CHICAGO

SINGLET-OXYGEN-MEDIATED INACTIVATION OF

ACETYLCHOLINESTERASE: A COMPARISON OF PURIFIED ENZYME IN SOLUTION AND ENZYME BOUND TO K562 LEUKEMIA CELLS

\author{
A DISSERTATION SUBMITTED TO \\ THE FACULTY OF THE GRADUATE SCHOOL \\ IN CANDIDACY FOR THE DEGREE OF \\ DOCTOR OF PHILOSOPHY
}

DEPARTMENT OF MOLECULAR AND CELLULAR BIOCHEMISTRY

BY

GAIL D. DEADWYLER

CHICAGO, ILLINOIS

MAY 1997 
Copyright by Gail D. Deadwyler, 1997

All rights reserved. 


\section{ACKNOWLEDGMENTS}

I would like to thank Dr. Jeffrey Kanofsky for his great support and guidance during my graduate training. I would like to thank Dr. Paul Sima for his invaluable assistance and advice. I would like to thank the Molecular and Cellular Biochemistry Department for their support, especially Dr. Richard Schultz, Dr. Allen Frankfater, Dr. William Simmons and Janet Flores. I would also like to thank Dr. Robert Wurster and Dr. Ronald Belusko for their comments and suggestions. Lastly, I would like to thank my family and friends for their patience and understanding. 


\section{TABLE OF CONTENTS}

ACKNOWLEDGEMENTS . . . . . . . . . . . . . . . iii

LIST OF ILLUSTRATIONS . . . . . . . . . . . . . . . . vi

LIST OF TABLES . . . . . . . . . . . . . . . . . . . viii

\section{CHAPTER}

1.

INTRODUCTION ................ 1

2.

REVIEW OF RELATED LITERATURE. . . . . . . . . . 4

Overview ................. 4

Singlet-Oxygen Chemistry . . . . . . . . . . 4

Structure And Function Of Human Erythrocyte

Acetylcholinesterase (ACE) . . . . . . . . . 12

Singlet-Oxygen-Mediated Acetylcholinesterase (ACE)

Inactivation And Singlet-Oxygen-Mediated

Cell Damage. . . . . . . . . . . . . . 15

Hypothesis. . . . . . . . . . . . . . 17

Specific Aims . . . . . . . . . . . 18

Significance ............. . . 20

3. MATERIALS AND METHODS ............. 22

Materials . . . . . . . . . . . . . 22

Experimental Methods. . . . . . . . . . . 23

K562 Erythroleukemia Cells . . . . . . . . . 23

Labeling Of K562 Cells With

5-(N-Hexadecanoyl)-Aminoeosin (E-16). . . . . . 24

Assay For E-16 In K562 Cells . . . . . . . . . . . . . . 24

Irradiation Of Purified Human Recombinant

Acetylcholinesterase (ACE) And K562 Cells . . . . . 25

Reciprocity Experiments For Human Recombinant

ACE In Solution And K562 Cells. . . . . . . . . 26

Assays For ACE On The Surface Of K562 Cells And For

Human Recombinant ACE In Solution . . . . . . . 27 
TO-PRO-3 Iodide Assay For K562 Cells. . . . . . . . . 28

Measurement Of Singlet-Oxygen Phosphorescence

Decay At $1270 \mathrm{~nm}$. . . . . . . . . . . 29

Lifetime Of Singlet Oxygen In Buffers

Containing Human Recombinant ACE. . . . . . 30

Singlet-Oxygen Quenching Constants . . . . . . . . 30

Measurements Of Singlet-Oxygen Quencher

And Deuterium-Oxide Solvent

Concentrations Within K562 cells. . . . . . . . 30

Statistical Analysis . . . . . . . . . . . . 32

4. RESULTS .................. . . . . . . . . .

Studies With Purified Acetylcholinesterase (ACE). . . . . . 33

Theoretical Mathematical Model Of

Singlet-Oxygen Quenching And Diffusion . . . . . 47

Studies With K562 Erythroleukemia Cells . . . . . . . 78

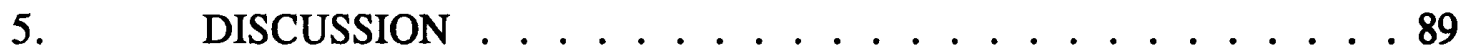

Studies With Purified Acetylcholinesterase (ACE). . . . . . 92 Theoretical Mathematical Model Of

Singlet-Oxygen Quenching And Diffusion . . . . . 96

Studies With K562 Erythroleukemia Cells . . . . . . . . 104

Summary And Conclusions . . . . . . . . . . . . 108

Photodynamic Therapy And

Possible Mechanisms Of Action . . . . . . . 111

REFERENCES . . . . . . . . . . . . . . . . . . 117

VITA ......................... 134 


\section{LIST OF ILLUSTRATIONS}

Figure

1. Effect Of Azide Anion Upon The Kinetics Of Inactivation Of Human Recombinant ACE By Eosin Y And Light. Water Solvent, pH 7.4. . . . . . . . . . . . . . 35

2. Effect Of Light Fluence Rate On The Inactivation Lifetime Of Human Recombinant ACE And Of ACE On The K562 Cells . . . . . . . . . . . . . . 37

3. Inhibition Of Human Recombinant ACE By Singlet-Oxygen Quenchers. Water Solvent, $\mathrm{pH}$ 7.4 . . . . . . . . 41

4. Inhibition Of Human Recombinant ACE By Singlet-Oxygen Quenchers. Deuterium-Oxide Solvent, pD 7.4 . . . . . . . 42

5. Geometry Of Theoretical Model. . . . . . . . . . . . . 49

6. The Theoretical Mathematical Model Depicted In Cartoon Fashion . . . . . . . . . . . . 58

7. Typical Stern-Volmer Plots For Solubilized Cell Pellets . . . . . . 60

8. Comparison Between Theory And Experiment For The K562 Cells. The Singlet-Oxygen Quencher Is Sodium Azide . . . . 66

9. Comparison Between Theory And Experiment For The K562 Cells. The Singlet-Oxygen Quencher Is Ni-Chelate 1 . . . . 67

10. Comparison Between Theory And Experiment For The K562 Cells. The Singlet-Oxygen Quencher Is Ni-Chelate 2 . . . . 68

11. Comparison Between Theory And Experiment For The K562 Cells. Deuterium-Oxide Solvent . . . . . . . . . 69 
13. Comparison Between Theory And Experiment. SingletOxygen Lifetime In The Cytoplasm Is Held Constant At $1 \mu \mathrm{s}$. . . . . . . . . . . . . . . . . 74

14. Comparison Between Theory And Experiment. SingletOxygen Lifetime In The Cell Membrane Is Held Constant At $1 \mu \mathrm{s}$. . . . . . . . . . . . . . 75

15. Net Fluorescence Intensity Versus Varying E-16 Concentration.

The E-16 Concentrations Are 0, 0.25, 0.50, 0.75, 1.0, 1.5 , And $2.0 \mu \mathrm{M}$, Respectively . . . . . . . . . . . 82

16. Effect Of Azide Anion Upon The Kinetics Of ACE Inactivation On The Surface Of The K562 Cells . . . . . . 84

17. Protection Of Cell Membrane Integrity In The K562 Cells. Sodium Azide Is The Quencher . . . . . . . . . . . .86 


\section{LIST OF TABLES}

Table

1. Comparison Of "Apparent" Singlet-Oxygen Quenching Constants Determined From The Inhibition Of The Inactivation Of Human Recombinant ACE And Singlet-Oxygen Quenching Constants Determined By Standard Methods . . . . . . . . . . . 45

2. Parameters Used For Theoretical Calculations . . . . . . . . . . . . 51

3. Effect Of Singlet-Oxygen Quenchers And Of Deuterium-Oxide Solvent

On Singlet-Oxygen Quenching By Cell Pellets. . . . . . . . 63

4. Theoretical Effect Of Various Parameters Upon The Singlet-Oxygen

Exposure To ACE On The K562 Cell Surface. Quenchers Added

To The External Buffer. . . . . . . . . . . . . . . . . . . . . . 77

5. Comparison Of Photochemical Inactivation Of ACE On K562 Leukemia Cells Caused By E-16 And Eosin Bound To Dextran . . . . . . . . 79

6. Protection Of Cell Membrane Integrity On The K562 Cells Using Various

Singlet-Oxygen Quenchers ..............88 


\section{CHAPTER 1 \\ INTRODUCTION}

Singlet oxygen is a very reactive oxygen species. It is reactive because it has no unpaired electrons and has $23 \mathrm{kcal} / \mathrm{mol}$ more energy than ground state oxygen (1). Ground state oxygen, on the other hand, contains two unpaired electrons and its reactivity is limited by the Wigner spin conservation rule (2). Due to the high reactivity of singlet oxygen, it has been shown to react with many biological molecules, particularly proteins (3-5). Certain photosensitizers generate singlet oxygen and a corresponding cell toxicity in biological systems $(6,7)$. The evidence supporting a critical role for singlet-oxygen-mediated cell toxicity has been based on the effects of deuteriumoxide solvent and various singlet-oxygen quenchers (5). Also, much of the evidence that supports singlet-oxygen-mediated cell death is based on simple model systems $(8,9)$. In these simple model systems, the generation of singlet oxygen is usually easy to measure because the lifetime of singlet oxygen is relatively long (10). The lifetime of singlet oxygen is shortened by adding singlet-oxygen quenchers or lengthened by changing the solvent from water to deuterium oxide. These experimental manipulations can cause large changes in the singlet-oxygen concentration in model systems. For example, target molecule oxidation can be increased by a factor of 21 when water is replaced by deuterium oxide $(11,12)$.

Since living cells are complex, it is not entirely clear whether the results from 
the simple model systems apply directly to intact cells. The measurement of singletoxygen generation within intact cells has proven to be difficult because of the short singlet-oxygen lifetime within cells, between 1.0 and $0.10 \mu \mathrm{s}$ (13). Since the singletoxygen lifetime within cells is very short, the effects of deuterium-oxide solvent and modest concentrations of singlet-oxygen quenchers should be very small. This is because a reasonable assumption was made that most of the singlet oxygen generated will react with the high concentration of biological molecules present within the cell and become quenched. However, for some cell lines and photosensitizers, the effects of deuteriumoxide solvent and various singlet-oxygen quenchers have been reported to be much larger than expected (14).

Acetylcholinesterase (ACE) is present on the surface of many cell types. It is covalently anchored to the outer cell membrane via a glycoinositol phospholipid $(15,16)$. Many investigators have found that ACE is inactivated by singlet oxygen (17-20). Also, there has been evidence that suggests ACE is relatively insensitive to other reactive intermediates that may be produced in photosensitization reactions such as, hydroxyl radical and superoxide ion $(19,20)$. Thus, under appropriate photosensitization conditions, ACE can be used as a probe of singlet-oxygen-induced membrane damage.

As stated previously, there is some discrepancy in the literature as to the mechanisms by which deuterium-oxide solvent and various singlet-oxygen quenchers influence singlet-oxygen-mediated cell death (10). One approach to the analysis of singlet-oxygen-mediated cytotoxicity is to use a mathematical model that accounts for singlet-oxygen quenching and diffusion in various cell compartments. Baker and Kanofsky have detected singlet-oxygen emission in L1210 leukemia cells labeled with 
polyporphyrins (21) and 5-(N-hexadecanoyl)-aminoeosin (E-16) (22). The kinetics of singlet-oxygen emission and absolute intensity of singlet-oxygen emission from E-16labeled L1210 cells were in agreement with a theoretical mathematical model of singletoxygen quenching and diffusion (22).

In this dissertation, a series of experiments that looked at the effects of deuterium-oxide solvent and various singlet-oxygen quenchers upon singlet-oxygenmediated ACE inactivation and singlet-oxygen-mediated cell damage are described. The inactivation of $\mathrm{ACE}$ in aqueous solution (an example of a simple model system) was compared with the inactivation of ACE bound to the surface of K562 cells. These experiments were performed in order to test the hypothesis that the effects of deuteriumoxide solvent and various singlet-oxygen quenchers upon singlet-oxygen-mediated ACE inactivation and singlet-oxygen-mediated cell damage can be predicted by mathematical equations that model singlet-oxygen diffusion rates and lifetimes. 


\section{CHAPTER 2}

\section{REVIEW OF RELATED LITERATURE}

\section{Overview}

The purpose of this project was to determine whether the effects of deuteriumoxide solvent and various singlet-oxygen quenchers upon singlet-oxygen-mediated cell damage and singlet-oxygen-mediated ACE inactivation could be predicted by mathematical equations that model singlet-oxygen diffusion rates and lifetimes. Therefore, in the following sections, singlet-oxygen chemistry, the structure and function of ACE, recent accomplishments in singlet-oxygen-mediated ACE inactivation and cell membrane integrity, and the significance of this project will be discussed.

\section{Singlet-Oxygen Chemistry}

Photosensitized oxidations have been of interest to biologists and chemists since Raab discovered in 1900 that microorganisms are killed by light in the presence of photosensitizers and oxygen (23). These conditions cause pathological effects in many organisms, including humans (23). These effects, referred to as "photodynamic action", cause cell damage, induction of mutations or cancer, and cell death as a result of 
photooxidation of sensitive cell constituents (23). Nucleic acids can also become damaged largely as a result of the oxidation of guanine residues, both invitro and invivo (23). In addition, enzymes can become deactivated, polypeptides and proteins can become damaged, and carbohydrates can become degraded (23).

There have been many advances in the understanding of the mechanism of photosensitized oxidations. The term "photosensitization" refers to a light-activated process in which the presence of a photosensitizer, usually a dye or biological pigment, leads to changes in a substrate that otherwise would not take place (24). The pathways of photosensitized reactions are divided into two broad categories, called Type I and Type II reactions, respectively (24). The pathway that is actually followed in a given system is a sensitive function of the prevailing conditions (23). Usually the reactions proceed by way of an excited triplet-state sensitizer because it has a much greater lifetime than the excited singlet-state sensitizer (23). An excited triplet-state sensitizer is any species that contains two unpaired electrons. An excited singlet-state sensitizer is any species that contains paired electrons. As shown below, the ground-state photosensitizer absorbs a photon of light, resulting in the formation of the excited singlet-state photosensitizer.

$$
S+h v \rightarrow S^{*}(\text { singlet }) \rightarrow S^{*}(\text { triplet }) \rightarrow \text { reaction }
$$

where $S$ is the ground-state photosensitizer, $S^{*}$ (singlet) is the excited singlet-state photosensitizer, and $S^{*}$ (triplet) is the excited triplet-state photosensitizer. This excited singlet-state photosensitizer then undergoes intersystem crossing spontaneously to form 
the excited triplet-state photosensitizer (25). Thus, the most effective photosensitizers used in photosensitized oxidations are those which give a long-lived triplet state in high quantum yield (23).

Many photosensitized processes in biological systems consume molecular oxygen and are thus known as aerobic photooxidations (23). Within this category there are two types of reactions, those in which the primary interaction of the excited triplet-state photosensitizer is with the substrate (Type I) and those in which the interaction is with oxygen (Type II) (23). The efficiency of each path depends on the relative values of the oxygen and substrate concentrations, the rates of reaction of the excited triplet-state photosensitizer with the substrate and with oxygen and the rate of excited triplet-state photosensitizer decay (23). Since this project is concerned with singlet-oxygen-mediated ACE inactivation and singlet-oxygen-mediated cell damage, the Type II process will be discussed.

In a Type II process, the excited triplet-state photosensitizer reacts with oxygen in its native ground state via energy transfer to form singlet oxygen as shown below (23).

$$
S^{*}(\text { triplet })+\mathrm{O}_{2}\left({ }^{3} \Sigma_{g}^{-}\right) \rightarrow S+O_{2}\left({ }^{1} \Delta_{g}\right)
$$

The excited triplet-state photosensitizer decays back to the ground state after reacting with ground-state oxygen. Oxygen is very reactive when it is in the singlet state. In this state, it has no unpaired electrons and has $23 \mathrm{kcal} / \mathrm{mol}$ more energy than ground-state oxygen (1). In contrast, ground-state oxygen has an unusual electronic structure 
consisting of two unpaired electrons (1). Any molecule that reacts with ground-state oxygen must have unpaired electrons. As a result, the kinetic reactivity of ground-state oxygen is severely restricted by the Wigner spin conservation rule (2). While other electronically excited states of oxygen exist, it is the ${ }^{1} \Delta_{\mathrm{g}}$ state of oxygen that has been implicated in the biological damage caused by light and many photosensitizing agents (1). In the biological environment, the half-life of singlet oxygen ranges from 1.0 to $0.10 \mu \mathrm{s}$, during which time it can diffuse mean radial distances of at least $100 \mathrm{~nm}$ (26). Thus, singlet-oxygen can react at loci remote from the site of generation and cause biological damage (26).

Singlet oxygen has been shown to react with many important constituents of cells, including bilirubin, amino acids, proteins, cholesterol and the bases of nucleic acids (35). Nilsson et al. performed experiments that constituted the first proof that singlet oxygen is involved in the photooxidation of three amino acids: tryptophan, methionine and histidine (5). In these experiments, a pulse of red light from a ruby laser (20 nsec duration, $1 \mathrm{~J}$ energy) was used to produce about $5 \times 10^{-5} \mathrm{M}$ singlet oxygen in $<200$ nsec in an oxygenated solution of methylene blue in 1:1 water-methanol. Since singlet oxygen reacts efficiently with 1,3-diphenylisobenzofuran (DPBF), the rate of bleaching of this colored acceptor was used to measure the lifetime of singlet oxygen. The authors found that when tryptophan $\left(5 \times 10^{-3} \mathrm{M}\right)$, histidine $\left(4 \times 10^{-3} \mathrm{M}\right)$, and methionine $\left(5 \times 10^{-3}\right.$ M) were added to the 1:1 water-methanol solution, a decrease in the duration of photobleaching due to the deactivation of singlet oxygen was observed. This contrasted with the quenching of the triplet-state photosensitizer by the DPBF acceptor, which produced only a decrease in the yield of singlet oxygen without affecting its decay rate. 
The addition of sodium azide $\left(10^{-2} \mathrm{M}\right)$, a singlet-oxygen quencher, at a concentration too low to affect the triplet state of methylene-blue, inhibited the photooxidation of these amino acids to a degree predictable from the lifetime shortening of singlet oxygen by sodium azide.

Perhaps, the most unambiguous test for a singlet-oxygen reaction was based on the comparison of the photooxidation of tryptophan in $1: 1 \mathrm{H}_{2} \mathrm{O}: \mathrm{CH}_{3} \mathrm{OH}$ and $1: 1$ $\mathrm{D}_{2} \mathrm{O}: \mathrm{CD}_{3} \mathrm{OD}(5)$. The lifetime of singlet oxygen in $1: 1 \mathrm{H}_{2} \mathrm{O}: \mathrm{CH}_{3} \mathrm{OH}$ is $3.5 \mu \mathrm{s}$ and 35 $\mu \mathrm{S}$ in 1:1 $\mathrm{D}_{2} \mathrm{O}: \mathrm{CD}_{3} \mathrm{OD}$. Nilsson et al. predicted that if the acceptor concentration was kept low enough to prevent significant quenching of singlet oxygen, a 10 -fold increase in the efficiency of photooxidation would be expected in going from the protonated to the deuterated solvent. This was exactly the result he found for the photooxidation of tryptophan. Thus, the use of deuterated solvents can provide a powerful diagnostic tool for identification of singlet-oxygen reactions due to the extraordinary large deuterium effect on the singlet-oxygen lifetime.

Singlet oxygen can also react with cholesterol to form specific singlet-oxygen products. Korytowski et al. have identified $5 \alpha$ and $6 \beta$ cholesterol hydroperoxides that are characteristic of a Type II singlet-oxygen mediated process (27). These authors studied the photooxidation of cholesterol in homogeneous solution using methanol and pyridine solvents and in radiolabeled L1210 murine leukemia cells. The photosensitizer used in these experiments was chloroaluminum phthalocyanine tetrasulfonate (AlPcS) and the light source was a quartz-halogen lamp. The authors used reverse phase high performance liquid chromatography (HPLC) with reductive mode electrochemical detection in conjunction with normal phase HPLC with radiochemical detection, for 
highly sensitive and selective identification and quantitation of membrane cholesterol hydroperoxides. Using these methods, Korytowski et al. isolated the singlet-oxygen specific products, $5 \alpha$ and $6 \beta$ cholesterol hydroperoxides in relatively high yields from the radiolabeled $\mathrm{L} 1210$ cells (27).

Much of the evidence in the literature that supports singlet-oxygen-mediated cell death is based on simple chemical and biochemical model systems rather than from studies of living cells $(8,9)$. These model systems typically consist of oxygen, some type of photosensitizer and a target molecule. Singlet oxygen is generated by a Type II mechanism in these simple model systems (10). As illustrated previously:

$$
\begin{gathered}
S+h v \rightarrow S^{*} \text { (singlet) } \\
S^{*}(\text { singlet }) \rightarrow S^{*} \text { (triplet) } \\
S^{*}(\text { triplet })+\text { Solvent } \rightarrow S+\text { Solvent } \\
S^{*}(\text { triplet })+O_{2}\left({ }^{3} \Sigma_{g}{ }^{-}\right) \rightarrow S+O_{2}\left({ }^{1} \Delta_{g}\right) \\
O_{2}\left({ }^{1} \Delta_{g}\right)+T \rightarrow T_{o x} \\
O_{2}\left({ }^{1} \Delta_{g}\right)+\text { Solvent } \rightarrow O_{2}\left({ }^{3} \Sigma_{g}{ }^{-}\right)+\text {Solvent }
\end{gathered}
$$


where $S$ is the ground-state photosensitizer, $S^{*}$ (singlet) and $S^{*}$ (triplet) are the excited singlet and triplet-state photosensitizer, respectively, $T$ is the target molecule, $T_{o x}$ is the oxidized target molecule, $\mathrm{O}_{2}\left({ }^{1} \Delta_{\mathrm{g}}\right)$ is singlet oxygen and $\mathrm{O}_{2}\left({ }^{3} \Sigma_{\mathrm{g}}^{-}\right)$is ground-state oxygen. If the rate constants for Reactions 3-8 are known and the concentrations of photosensitizer, oxygen and target molecule are known, one can calculate an accurate quantum yield value for the photooxidation of the target molecule.

Since the lifetime of singlet oxygen is relatively long in these simple model systems, it is generally easy to measure the generation of singlet oxygen (10). The lifetime of singlet oxygen in pure water is $3.1 \mu \mathrm{s}(11)$ and $68 \mu \mathrm{s}$ in pure deuterium-oxide solvent (12). Thus, target molecule oxidation can be increased, theoretically, by a factor of 21 when water is replaced by deuterium-oxide solvent. In addition, the use of modest concentrations of singlet-oxygen quenchers will reduce target molecule oxidation. For example, the addition of $10.0 \mathrm{mM}$ histidine (singlet-oxygen quenching constant $4.4 \times 10^{7}$ $\mathrm{M}^{-1} \mathrm{~S}^{-1}$ ) to a simple model system will reduce target molecule oxidation by as much as $59 \%$ with water solvent and $97 \%$ with deuterium-oxide solvent (10). The detection of singlet oxygen can be measured with traps such as cholesterol (see Korytowski et al.) or by measuring the emission of singlet oxygen at $1270 \mathrm{~nm}$ using steady-state (28) or timeresolved methods (29). Using direct photomultiplier detection with wide observation slits on the spectrometer and a phosphoroscopic light chopper, Krasnovsky was the first to demonstrate the singlet-oxygen infrared emission at $1268 \mathrm{~nm}$ by direct spectroscopic observation in dye sensitization using various chlorophylls and related molecular dyes in $\mathrm{CCl}_{4}$ solution (30).

As discussed previously, much of the evidence that supports singlet-oxygen- 
mediated cell damage is based on simple model systems. Living cells are much more complex and it is not clear whether the results from these simple model systems apply directly to intact cells. Evidence in the literature states that the lifetime of singlet oxygen in the cytoplasm and the membrane ranges from 1.0 to $0.10 \mu \mathrm{s}$ (13). Since the singletoxygen lifetime within cells is very short, the effects of deuterium-oxide solvent and modest concentrations of singlet-oxygen quenchers should be very small. This is because a reasonable assumption was made that the majority of the singlet oxygen generated will react with the high concentration of biological molecules present within the cell and become quenched. Very little of the singlet oxygen will be quenched by the water solvent in the buffer, so replacing the water solvent with deuterium oxide (which is much less effective in quenching singlet oxygen) should only have a minor effect. Similarly, a very large concentration of singlet-oxygen quencher needs to be added to the cell in order to effectively compete with the large concentration of biological molecules present within the cell. However, for some cell lines and photosensitizers, the effects of deuterium-oxide solvent and singlet-oxygen quenchers are much larger than expected. For example, when HeLa cells were incubated with the membrane-bound photosensitizer, toluidine blue, a deuterium-oxide solvent effect of about 1.4 was observed by T. Ito (14). Accordingly, these cells were killed 1.4 times faster in deuterium-oxide solvent than in water solvent. Experimental results also showed that when $1.0 \mathrm{mM}$ histidine in water was added to this system, over $90 \%$ of the cells survived a 30 minute irradiation time, whereas about $70 \%$ of the cells survived in water solvent alone and only $50 \%$ survived in deuterium-oxide solvent. 


\section{Structure And Function Of Human Erythrocyte Acetylcholinesterase (ACE)}

Acetylcholinesterase (ACE) occurs in multiple molecular forms in different tissues of vertebrates and invertebrates (31). Some of these forms are soluble while others are associated with the extracellular surface of cells by different mechanisms of attachment (32-34). Members of one subset of attached forms consist of two or three tetramers of catalytic subunits linked to a collagen-like structure that allows attachment to the basal lamina (31). A second class of cell-bound forms consists of tetramers of catalytic subunits attached to a $20-\mathrm{kDa}$ non-catalytic subunit embedded in the plasma membrane (31). Acetylcholinesterase (ACE) on the surface of human erythrocytes is an amphipathic globular dimeric protein that is anchored in the plasma membrane by a covalently attached glycoinositol phospholipid $(15,16)$. Cross-linking studies have confirmed the structure of human ACE and showed that the dimer is built up of two identical subunits which are interlinked by disulfide bonds (35). Purified human ACE has been found to have a molecular weight of about 160,000 with the two identical subunits having a molecular weight of about 80,000 (35).

Acetylcholinesterase (ACE) is a serine hydrolase that plays a key role in cholinergic transmission (35). It is localized in certain areas of the central nervous system and in organs that are controlled by the autonomic (parasympathetic) nervous system such as, various secretory glands and parts of the gastrointestinal tract (35). Furthermore, it is present in neuromuscular junctions where impulses are transmitted from nerves to skeletal muscle fibers (35). At all of these sites, acetylcholine acts as the neurotransmitter substance (35). By rapid hydrolysis of the neurotransmitter, ACE 
effectively terminates the chemical impulse (35). This efficient inactivation prevents reexcitation after the stimulated cell has recovered from the first action potential (35). The importance of ACE is best documented by the fact that irreversible inhibition induces a constant excitation of the parasympathetic nervous system and muscle tissues which ultimately leads to death (36). No well-defined role has been ascribed to ACE in erythrocyte membranes (37).

Many studies to elucidate structural and functional properties of ACE were carried out with enzyme purified from the electric organ of the electric ray, Torpedo californica (35). The relative abundance of ACE in this electric ray and the presence of multiple molecular forms makes this enzyme source well suited for comparative studies of primary structures (38). The three-dimensional structure of ACE was determined from Torpedo californica by X-ray crystallography (39). The ACE molecule was found to have an ellipsoidal shape with dimensions about $45 \AA$ by $60 \AA$ by $65 \AA$ (39). It belongs to the class of $\alpha / \beta$ proteins and consists of a 12 -stranded central mixed $\beta$ sheet surrounded by $14 \alpha$ helices (39). The first and last pairs of strands each form $\beta$-hairpin loops that are only loosely hydrogen bonded to the eight central superhelically twisted strands (39).

Perhaps, the most remarkable feature of the structure is a deep and narrow gorge, about $20 \AA$ long, that penetrates halfway into the enzyme and widens out close to its base (39). This cavity is called the "active site gorge" because it contains the ACE catalytic triad (39). The catalytic triad, Serine $200-$ Histidine $440-$ Glutamic acid 327 , is located near the bottom of the gorge (40). This "active site gorge" is also lined with the rings of 14 aromatic amino acid residues which account for about $40 \%$ of its surface area (40). 
The presence of tryptophan in the active site of ACE was also predicted by spectroscopic and chemical modification studies (41). In an affinity-labelling study of Weise et al., Tryptophan-84 was identified as being part of the putative "anionic" binding site for the trimethylammonium group of acetylcholine (42). Kinetic studies have also indicated that ACE contains an esteratic subsite which interacts with the ester-bond region and mediates catalysis (43).

Site-directed mutagenesis was used to analyze the catalytic triad of recombinant human ACE (43). The putative three-dimensional locations of the human ACE residues targeted for mutagenesis were deduced from the X-ray structure of Torpedo ACE (43). Human ACE and Torpedo ACE are likely to have a similar fold as indicated by sequence homology (44) and comparative modeling studies (45). Shafferman et al. determined that Serine-203 and Histidine-447 of human ACE were analogous to Serine-200 and Histidine440 of Torpedo ACE (43). Also, Glutamic acid-334 in human ACE was found to be analogous to Glutamic acid-327 of Torpedo ACE (43). This was the first biochemical evidence for the involvement of a glutamate in a hydrolase triad of human ACE, thus supporting the use of the X-ray crystal structure of the Torpedo californica ACE as a model for human ACE (39). Evidence for the involvement of Serine-203, Histidine-447 and Glutamic acid-334 in the catalytic triad of human ACE was provided by substitution of these amino acid residues for alanine residues (43). Of the 20 amino acid positions mutated so far in human ACE, these were unique in abolishing detectable enzymatic activity, yet allowing proper production, folding and secretion (43). 


\section{Singlet-Oxygen-Mediated Acetylcholinesterase (ACE) Inactivation And Singlet-}

\section{Oxygen-Mediated Cell Damage}

In the literature, many authors have found that ACE is inactivated by singlet

oxygen. The inhibition of ACE in erythrocyte membranes has been studied in many intensity and wavelength-dependent photosensitization experiments because it is a relatively simple and biologically relevant endpoint (46). For example, Lambert et al. studied the intensity dependence of the rose bengal-photosensitized inhibition of red blood cell ACE (20). In these experiments, red blood cell membrane suspensions containing $5.0 \mu \mathrm{M}$ rose bengal were irradiated with $532 \mathrm{~nm}, 8 \mathrm{~ns}$ laser pulses with energies between 1 and $98.5 \mathrm{~mJ}$. A constant dose (7J) was delivered to all samples by varying the total number of pulses. At incident energies greater than about $4.5 \mathrm{~mJ} /$ pulse, the efficiency for photosensitized enzyme inhibition decreased as the energy/pulse increased. The depletion of the ground-state photosensitizer molecules by the large number of photons/pulse explained the decreased efficiency for photosensitized enzyme inhibition as the energy/pulse increased. The number of singlet-oxygen molecules produced at each intensity was calculated from a mathematical model and from laser flash photolysis results. The results indicated that the photosensitized inhibition of ACE was exclusively mediated by singlet oxygen, even at the highest laser intensities employed. There has also been evidence that suggests $\mathrm{ACE}$ is relatively insensitive to other reactive intermediates that may be produced in photosensitization reactions such as, hydroxyl radical and superoxide ion $(19,20)$. Thus, in appropriately selected conditions, ACE may be expected to be a reliable probe of singlet-oxygen exposure at the cell membrane 
surface.

As stated above, the inactivation of ACE, under appropriately selected conditions, may be an reliable indicator of the cell membrane exposure to singlet oxygen. Determining the effects on cell membrane integrity can be another indicator of the cell membrane exposure to singlet oxygen. Cell membranes are critical sites for photosensitized damage to cells (17). However, little is known about which sites in the cell membranes are most sensitive to photosensitized damage and how the sensitivity of these sites varies with the location or distribution of the dye molecules in the cell membrane (17). Knowledge of this may lead to schemes for targeting of specific sites in cell membranes (17).

Kochevar et al. assessed membrane integrity in rose bengal and merocyanine 540-labeled $\mathrm{P}_{388 \mathrm{D}_{1}}$ cells (a monocyte/macrophage line) by Trypan Blue exclusion (17). Rose bengal and merocyanine 540 are photosensitizers that both localize in the cell membrane and produce singlet oxygen $(6,7)$. The premise of this assay is that undamaged cells are not permeable to Trypan Blue and damaged cells are permeable to this dye. Cells that take up Trypan Blue are then counted with a hematocytometer. The authors found that a significant amount of chemical damage must occur to membrane components in order to produce a measurable change in permeability to Trypan Blue (17). Kochevar et al. suggested that the specific damage to cell membranes may involve both protein and lipid sites (17). Thus, assessing cell membrane integrity can be another indicator of the cell membrane exposure to singlet oxygen.

In the above mentioned sections, singlet-oxygen chemistry, structure and function of ACE, and recent accomplishments in singlet-oxygen-mediated ACE inactivation and 
cell membrane integrity were discussed. The purpose of this dissertation was to perform a series of experiments that investigated the effects of deuterium-oxide solvent and various singlet-oxygen quenchers upon singlet-oxygen-mediated ACE inactivation and singlet-oxygen-mediated cell damage. The inactivation of ACE in aqueous solution (an example of a simple model system) was compared to the inactivation of ACE bound to the surface of K562 cells. These experiments were performed in order to test the hypothesis that the inactivation of ACE on the K562 cell surface and singlet-oxygenmediated cell damage can be predicted by mathematical equations that model singletoxygen diffusion rates and lifetimes. Analysis of the data using this model is expected to provide an estimate of the lifetime of singlet oxygen close to the surface of the cell. John G. Parker has carried out a similar analysis of the effects of deuterium-oxide solvent on photosensitized cytotoxicity (private communication).

\section{Hypothesis}

The overall hypothesis of this dissertation is two-fold. First, the inactivation of acetylcholinesterase (ACE), an enzyme located on the outer cell surface of K562 erythroleukemia cells, is a good indicator of the cell membrane exposure to singlet oxygen. Second, the effects of deuterium-oxide solvent and various singlet-oxygen quenchers upon singlet-oxygen-mediated ACE inactivation and singlet-oxygen-mediated cell damage can be predicted by mathematical equations that model singlet-oxygen diffusion rates and lifetimes. 


\section{Specific Aims}

In order to test these hypotheses, a series of experiments were performed.

\section{Specific Aim 1}

Model studies were carried out in which the photochemical inactivation of ACE was studied in solution. Eosin $\mathrm{Y}$ was the photosensitizer used to generate singlet oxygen in these experiments. The deuterium-oxide solvent effect and the effect of several singlet-oxygen quenchers: methionine, (disodium [(NN'-ethylene)bis(5sulphosalicylideneimminato)]nickelate (II) (Ni-chelate 1$)$, disodium [(NN'-2,3 propionic acid)bis(5-sulphosalicylideneimminato)]nickelate (II) (Ni-chelate 2), and sodium azide were determined and compared with the expected theoretical effects.

\section{Specific Aim 2}

The effect of light intensity on the rate of ACE inactivation in solution was studied. For example, if the light intensity was decreased by a factor of 2 , it should then take twice as long to inactivate the enzyme. This experiment tested for reciprocity.

\section{Specific Aim 3}


studied. The lipophilic anionic photosensitizer used to generate singlet oxygen was 5-(Nhexadecanoyl)-aminoeosin (E-16). In addition, the effects of light intensity, deuteriumoxide solvent versus water solvent, and the effects of the previously mentioned singletoxygen quenchers, except methionine, upon the rate of $\mathrm{ACE}$ inactivation were determined.

\section{Specific Aim 4}

Control experiments were carried out in which the rate of ACE inactivation on the surface of the K562 cells using eosin bound to high molecular-weight dextran, a water-soluble photosensitizer that does not bind to the cell surface, was measured. The amount of ACE cleaved from the cell surface during irradiation and the amount of the lipophilic anionic photosensitizer (E-16) that partitioned into the K562 cell membranes was measured. Also, the potential release of significant amounts of the K562 cell contents into the buffer during photosensitization was assessed.

\section{Specific Aim 5}

Finally, the effect on cell membrane integrity as a result of changes in singletoxygen concentration caused by the previously mentioned singlet-oxygen quenchers, except methionine, were studied. Membrane integrity was assessed by DNA-staining with the normally impermeable dye TO-PRO-3 iodide. 
From these experiments, it was determined whether the effects of deuterium-oxide solvent and various singlet-oxygen quenchers upon singlet-oxygen-mediated cell damage and singlet-oxygen-mediated ACE inactivation could be predicted by mathematical equations that model singlet-oxygen diffusion rates and lifetimes.

\section{Significance}

Photosensitizer-based therapies have been under investigation for some time and several thousand patients have been treated under various protocols (47-54). The use of photosensitizers and bronchoscopic light delivery has produced long-term remissions in early-stage non-small-cell lung cancer (50). Photosensitizer-based treatment of some systemic T-cell lymphomas (Sezary syndrome) has now been approved in the United States (51). Recent studies with obstructing esophageal cancer has shown that photodynamic therapy produces more durable relief of esophageal obstruction and improved performance status of patients when compared to laser tissue ablation without the use of a photosensitizer (52). Photosensitizer-based treatment of obstructing esophageal cancer has now been approved by the Federal Drug Administration. Protocols in a variety of other cancers and in the purging of bone marrow preparations of cancer cells prior to reinfusion in autologous bone marrow transplants are being evaluated $(53,54)$.

Singlet oxygen is believed to be the major mediator of cytotoxicity in these photosensitizer-based therapies. Since cancer is the second leading cause of morbidity and mortality in the United States, an enhanced understanding of photosensitizer-based 
therapies should lead to improvements in these forms of cancer treatment and ultimately to better patient care. Perhaps, the use of a theoretical mathematical model derived from the known properties of singlet oxygen, as presented in this dissertation, can lead to unique insights into the mechanisms of photosensitization. Since this model was used with K562 erythroleukemia cells, other malignant cell lines can ideally be used in the same manner. If the theoretical mathematical model predicts a large singlet-oxygen lifetime in the cytoplasm and the cell membrane, the model can potentially be used to select conditions that optimize the selectivity of photosensitization reactions to kill malignant cells while sparing normal cells. 


\section{CHAPTER 3}

\section{MATERIALS AND METHODS}

\section{$\underline{\text { Materials }}$}

The K562 cells were purchased from American Type Culture Collection (Rockville, MD). Dulbecco's phosphate-buffered saline was purchased from BioWhittaker (Walkersville, MD). Deuterium-oxide solvent (99.9\%) was purchased from Cambridge Isotope Laboratories (Andover, MA). Buffers made with deuteriumoxide solvent were adjusted to $\mathrm{pD}$ 7.4. Using the relationship described by Salomma et $a l .$, the $\mathrm{pD}$ is equal to the $\mathrm{pH}$ measured with a glass electrode plus 0.40 (55). Sodium azide was purchased from Fisher Scientific Co. (Pittsburgh, PA). Eosin Y was purchased from Matheson Coleman and Bell (Norwood, OH). Meso-tetra(4sulfonatophenyl)porphine (TPPSO) was purchased from Porphyrin Products (Logan, UT). The singlet-oxygen quenchers: disodium [(NN'-ethylene)bis(5sulphosalicylideneimminato)]nickelate(II) (Ni-chelate 1$)$ and disodium [(NN'-2,3 propionic acid)bis(5-sulphosalicylideneimminato)]nickelate(II) (Ni-chelate 2) were prepared by the method according to Botsivali et al. (56). Molecular Probes, Inc. (Eugene, OR) was the source of 5-(N-hexadecanoyl)-aminoeosin (E-16), eosin bound to high molecular-weight dextran and TO-PRO-3 iodide. Human recombinant 
acetylcholinesterase (ACE), RPMI-1640 with 25 mM HEPES and L-glutamine, 5000 units $/ \mathrm{ml}$ penicillin and $5.0 \mathrm{mg} / \mathrm{ml}$ streptomycin solution, iron-supplemented calf serum, glucose, methionine, acetylthiocholine chloride, 5,5'-dithio-bis(2-nitrobenzoic acid) (DTNB), sodium lauryl sulfate (SLS), and Triton X-100 were purchased from Sigma Chemical Co. (St. Louis, MO).

\section{Experimental Methods}

\section{K562 Erythroleukemia Cells}

The $\mathrm{K} 562$ cells were maintained at $37^{\circ} \mathrm{C}$ in their logarithmic growth phase and harvested when the cell density reached $1 \times 10^{6}$ cells $/ \mathrm{ml}$. The cell culture media consisted of $84 \%$ RPMI-1640 with $25 \mathrm{mM}$ HEPES and L-glutamine, $15 \%$ heatinactivated iron-supplemented calf serum and $1 \%$ of 5000 units $/ \mathrm{ml}$ penicillin and 5.0 $\mathrm{mg} / \mathrm{ml}$ streptomycin. After the cells were harvested, they were placed into $50 \mathrm{ml}$ polypropylene centrifuge tubes (Corning, Corning, NY) and centrifuged (2000 rpm, 5 minutes) in a IEC Model CRU-5000 centrifuge (Needham HTS, MA). The supernatant was discarded after centrifugation. After the cells were collected into one $50 \mathrm{ml}$ polypropylene centrifuge tube, they were washed once with Dulbecco's phosphatebuffered saline containing $1.0 \mathrm{mg} / \mathrm{ml}$ of glucose and then suspended at a concentration of $5 \times 10^{6}$ cells $/ \mathrm{ml}$. The cell concentration was determined by using an Elzone 80 particle counter (Particle Data, Elmhurst, IL). After the cell concentration was determined, the solution was divided into two $15 \mathrm{ml}$ polypropylene centrifuge tubes (Corning, Corning, NY). These tubes were then centrifuged (2000 rpm, 5 minutes) and 
the supernatant was discarded. The control-labeled tube was washed once with phosphate-buffered saline/glucose solution $\mathrm{pH}$ or $\mathrm{pD}$ 7.4. The experimental-labeled tube was washed once with phosphate-buffered saline/glucose solution containing the appropriate concentration of singlet-oxygen quencher and then adjusted to $\mathrm{pH}$ or $\mathrm{pD}$ 7.4. After washing, the cells were centrifuged ( $2000 \mathrm{rpm}, 5$ minutes). The supernatant was then discarded and the cells were then resuspended to $5 \times 10^{6}$ cells $/ \mathrm{ml}$.

\section{Labeling Of K562 Cells With 5-(N-Hexadecanoyl)-Aminoeosin (E-16)}

From this point on, every procedure was done in the dark with minimal light. After suspending the cells to $5 \times 10^{6}$ cells $/ \mathrm{ml}$, a $400 \mu \mathrm{M}$ stock E-16 solution and the control and experimental-labeled tubes were placed in a $37^{\circ} \mathrm{C}$ water bath for 5 minutes. After 5 minutes, $1.0 \mu \mathrm{M}$ E-16 was added to the control and experimental-labeled tubes. The tubes were placed inside an incubator (NAPCO model $5100 \mathrm{CO}_{2}$ Incubator, Tualatin, $\mathrm{OR})$ at $37^{\circ} \mathrm{C}$ with continuous rocking for 30 minutes.

\section{Assay For E-16 In K562 Cells}

After irradiation, both the control and experimental-labeled tubes were centrifuged (2000 rpm, 5 minutes) and the supernatant was discarded. The cells were then suspended to a concentration of $4 \times 10^{5}$ cells $/ \mathrm{ml}$ with $70 \mathrm{mM}$ sodium lauryl sulfate (SLS) in phosphate-buffered saline/glucose. The cells were dispersed for 5 minutes with a vortex mixer (Scientific Products, McGaw Park, IL). Aliquots, $3.0 \mathrm{ml}$ in volume, were pipetted 
into UV grade fluorometric methacrylate disposable cuvettes (Spectrocell, Oreland, PA) and the fluorescence of E-16 was measured using an excitation wavelength of $390 \mathrm{~nm}$ and an emission wavelength of $540 \mathrm{~nm}$. The fluorescence was measured with a PerkinElmer LS-5B Luminescence Spectrometer (Norwalk, CT). The slit widths for excitation and emission were set at $5.0 \mathrm{~nm}$ and $3.0 \mathrm{~nm}$, respectively, and the fixed scale was set at 0.10 . A calibration curve was obtained by the addition of known quantities of E-16 to unlabeled cells and was found to be linear in the $0-0.10 \mu \mathrm{M}$ concentration range.

\section{Irradiation Of Purified Human Recombinant Acetylcholinesterase (ACE) And}

\section{K562 Cells}

Irradiations of the purified human recombinant ACE solutions and the K562 cells was done with a Logan Porta-View light box (Logan Electric Spec. Mfg. Co., Chicago, IL). This light box contained a 15 watt F15T8/D30 fluorescent light tube (Osram Sylvania, Inc., Danvers, MA) and a plastic filter that diffused the light. This plastic filter blocked light transmission with wavelengths less than $380 \mathrm{~nm}$. Blocking ultraviolet light was critical during irradiation because ultraviolet light has been shown to generate radicals with some photosensitizers and these radicals could in turn inactivate ACE (18). The fluence rate of light within the absorption band of eosin (460 to $560 \mathrm{~nm}$ ) was measured using a SD-1100-12-22-181 photodetector (Silicon Detector Corp., Newbury Park, CA) and a series of short wavelength cutoff filters (Hoya Optics, Inc., Fremont, CA). Cell suspensions and purified human recombinant ACE solutions were agitated continuously during the irradiations to ensure sufficient oxygenation. A model OM-3 
oxygen meter using a model MI-730 micro-oxygen electrode (Microelectrodes, Inc., Londonderry, $\mathrm{NH}$ ) was utilized in order to ensure that there was no significant depletion of oxygen at the bottom of the samples.

\section{Reciprocity Experiments For Human Recombinant ACE In Solution And K562 \\ Cells}

For these experiments, $35.5 \times 25.5 \mathrm{~cm}$ neutral density filters (Edmund Scientific, Barrington, NJ) were used to reduce the light intensity. The light intensity was measured with a Circuitmate DM800 multimeter (Beckman Industrial Co., Brea, CA). The neutral density filters were placed on top of the Logan Porta-View light box. Samples containing either $1.5 \mathrm{ml}$ of $1.0 \mu \mathrm{M} \mathrm{E}-16-$ labeled $\mathrm{K} 562$ cells $\left(5 \times 10^{6}\right.$ cells $\left./ \mathrm{ml}\right)$ or samples containing $1.5 \mathrm{ml}$ of stock human recombinant $\mathrm{ACE}$ (1:250 dilution), 0.5\% Triton X-100 in $100 \mathrm{mM}$ phosphate buffer, $\mathrm{pH}$ or $\mathrm{pD} 7.4$, and $50 \mu \mathrm{M}$ eosin $\mathrm{Y}$ were pipetted into 35 x $10 \mathrm{~mm} 50 \mathrm{ml}$ Pyrex glass beakers (Corning, Corning, NY). These beakers were placed $1.0 \mathrm{~cm}$ above the neutral density filters and were then agitated continuously for various irradiation times. When multiple neutral density filters were used, they were stacked on top of each other, always in the same order. A maximum of 5 neutral density filters was used for these experiments. After irradiation, the samples were assayed for ACE activity. 


\section{Assays For ACE On The Surface Of K562 Cells And For Human Recombinant ACE In Solution}

The procedure used for measuring the activity of ACE was described by Ellman et al. (57). When deuterium-oxide solvent was used in this assay, the phosphate buffer was adjusted to $\mathrm{pD}$ 7.4. For the human recombinant $\mathrm{ACE}$ in solution experiments, aliquots were taken from each $50 \mathrm{ml}$ Pyrex glass beaker after irradiation. The final concentration of reagents in the sample cuvette was $0.91 \mathrm{mM}$ acetylthiocholine chloride, $0.91 \mathrm{mM} 5,5$ '-dithiobis(2-nitrobenzoic acid) (DTNB), 0.036 to 0.072 units/ml of human recombinant ACE and 0.5\% Triton X-100 in $100 \mathrm{mM}$ phosphate buffer, $\mathrm{pH}$ 7.4. The control cuvette contained the same reagents, except water was substituted for acetylthiocholine chloride. When singlet-oxygen quenchers were used, the same concentration was present in the sample and control cuvette.

For the experiments that involved measuring the ACE activity on the surface of the K562 cells, aliquots were taken from each $50 \mathrm{ml}$ Pyrex glass beaker after irradiation. The aliquots were placed into $15 \mathrm{ml}$ polypropylene centrifuge tubes and centrifuged ( $2000 \mathrm{rpm}, 5$ minutes). After centrifugation, the supernatant was discarded and $1.0 \mathrm{ml}$ of $0.5 \%$ Triton $\mathrm{X}-100$ in $100 \mathrm{mM}$ phosphate buffer, $\mathrm{pH} 7.4$ was added to the cell pellet. The pellet was dispersed by vortexing for 5 minutes. After vortexing, the samples were centrifuged ( $2000 \mathrm{rpm}, 5$ minutes) and then placed in a room temperature water bath for 5 minutes. The supernatant was then measured for ACE activity. The sample cuvette contained dispersed cells at a final concentration of $2.67 \times 10^{6}$ cells $/ \mathrm{ml}$, 
the same reagents, except water was substituted for acetylthiocholine chloride. When singlet-oxygen quenchers were used, the concentration was the same in the sample and the control cuvette.

An unirradiated sample was used in these experiments as a dark control. The rate of increase in the absorbance at $412 \mathrm{~nm}$ was assumed to be proportional to the activity of ACE. The spontaneous hydrolysis of acetylthiocholine chloride was also measured and then subtracted from each absorbance reading. The absorbance measurements were taken in an Perkin-Elmer Lambda 3A UV/VIS Spectrophotometer (Perkin-Elmer, OakBrook, IL). Control experiments were done to make sure that the ACE was not being cleaved from the surface of the K562 cells during irradiation. For these experiments, the supernatant from the irradiated cells was assayed for ACE activity as described above. As a final control, the $\mathrm{K} 562$ cells were incubated with $1.0 \mu \mathrm{M}$ eosin bound to high molecular weight dextran, a water-soluble photosensitizer that does not bind to the cell surface. In this case, most of the singlet oxygen will be generated in the buffer where it will then become quenched. The enzyme activity was assayed as previously described.

\section{TO-PRO-3 Iodide Assay For K562 Cells}

After the cells were irradiated for various lengths of time, $1.0 \mathrm{ml}$ aliquots of 5 $\times 10^{6}$ cells $/ \mathrm{ml}$ were taken from the $50 \mathrm{ml}$ Pyrex glass beakers and pipetted into $12 \times 75$ $\mathrm{mm}$ borosilicate disposable culture tubes (Fisher Scientific, Pittsburgh, PA). A $1.0 \mathrm{ml}$ aliquot of $2.0 \mu \mathrm{M}$ TO-PRO-3 iodide in phosphate-buffered saline/glucose was also 
pipetted into the borosilicate culture tubes. This $2.0 \mathrm{ml}$ solution was then placed into a $37^{\circ} \mathrm{C}$ water bath for 12 minutes. The samples were then pipetted into methacrylate UV grade fluorometric disposable cuvettes. The fluorescence was measured in a PerkinElmer LS-5B Luminescence Spectrometer. The excitation wavelength was $642 \mathrm{~nm}$ and the emission wavelength was $661 \mathrm{~nm}$. The slit widths were $5.0 \mathrm{~nm}$ and $3.0 \mathrm{~nm}$ for excitation and emission, respectively. The fixed scale was 1.0.

\section{Measurement Of Singlet-Oxygen Phosphorescence Decay At 1270 nm}

A time-resolved phosphorescence spectrometer, similar in design to those utilized by several investigators was used to measure the singlet-oxygen phosphorescence decay at $1270 \mathrm{~nm}(21,58,59)$. A flash-pump organic dye laser was used to produce a short pulse of light at $510 \mathrm{~nm}$ using Coumarin 510 (Exciton, Inc., Dayton, OH). The laser energy output, measured with a Scientech 365 power and energy meter (Boulder, CO), was usually $10 \mathrm{~mJ}$. Emission at a right angle to the laser beam passed through a 0.50 $\mathrm{cm}$ thick silicon filter and then a $1268 \mathrm{~nm}$ interference filter (50 $\mathrm{nm}$ bandwidth) into an EO-817P liquid nitrogen-cooled infrared detector (North Coast Optical Systems and Sensors, Santa Rosa, CA), where high sensitivity was achieved. Individual decay curves were recorded with a Hameg HM 208 digital storage oscilloscope (Hameg, Inc., West Germany). The individual decay curves were then transferred to an IBM PC computer (IBM, Armonk, NY) with a National Instruments GPIB-PC2A interface. For each experiment, three decay curves were averaged. A nonlinear least squares program was used to calculate an exponential decay constant for the singlet-oxygen phosphorescence. 


\section{Lifetime Of Singlet Oxygen In Buffers Containing Human Recombinant ACE}

The lifetime of singlet oxygen was measured in samples containing $0.5 \%$ Triton $\mathrm{X}-100$ in $100 \mathrm{mM}$ phosphate buffer, pD 7.4, human recombinant ACE (1:250 dilution) and $50 \mu \mathrm{M}$ eosin $\mathrm{Y}$. The samples were then pipetted into methacrylate UV grade fluorometric disposable cuvettes. The decay of singlet-oxygen phosphorescence was measured at $1270 \mathrm{~nm}$ with pulsed laser excitation as described previously.

\section{Singlet-Oxygen Quenching Constants}

The singlet-oxygen quenching constants for sodium azide, methionine, disodium [NN'-ethylenebis(5-sulphosalicylideneimminato)]nickelate(II)(Ni-chelate1), anddisodium [NN'-2,3-propionic acid)bis(5-sulphosalicylideneimminato)]nickelate(II) (Ni-chelate 2) were calculated from the lifetime of $1270 \mathrm{~nm}$ emission as described previously. When measurements of quenching constants were needed, $25 \mu \mathrm{M}$ meso-tetra(4-sulfonatophenyl)porphine (TPPSO) was used as a photosensitizer along with $100 \mathrm{mM}$ phosphate buffer, pD 7.4. The concentration ranges used for sodium azide, methionine, Ni-chelate 1 , and Ni-chelate 2 were 0 to $150 \mu \mathrm{M}, 0$ to $2.4 \mathrm{mM}, 0$ to $20 \mu \mathrm{M}$ and 0 to $32 \mu \mathrm{M}$, respectively.

\section{Measurements Of Singlet-Oxygen Quencher And Deuterium-Oxide Solvent Concentrations Within K562 Cells}


quenchers used penetrated into the K562 cells needed to be determined. Any penetration of singlet-oxygen quenchers into the cytoplasm of these cells would be expected to lower the lifetime of singlet oxygen within this compartment. Any penetration of deuteriumoxide solvent into the cytoplasm of these cells would be expected to increase the singletoxygen lifetime within this compartment. With this reasoning, the singlet-oxygen quenching rate of K562 lysates were measured as described previously (60). Samples containing a cell concentration of $5 \times 10^{6}$ cells $/ \mathrm{ml}$, with and without added singlet-oxygen quencher, were incubated in a $37^{\circ} \mathrm{C}$ incubator with continuous rocking for 30 minutes. After incubation, samples were centrifuged for 5 minutes at $2000 \mathrm{rpm}$. The supernatant was discarded and the cell pellets from each sample were weighed (Mettler AE 100 Analytical Balance, Hightstown, NJ). The pellets were then solubilized with $70 \mathrm{mM}$ sodium lauryl sulfate (SLS) in $100 \mathrm{mM}$ phosphate buffer, pD 7.4 at a cell concentration of $1 \times 10^{7}$ cells $/ \mathrm{ml}$. Each sample was vortexed for 5 minutes. Serial dilutions were then made of the stock solution with additional $70 \mathrm{mM}$ SLS in $100 \mathrm{mM}$ phosphate buffer, pD 7.4. The cell concentrations used were $0,2,4,6,8$, and $10 \times 10^{6}$ cells $/ \mathrm{ml}$. Aliquots, $1.0 \mathrm{ml}$ in volume, were pipetted into methacrylate UV grade fluorometric disposable cuvettes and $50 \mu \mathrm{M}$ TPPSO in $\mathrm{D}_{2} \mathrm{O}$ was then added as a photosensitizer. The samples were kept in a $37^{\circ} \mathrm{C}$ water bath to prevent precipitation of the SLS. The lifetimes of the decay of the $1270 \mathrm{~nm}$ singlet-oxygen emission were measured following $10 \mathrm{~mJ}$ laser pulses at $510 \mathrm{~nm}(13,59)$. The resulting lifetimes were plotted in the Stern-Volmer format. The difference between the quenching rates of cell lysates previously incubated with a singlet-oxygen quencher and control cell lysates, gave the quenching rate due to quenchers that penetrated the K562 cells. For the deuterium-oxide solvent versus water 
solvent experiments, the procedure was the same except no singlet-oxygen quenchers were used.

\section{Statistical Analysis}

Each experiment was done at least three times and the results were reported as the mean \pm the standard error of the mean. Activity curves for ACE versus irradiation time were fit to a single exponential decay using a nonlinear least-squares program (PSI Plot, Polysoftware International, Salt Lake City, UT). For experiments with K562 cells, the experimental data was fit to the mathematical model using the nonlinear least-squares program. For each set of parameters, the sum of the squares of the difference between the experimental data and the theoretical curves were determined by Equation 9:

$$
E=\sum_{i=1}^{n}\left(R_{\exp }-R_{\text {theory }}\right)^{2}
$$

where $\mathbf{R}$ was the ratio of acetylcholinesterase inactivation lifetimes, $\mathrm{n}$ was the number of data points, and $\mathrm{E}$ was the sum of the squares of the errors. The least-squares program selected the parameters (eg., singlet-oxygen lifetime in the cell) that gave the smallest value of $\mathrm{E}$. The correlation coefficient was used as a measure of the adequacy of the fit and was determined for the set of parameters that minimized the error. 


\section{CHAPTER 4}

\section{RESULTS}

\section{Studies With Purified Acetylcholinesterase (ACE)}

In order to show that the inactivation of ACE was a good indicator of the cell membrane exposure to singlet oxygen, the inactivation of this enzyme was first studied in solution. From these studies, it was then determined if the inactivation of ACE was a reliable, quantitative measure of the steady-state singlet-oxygen concentration. This simple model system contained phosphate buffer $\mathrm{pH} 7.4$, recombinant $\mathrm{ACE}$, eosin $\mathrm{Y}$ (photosensitizer), and a singlet-oxygen quencher. In this assay, the enzyme, ACE, cleaves the substrate, acetylthiocholine, forming thiocholine. The thiocholine then reacts with DTNB, another reagent in the cuvette, forming a yellow compound. The absorbance of this yellow compound at $412 \mathrm{~nm}$ was used to estimate the enzyme activity. From a plot of the normalized ACE activity versus time, ACE inactivation lifetimes were determined. These lifetimes were then evaluated to see if they were related to the steady-state concentration of singlet oxygen in the irradiated system.

From the control, bottom curve in Figure 1, it was found that ACE decays according to first-order kinetics. The decrease in the enzyme activity over time was found to be proportional to the concentration of the active enzyme, $[A]$. Also, the 
addition of various concentrations of sodium azide, a singlet-oxygen quencher with a high singlet-oxygen quenching constant, to this system resulted in the first-order decay of ACE. Very long irradiation times were needed for these experiments because of the presence of water solvent, short singlet-oxygen lifetime, $3.1 \mu \mathrm{s}$. Also, increasing concentrations of sodium azide increased the rate of ACE inactivation. 


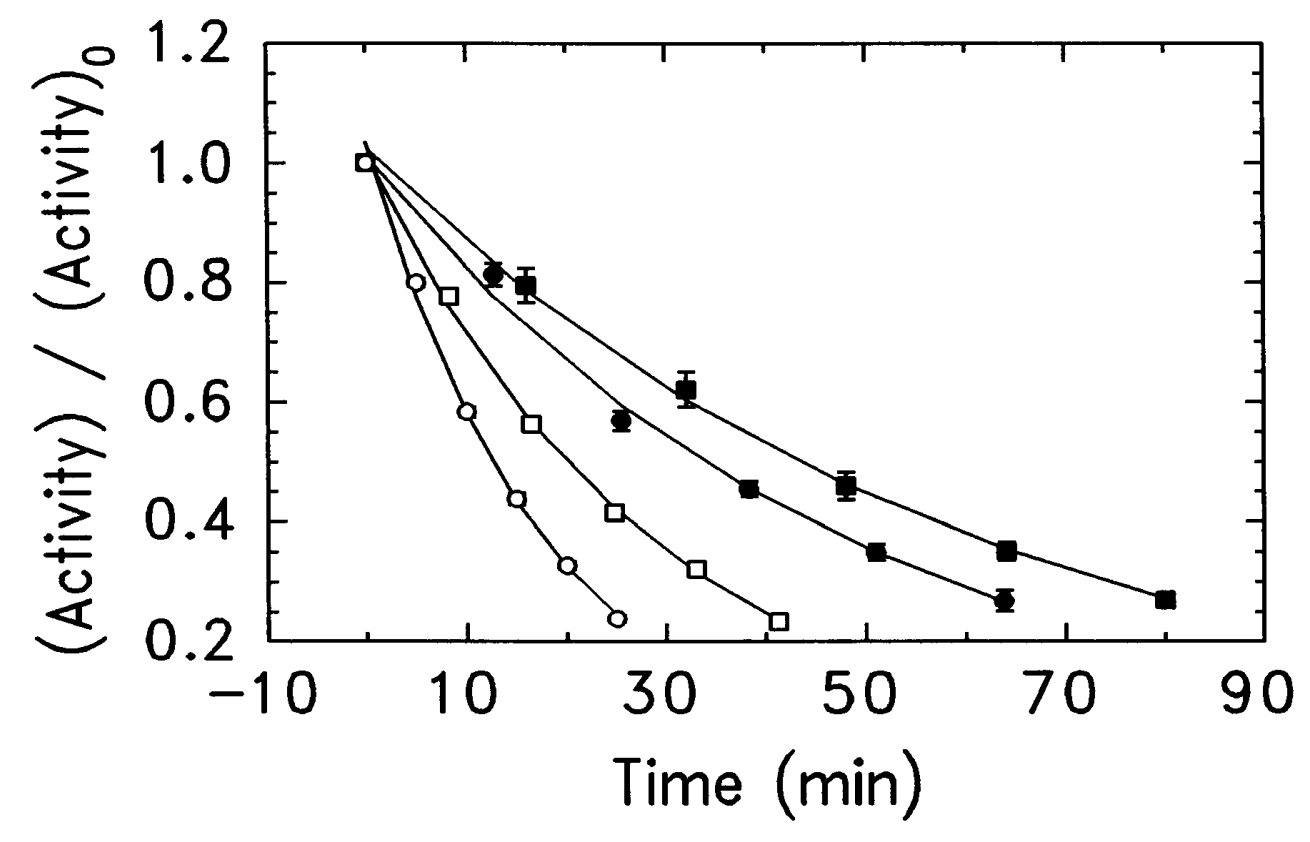

Figure 1. Effect Of Azide Anion Upon The Kinetics Of Inactivation Of Human Recombinant ACE By Eosin Y And Light. Water Solvent, pH 7.4. 
In Figure 1, the conditions were $100 \mathrm{mM}$ sodium phosphate buffer, $\mathrm{pH} 7.4,0.5 \%$ Triton $\mathrm{X}-100(\mathrm{v} / \mathrm{v}), 50 \mu \mathrm{M}$ eosin $\mathrm{Y}, 0.05$ units/ml human recombinant $\mathrm{ACE}$ and $600 \mu \mathrm{W} / \mathrm{cm}^{2}$ light fluence. The sodium azide concentrations used were $0 \mathrm{mM}(\bigcirc), 0.5 \mathrm{mM}(\square), 1.5$ $\mathrm{mM}(\bigcirc)$, and $2.0 \mathrm{mM}(\boldsymbol{\square})$. For the upper three curves, each point was the average of 3 experiments \pm the standard error of the mean (SEM). For the lowest curve, each point was the average of 9 experiments \pm SEM. The curves resulted from a non-linear least-squares fit to a first-order decay. The correlation coefficients for the curves from top to bottom were $0.9993,0.9980,0.9994$, and 0.9990 , respectively.

Next, experiments were performed in order to determine whether variations in the light intensity also caused variations in the rate of ACE inactivation. These sets of experiments tested for reciprocity. For example, if the light intensity was decreased by a factor of 2 , it should then take twice as long to inactivate ACE. The results shown in Figure 2 demonstrated that rate of singlet-oxygen-mediated ACE inactivation was proportional to the inverse of the light intensity. 


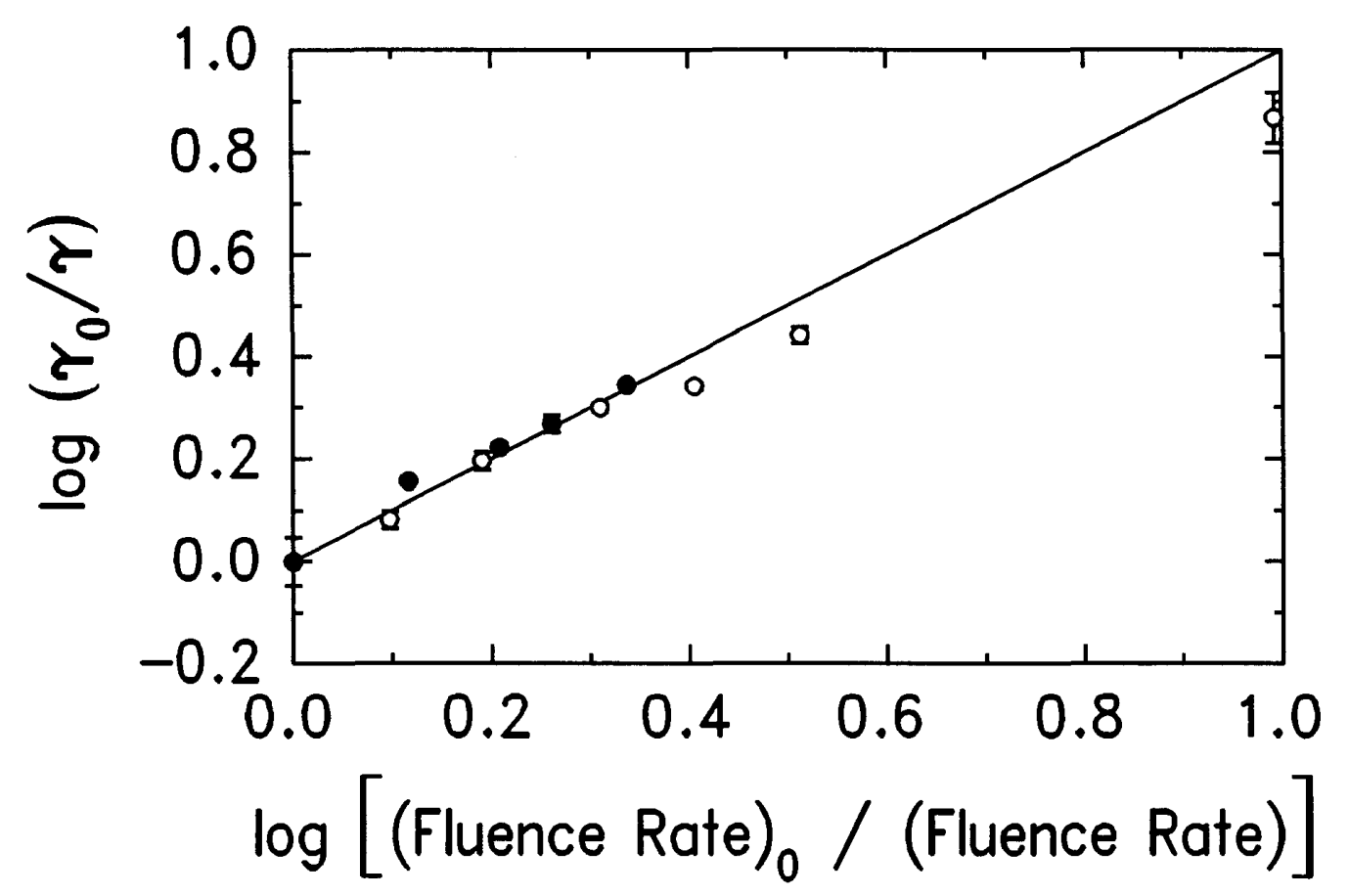

Figure 2. Effect Of Light Fluence Rate On The Inactivation Lifetime Of Human Recombinant ACE And Of ACE On The K562 Cells. 
In Figure 2, the data for human recombinant $\mathrm{ACE}$ and for $\mathrm{ACE}$ on the surface of the K562 cells were denoted by the symbols $\bigcirc$ and $\bullet$, respectively. For human recombinant $\mathrm{ACE}$, the conditions were deuterium-oxide solvent, $100 \mathrm{mM}$ sodium phosphate buffer, pD 7.4, $0.5 \%$ Triton $\mathrm{X}-100(\mathrm{v} / \mathrm{v}), 50 \mu \mathrm{M}$ eosin $\mathrm{Y}$, and 0.05 units $/ \mathrm{ml}$ ACE. For ACE on the K562 cells, the conditions were $5 \times 10^{6}$ cells $/ \mathrm{ml}, 1.0 \mu \mathrm{M} \mathrm{E}-16$, $1.0 \mathrm{mg} / \mathrm{ml}$ glucose and phosphate-buffered saline made with water solvent, $\mathrm{pH}$ 7.4. Each point was the average of 3 experiments \pm SEM.

The results from Figures 1 and 2 combined demonstrated that the rate of ACE inactivation in solution was proportional to the concentration of the active enzyme, $[\mathrm{A}]$, and the steady-state singlet-oxygen concentration, $\left[{ }^{1} \mathrm{O}_{2}\right]$. Therefore, these results obeyed a simple second-order rate expression.

$$
\frac{d[A]}{d t}=-k[A]\left[{ }^{1} O_{2}\right]
$$

Here $\mathrm{k}$ is the rate constant for enzyme inactivation and $\mathrm{t}$ is time.

It was next necessary to select several singlet-oxygen quenchers that inhibited the inactivation of ACE by lowering the steady-state concentration of singlet oxygen and not by other mechanisms. The data for these experiments were presented in Figures 3 and 4. The singlet-oxygen quenchers used for these experiments were methionine, sodium azide, Ni-chelate 1 and $\mathrm{Ni}$-chelate 2 . These singlet-oxygen quenchers were chosen because of the following characteristics: large singlet-oxygen quenching constants, hydrophilic solubility and low reactivity with the excited triplet-state of the 
photosensitizer, 5-(N-hexadecanoyl)-aminoeosin, (E-16) $(19,56,70,84)$. These singletoxygen quenchers also represented two different classes of quenching: physical and chemical. The nickel chelates are physical quenchers (56). They react with singlet oxygen and the energy is transferred to the buffer in the form of heat. Methionine is a chemical quencher and reacts with singlet oxygen to form a sulfoxide (70). Sodium azide can be classified as a physical or chemical quencher (84). As a chemical quencher, sodium azide forms an azide radical. These chemical products did not interfere with the ACE assay because the expected results were obtained.

The data in Figures 3 and 4 were plotted according to the Stern-Volmer equation show in Equation 11.

$$
\frac{\tau_{0}^{*}}{\tau^{*}}=1+\tau k C
$$

where $\tau_{\mathrm{o}}{ }^{*}$ is the ACE inactivation lifetime in the absence of added quencher, $\tau^{*}$ is the ACE inactivation lifetime in the presence of added quencher, $\mathrm{C}$ is the concentration of the singlet-oxygen quencher, $\mathrm{k}$ is the singlet-oxygen quenching constant and $\tau$ is the lifetime of singlet oxygen in the solutions used.

The lines shown in Figures 3 and 4 were the theoretical results expected for an ideal singlet-oxygen quencher having no other effect on the system. All of the data points were close to the theoretical lines in both water solvent and in deuterium-oxide solvent. Therefore, the actions of these singlet-oxygen quenchers could be explained quantitatively by assuming that their only mechanism of action was to quench singlet 
oxygen. As a control, the addition of glycine, an amino acid that has a small quenching constant, to this system did not effect the rate of ACE inactivation. 


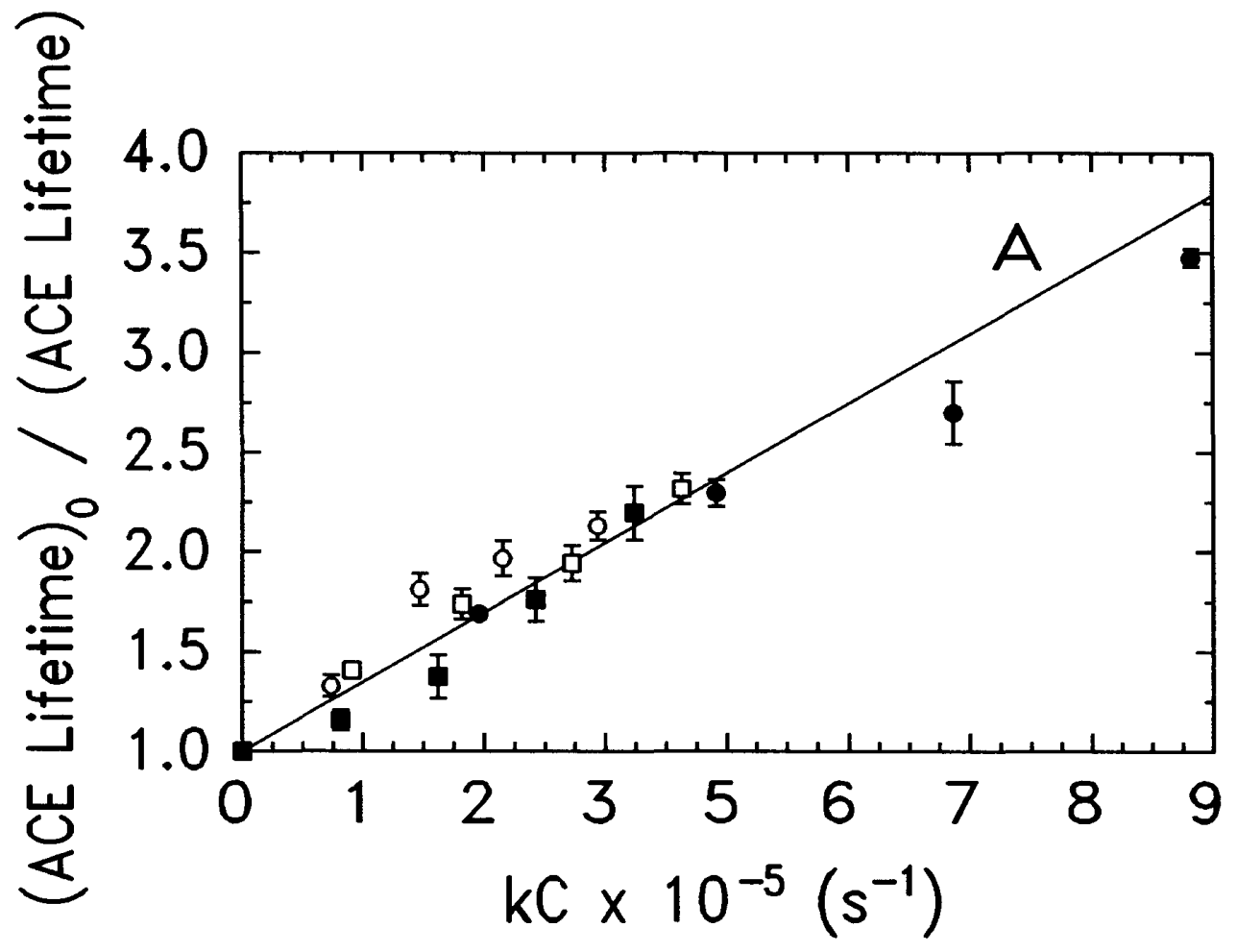

Figure 3. Inhibition Of Human Recombinant ACE By Singlet-Oxygen Quenchers. Water Solvent, pH 7.4. 


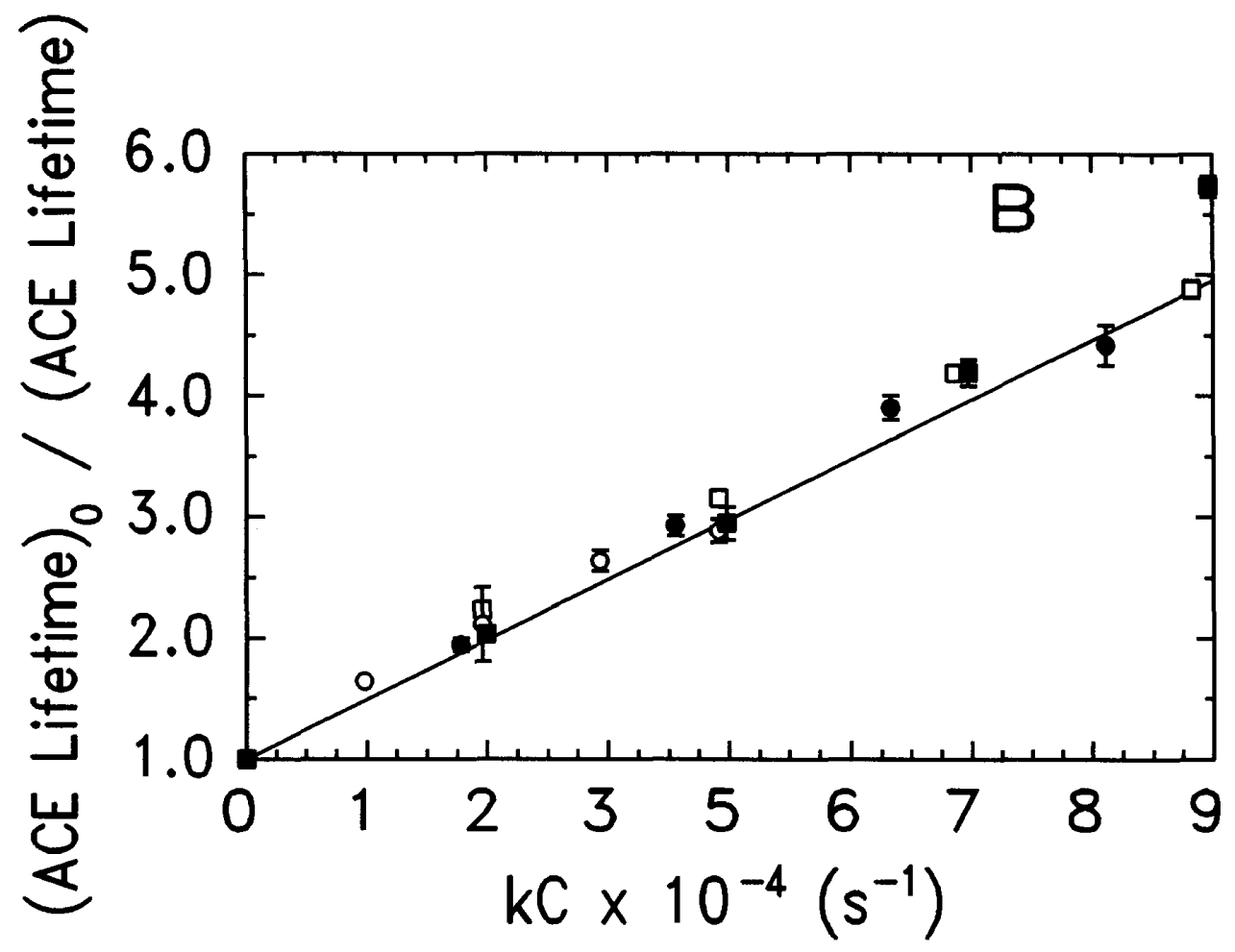

Figure 4. Inhibition Of Human Recombinant ACE By Singlet-Oxygen Quenchers. Deuterium-Oxide Solvent, pD 7.4. 
In Figures 3 and 4 , the abscissa, labeled $\mathrm{kC}$, was the product of the singlet-oxygen quencher concentration, $\mathrm{C}$, and the singlet-oxygen quenching constant, $\mathrm{k}$. The ordinate was the ratio of the ACE inactivation lifetime in the absence of the singlet-oxygen quencher, (ACE Lifetime), to the ACE inactivation lifetime in the presence of the singlet-oxygen quencher, (ACE Lifetime). In Figures 3 and 4, the conditions were 100 $\mathrm{mM}$ sodium phosphate buffer, $\mathrm{pH}$ or $\mathrm{pD} 7.4,0.5 \%$ Triton $\mathrm{X}-100(\mathrm{v} / \mathrm{v}), 50 \mu \mathrm{M}$ eosin $\mathrm{Y}$, 0.05 units $/ \mathrm{ml}$ human recombinant $\mathrm{ACE}$ and $600 \mu \mathrm{W} / \mathrm{cm}^{2}$ fluence rate. The symbols: $\bigcirc, \odot, \square$, and $\square$ refer to the singlet-oxygen quenchers, methionine, sodium azide, $\mathrm{Ni}$ chelate 1 and $\mathrm{Ni}$-chelate 2, respectively. Each point was the average of 3 experiments \pm SEM.

In order to estimate the singlet-oxygen quenching constant for each quencher from the ACE inactivation experiments, the lifetime of singlet oxygen in the buffer solutions used was calculated. These values for the singlet-oxygen lifetimes were then plugged into the Stern-Volmer equation and solved for $\mathrm{k}$, the singlet-oxygen quenching constant. The lifetime of singlet oxygen in the deuterium-oxide buffer was measured from the decay of $1270-\mathrm{nm}$ emission following pulsed-laser excitation of the eosin Y. These measurements were done in deuterium-oxide solvent because of the long singletoxygen lifetime. The singlet-oxygen lifetime measured was $44 \pm 1 \mu \mathrm{s}$. Most of the reduction in the singlet-oxygen lifetime compared to pure deuterium oxide, with a singletoxygen lifetime of $68 \mu \mathrm{s}(12)$, was due to quenching by eosin Y (61). A singlet-oxygen lifetime in water of $3.1 \mu \mathrm{s}$ (11) was used because the quenching by solutes was not enough to change this value significantly.

As shown in Table 1, the singlet-oxygen quenching constants calculated from 
Equation 11 were in excellent agreement with the singlet-oxygen quenching constants measured in this study using the decay of 1270-nm emission and singlet-oxygen quenching constants obtained from the literature $(3,26,56,62-72)$. For example, the singlet-oxygen quenching constant determined from the ACE experiments using the singlet-oxygen quencher Ni-chelate 1 in water and in deuterium-oxide solvent was 2.1 $\pm 0.1 \times 10^{9} \mathrm{M}^{-1} \mathrm{~s}^{-1}$. Using the decay of singlet-oxygen emission at $1270 \mathrm{~nm}$, the singletoxygen quenching constant was determined to be $2.0 \pm 0.1 \times 10^{9} \mathrm{M}^{-1} \mathrm{~s}^{-1}$. The singletoxygen quenching constant reported in the literature was $1.6 \times 10^{9} \mathrm{M}^{-1} \mathrm{~s}^{-1}$. All of these values were in excellent agreement with one another. 
Table 1. Comparison Of "Apparent" Singlet-Oxygen Quenching Constants Determined From The Inhibition Of The Inactivation Of Human Recombinant ACE And Singlet-Oxygen Quenching Constants Determined By Standard Methods.

Quencher Solvent $\quad$ Singlet-oxygen quenching constant

\begin{tabular}{llclc}
\hline & & $\begin{array}{c}\text { From acetylcholinesterase } \\
\text { experiments } \\
\left(\mathrm{M}^{-1} \mathrm{~s}^{-1}\right)\end{array}$ & $\begin{array}{l}\text { 1270-nm kinetics } \\
\text { This study } \\
\left(\mathrm{M}^{-1} \mathrm{~s}^{-1}\right)\end{array}$ & $\begin{array}{c}\text { Range of } \\
\text { literature values } \\
\left(\mathrm{M}^{-1} \mathrm{~s}^{-1}\right)\end{array}$ \\
\hline azide & $\mathrm{H}_{2} \mathrm{O}$ & $3.9 \pm 0.1 \times 10^{8}$ & & $5-20 \times 10^{8 *}$ \\
azide & $\mathrm{D}_{2} \mathrm{O}$ & $4.1 \pm 0.2 \times 10^{8}$ & $4.4 \pm 0.1 \times 10^{8}$ & $5-7 \times 10^{8} \dagger$ \\
methionine & $\mathrm{H}_{2} \mathrm{O}$ & $1.3 \pm 0.1 \times 10^{7}$ & & \\
methionine & $\mathrm{D}_{2} \mathrm{O}$ & $1.1 \pm 0.1 \times 10^{7}$ & $1.1 \pm 0.1 \times 10^{7}$ & $1.3-1.7 \times 10^{7} \ddagger$ \\
Ni-chelate 1 & $\mathrm{H}_{2} \mathrm{O}$ & $2.1 \pm 0.1 \times 10^{9}$ & & $1.6 \times 10^{9} \S$ \\
Ni-chelate 1 & $\mathrm{D}_{2} \mathrm{O}$ & $2.1 \pm 0.1 \times 10^{9}$ & $2.0 \pm 0.1 \times 10^{9}$ & \\
Ni-chelate 2 & $\mathrm{H}_{2} \mathrm{O}$ & $1.3 \pm 0.1 \times 10^{9}$ & & \\
Ni-chelate 2 & $\mathrm{D}_{2} \mathrm{O}$ & $1.6 \pm 0.2 \times 10^{9}$ & $1.4 \pm 0.1 \times 10^{9}$ &
\end{tabular}

"Schmidt and Rosenkranz (62), Seely (63), Gupta and Rohatgi-Mukherjee (64), Usui et al. (65), Harbour et al. (66), Haag and Mill (67), Wessels and Rodgers (68)

†Lindig and Rodgers (26), Hall and Chignell (69)

$\ddagger$ Lindig and Rodgers (26), Matheson and Lee (3), Devasagayam et al. (70), Rougee et al. (71), Michaeli and Feitelson (72)

§Botsivali et al. (56) 
Next, experiments were performed in order to determine the ratio for the ACE inactivation lifetime in water solvent and in deuterium-oxide solvent. The experimental ratio was determined by dividing the $\mathrm{ACE}$ inactivation lifetime in deuterium-oxide solvent by the ACE inactivation lifetime in water solvent. This ratio was $6.5 \pm 0.30$ at $\mathrm{pD}$ and $\mathrm{pH}$ 7.4. The theoretical ratio was determined by dividing the measured singletoxygen lifetime in the deuterium-oxide system $(44 \mu \mathrm{s})$ by the measured singlet-oxygen lifetime in water $(3.1 \mu \mathrm{s})$. Thus, the theoretical ratio was 14 .

The difference between the theoretical and experimental ratios suggested the presence of some type of isotope effect. This hypothesis was confirmed by comparing the inactivation lifetime of ACE in deuterium-oxide buffer containing $700 \mu \mathrm{M}$ azide ion with the inactivation lifetime in water buffer. The presence of $700 \mu \mathrm{M}$ azide ion reduced the lifetime of singlet oxygen in the deuterium-oxide buffer to $3.1 \mu \mathrm{s}$, identical to the lifetime in water buffer. The ratio expected without an isotope effect would be 1.0 , because the singlet-oxygen lifetimes would have been the same in water and deuteriumoxide buffer. However, the lifetime of ACE inactivation in deuterium-oxide buffer with $700 \mu \mathrm{M}$ sodium azide was $2.2 \pm 0.10$ times the lifetime of inactivation in water buffer. This confirmed the presence of an isotope effect.

One type of isotope effect is a primary isotope effect at the site of enzyme inactivation (73). In deuterium-oxide solvent, some of the hydrogen atoms on ACE may exchange with some of the deuterium atoms from the solvent. For example, exchange of a hydrogen for a deuterium at the $\mathrm{OH}$ bond on a tyrosine ring can cause a primary kinetic deuterium isotope effect as large as a factor of 11.5 (73). Perhaps, this is the reason for the discrepancy between the experimental and the theoretical ratios. 
A second type of isotope effect is a secondary solvent isotope effect (73). The ionized forms of deuterium oxide, $\mathrm{D}_{3} \mathrm{O}^{+}$and $\mathrm{OD}^{-}$, are less stable compared to neutral deuterium oxide, than the corresponding ionized forms of water. Similarly, the bond energy for ionizable deuterium atoms is greater than for ionizable hydrogen atoms on biological molecules, such as histidine. As a result, at equal $\mathrm{pH}$ and $\mathrm{pD}$, there are likely different amounts of ionization of various functional groups on ACE. The quenching constant for histidine is known to have a strong pD dependence between pD 7 and 8 (3). As a result, changing the solvent from deuterium oxide to water may change the quenching constant for histidine significantly. To assess this hypothesis, the inactivation of $\mathrm{ACE}$ at $\mathrm{pH}$ and $\mathrm{pD} 8.4$ was studied. The buffer used was $5.0 \mathrm{mM}$ sodium borate. The lifetime of photoinactivation of $\mathrm{ACE}$ at $\mathrm{pH}$ and $\mathrm{pD} 8.4$ was not significantly different from $\mathrm{pH}$ and $\mathrm{pD}$ 7.4. Furthermore, the ratio of inactivation lifetimes at $\mathrm{pH} 8.4$ and $\mathrm{pD} 8.4$ was $6.7 \pm 0.4$, essentially the same as the ratio at lower $\mathrm{pH}$. This suggested that the $\mathrm{pH}$ dependence of the histidine quenching constant cannot explain the anomalous ratio, but does not rule out other possible secondary solvent isotope effects.

\section{Theoretical Mathematical Model Of Singlet-Oxygen Quenching And Diffusion}

Having established that ACE inactivation was a reliable measure of the steadystate singlet-oxygen concentration in solution, a more complex system, the K562 cell line, was investigated. Figure 5 depicted the geometry of the model system for the K562 cells. This particular cell line was chosen because it contained significant amounts of the membrane-bound ACE and the cells grew as a suspension $(74,75)$. The photosensitizer, 
E-16, was selected for the K562 cell experiments because it was a lipophilic anionic eosin derivative that bound selectively to the outer cell surface of the K562 cells and had a large singlet-oxygen yield $(76,77)$. Since singlet oxygen was being generated directly on the cell surface and ACE was located on the outer cell surface, extending about 15 $\mathrm{nm}$ into the buffer, this enzyme would make an ideal probe for the singlet-oxygen concentration near the cell surface. Evidence in the literature states that the lifetime of singlet oxygen in the cytoplasm and in the cell membrane ranges from 1.0 to $0.10 \mu \mathrm{s}$ $(4,60,78)$. The majority of the singlet oxygen generated will be quenched by the high concentration of biological molecules present within the cell so, it was assumed that the effects of deuterium-oxide solvent and modest concentrations of singlet-oxygen quenchers should only have a minor effect on the rate of ACE inactivation. 


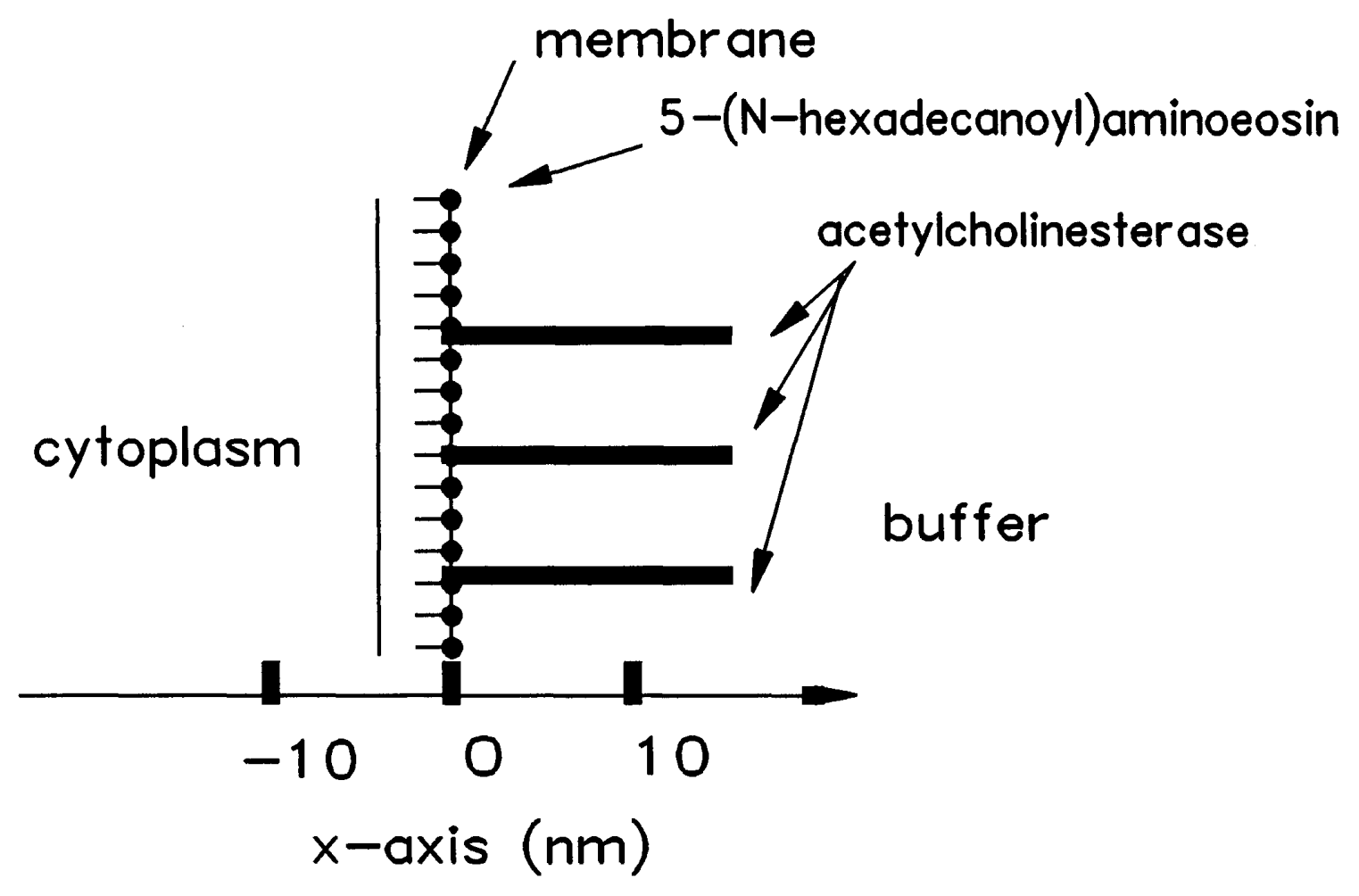

Figure 5. Geometry Of Theoretical Model. 
Much of the literature that supports singlet-oxygen-mediated cell damage is based on simple model systems and it is not clear whether the results from these simple model systems apply directly to intact cells. One approach to the analysis of singlet-oxygenmediated cytotoxicity is to use a mathematical model that accounts for singlet-oxygen quenching and diffusion in various cell compartments. The mathematical model used for the K562 cells was a modification of a published mathematical model of singlet-oxygen quenching and diffusion in the cell $(13,22,79-81)$. For example, Baker and Kanofsky detected singlet-oxygen emission in L1210 leukemia cells labeled with polyporphyrins (21) and 5-(N-hexadecanoyl)-aminoeosin (E-16) (22) following pulsed-laser excitation. The kinetics of singlet-oxygen emission and absolute intensity of singlet-oxygen emission from E-16-labeled L1210 cells were in agreement with a theoretical mathematical model of singlet-oxygen quenching and diffusion. In order to use this theoretical model, a number of parameters were needed including the singlet-oxygen lifetimes and singletoxygen transport parameters for each phase. These parameters were obtained from the literature $(75,82-88)$ and are given in Table 2 . 
Table 2. Parameters Used For Theoretical Calculations.

\begin{tabular}{lll}
\hline Parameter & Value & Reference
\end{tabular}

lifetime of singlet oxygen in water lifetime of singlet oxygen in deuterium oxide diffusion coefficient of oxygen in water diffusion coefficient of oxygen in the cell membrane diffusion coefficient of oxygen in the cell cytoplasm partition coefficient for oxygen between cell membrane and aqueous phases (buffer or cytoplasm) cell membrane thickness* $7.0 \times 106$
$4.0 \times 10$
4.4
$4.0 \mathrm{~nm}$ $2.0 \times 10^{-5} \mathrm{~cm}^{-2} \mathrm{~s}^{-1}$

Ogilby and Foote (82)

Parker and Stanbro (12)

$3.1 \mu \mathrm{s}$

Egorov et al. (11)

$68 \mu \mathrm{s}$

St-Denis and Fell (83)

$7.0 \times 10^{-6} \mathrm{~cm}^{-2} \mathrm{~s}^{-1} \quad$ Fischkoff and

Vanderkoii (84)

O'Loughlin et al. (85)

Fischkoff and

Vanderkoii (84)

Bougnoux et al. (86)

Cornell and

Separovic (87)

Subczynski et al. (88)

radius of ACE molecule

$7.4 \mathrm{~nm}$
Rosenberry and

Scoggin (75)

${ }^{*}$ The most abundant phospholipids present in K562 cells have 18 carbon lengths to the hydrocarbon tail (86). Phospholipids of this type form a bilayer with an $4 \mathrm{~nm}$ thickness $(87,88)$. 
In this model, a one-dimensional linear coordinate system was used rather than a spherical coordinate system because the 15 to $20 \mu \mathrm{m}$ diameter of the cell (89) was sufficiently large so that diffusion in a one-dimensional linear coordinate system was an excellent approximation to a spherical coordinate system $(79,80)$. The one dimensional $\mathrm{x}$ axis was divided into three regions: the cytoplasm, the membrane and the external buffer. Each region of the $\mathrm{x}$ axis was described by a Fick equation that accounted for singlet-oxygen diffusion with an additional term added to account for singlet-oxygen quenching. Each region was assumed to have homogeneous properties with respect to singlet-oxygen diffusion and quenching. For these experiments, time-independent equations were applied because constant intensity irradiation was utilized. Using these conditions, a steady-state singlet-oxygen concentration was quickly reached (90). The following equations illustrate this theoretical mathematical model of singlet-oxygen quenching and diffusion:

$$
0=D_{c} \frac{d^{2}\left[{ }^{1} O_{2}\right]_{c}}{d x^{2}}-\frac{\left[{ }^{1} O_{2}\right]_{c}}{\tau_{c}}
$$

for cytoplasm,

$$
0=D_{m} \frac{d^{2}\left[{ }^{1} O_{2}\right]_{m}}{d x^{2}}-\frac{\left[{ }^{1} O_{2}\right]_{m}}{\tau_{m}}
$$

for membrane and 


$$
0=D_{b} \frac{d^{2}\left[{ }^{1} O_{2}\right]_{b}}{d x^{2}}-\frac{\left[{ }^{1} O_{2}\right]_{b}}{\tau_{b}}
$$

for buffer

where $\left[{ }^{1} \mathrm{O}_{2}\right]_{\mathrm{c}},\left[{ }^{1} \mathrm{O}_{2}\right]_{\mathrm{m}}$ and $\left[{ }^{1} \mathrm{O}_{2}\right]_{\mathrm{b}}$ are the singlet-oxygen concentrations in the cytoplasm, membrane and buffer, respectively, $x$ is the one-dimensional linear axis, $D_{c}, D_{m}$, and $D_{b}$ are the singlet-oxygen diffusion coefficients in the cytoplasm, membrane and buffer, respectively, and $\tau_{\mathrm{c}}, \tau_{\mathrm{m}}$, and $\tau_{\mathrm{b}}$ are the singlet-oxygen lifetimes in the cytoplasm, membrane and buffer, respectively.

Two boundary conditions were applied at the inner membrane surface:

$$
\begin{gathered}
\left.K 1^{1} O_{2}\right]_{c}=\left[{ }^{1} O_{2}\right]_{m} \\
D_{c} \frac{d\left[^{1} O_{2}\right]_{c}}{d x}=D_{m} \frac{\left.d{ }^{1} O_{2}\right]_{m}}{d x}
\end{gathered}
$$

and at the outer membrane surface:

$$
\begin{gathered}
\left.\left[{ }^{1} O_{2}\right]_{m}=K{ }^{1} O_{2}\right]_{b} \\
D_{m} \frac{d\left[{ }^{1} O_{2}\right]_{m}}{d x}=D_{b} \frac{\left.d{ }^{1} O_{2}\right]_{b}}{d x}+k_{h v}
\end{gathered}
$$


where $\mathrm{K}$ is the partition coefficient for singlet oxygen between the membrane and both aqueous phases (cytoplasm and buffer) and $\mathrm{k}_{\mathrm{h} \nu}$ is the rate of photochemical production of singlet oxygen per unit membrane surface area. Equations 15 and 17 resulted from the assumption of a fast equilibrium at the inner and outer surfaces of the cell membrane. Equations 16 and 18 resulted from the conservation of singlet oxygen at the membrane surfaces. Therefore, Equation 16 states that the flux of singlet oxygen in the cytoplasm must be equal to the flux of singlet oxygen at the inner membrane surface. Equation 18 states that the flux of singlet oxygen at the outer membrane surface must be equal to the flux of singlet oxygen in the buffer plus an additional term that accounts for the photochemical generation of singlet oxygen.

The photosensitizer used for the experiments with the K562 cells, E-16, partitioned into the outer lamella of the cell membrane with the eosin moiety close to the cell surface (76). An assumption was made that all of the singlet oxygen would be generated at the outer membrane surface. Thus, the rate of singlet oxygen generation, $\mathrm{k}_{\mathrm{h} p}$, appeared in the boundary condition describing the flux of singlet oxygen at the outer membrane surface. The solutions to Equations 12, 13 and 14 were well known and were found in a diffusion table (90). Setting the origin of the one-dimensional $\mathrm{x}$ axis at the outer surface of the membrane, gave the following solutions:

$$
\begin{gathered}
{\left[{ }^{1} O_{2}\right]_{c}=B_{c} e^{\alpha e^{x}}} \\
{\left[{ }^{1} O_{2}\right]_{m}=A_{m} e^{-\alpha_{m} x}+B_{m} e^{\alpha_{m} x}}
\end{gathered}
$$




$$
\left[{ }^{1} O_{2}\right]_{b}=A_{b} e^{-\alpha_{b} x}
$$

where $B_{c}, A_{m}, B_{m}$, and $A_{b}$ are coefficients determined using the boundary conditions, and $\alpha_{c}=\left(\tau_{c} D_{c}\right)^{-1 / 2}, \alpha_{m}=\left(\tau_{m} D_{m}\right)^{-1 / 2}$, and $\alpha_{b}=\left(\tau_{b} D_{b}\right)^{-1 / 2}$.

In this project, the singlet-oxygen concentration to which the ACE molecules were exposed was of interest. This quantity was obtained by integrating the singletoxygen concentration in a narrow band of buffer just outside the surface of the membrane. The thickness of the band was equal to the diameter of the ACE molecule. From Equation 21:

$$
\int_{0}^{x_{A C E}}\left[{ }^{1} O_{2}\right]_{b} d x=\frac{A_{b}}{\alpha_{b}}\left(1-e^{-\alpha_{b} x_{A C E}}\right)
$$

where $\mathrm{X}_{\mathrm{ACE}}$ is the diameter of the ACE molecule. The solution to Equation 22 was found in an integration table. Coefficient, $A_{b}$, was obtained from the solution to Equations 1521.

$$
\begin{gathered}
A_{b}=\frac{k_{h v}(1+E)}{D_{b} \alpha_{b}(1+E)-K D_{m} \alpha_{m}(1-E)} \\
E=\frac{\left(D_{c} \alpha_{c}+K D_{m} \alpha_{m}\right) e^{2 \alpha_{2} m}}{\left(K D_{m} \alpha_{m}-D_{c} \alpha_{c}\right)}
\end{gathered}
$$


where $\mathrm{m}$ is the cell membrane thickness.

The amount of singlet oxygen quenched by the cell can be calculated in an analogous manner by integrating the singlet-oxygen concentration over the membrane and cytoplasm.

$$
\int_{-\infty}^{-m}\left[{ }^{1} O_{2}\right]_{c} d x+\int_{-m}^{0}\left[{ }^{1} O_{2}\right]_{m} d x=\frac{B_{c}}{\alpha_{c}}\left(e^{-\alpha_{c} m}\right)+\frac{A_{m}}{\alpha_{m}}\left(1-e^{\alpha_{m} m}\right)+\frac{B_{m}}{\alpha_{m}}\left(1-e^{-\alpha_{m} m}\right)
$$

The coefficients, $B_{c}, A_{m}$ and $B_{m}$, were given by the following expressions:

$$
B_{c}=\frac{\left(e^{\alpha_{m} m}+E e^{-\alpha_{m} m}\right) k_{k v}}{\left(e^{-\alpha_{c} m}\right)\left[D_{b} \alpha_{b}(1+E)-K D_{m} \alpha_{m}(1-E)\right]}
$$

$$
A_{m}=\frac{k_{h v} K}{D_{b} \alpha_{b}(1+E)-K D_{m} \alpha_{m}(1-E)}
$$

$$
B_{m}=\frac{k_{h v} K E}{D_{b} \alpha_{b}(1+E)-K D_{m} \alpha_{m}(1-E)}
$$

By using this model, the inhibition of ACE inactivation on the K562 cell surface by singlet-oxygen quenchers can be used to calculate the lifetime of singlet oxygen in the cell membrane and in the cytoplasm close to the membrane. 
The predictions of the theoretical model are depicted in a more readily understood manner in Figure 6. Since singlet oxygen is being generated directly on the outer cell membrane surface, it is concentrated within the membrane. The diffusion of singlet oxygen within the membrane is very efficient because the membrane is so thin. As a consequence, the concentration gradient of singlet oxygen within this compartment is very small. The diffusion of singlet oxygen into the cytoplasm from the inner membrane is shorter compared to the diffusion of singlet oxygen from the outer membrane into the buffer because it was assumed that the singlet oxygen will become quenched by the high concentration of biological molecules present in the cytoplasm. The diffusion of singlet oxygen into the buffer from the outer membrane is longer than the previous scenario because the buffer is basically composed of water solvent. As a result, the singletoxygen lifetime in water solvent is longer than the singlet-oxygen lifetime in the cytoplasm. In order to determine the steady-state singlet-oxygen concentration to which the ACE molecules were exposed, an integration was made from the membrane origin, 0 , to the diameter of the ACE molecules, $X_{\mathrm{ACE}}$, as shown in Figure 5. This integration was performed in the absence and presence of singlet-oxygen quencher and generated theoretical ratios. From various assumed singlet-oxygen lifetimes in the different cell compartments, theoretical curves were generated. The data from the ACE inactivation experiments were then fitted to the theoretical model to see if any correlation existed. The best fit corresponded to an estimate of the singlet-oxygen lifetime in the membrane and in the cytoplasm close to the membrane. 


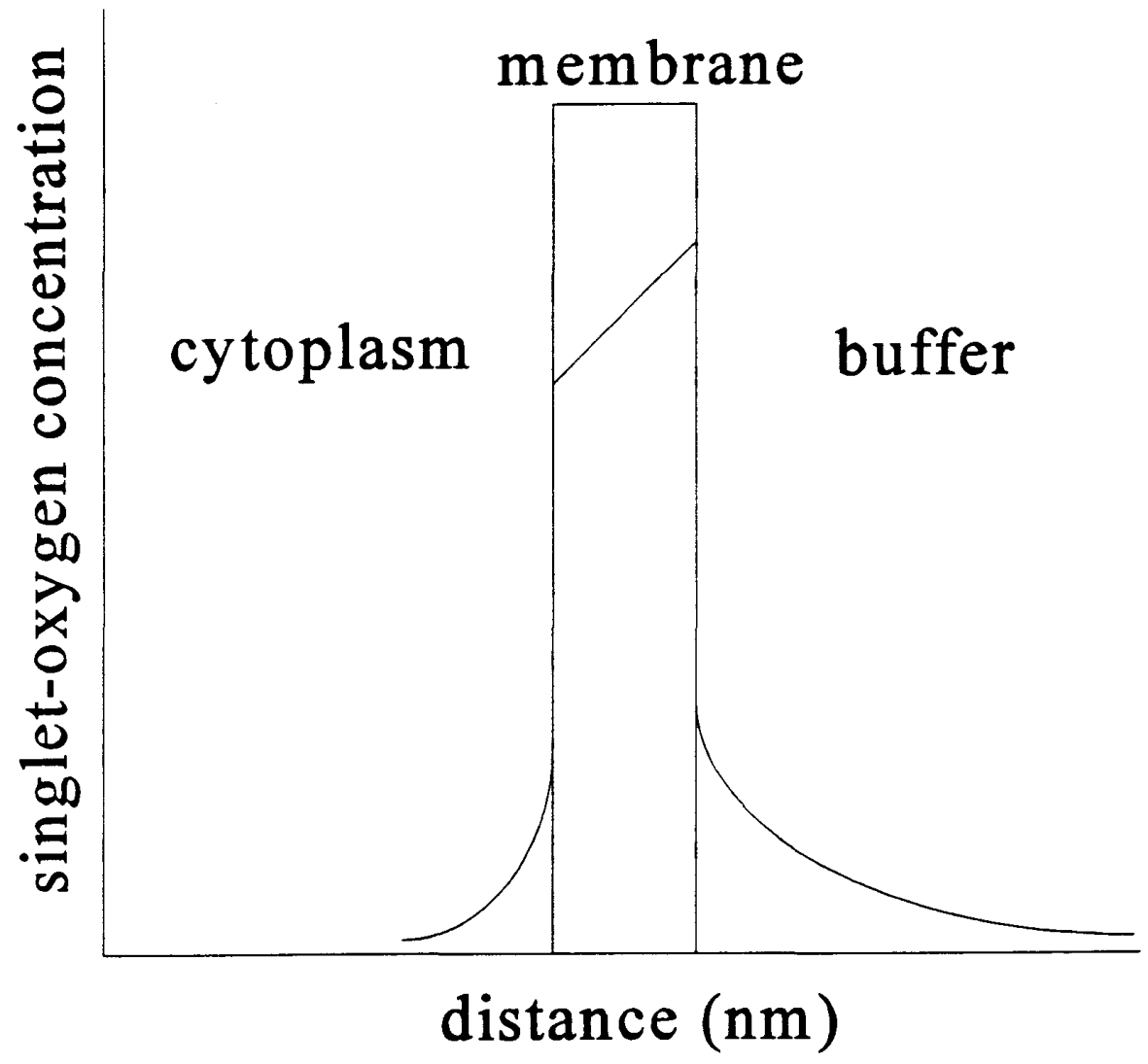

Figure 6. The Theoretical Mathematical Model Depicted In Cartoon Fashion. 
In order to apply this mathematical model, the concentrations of the hydrophilic singlet-oxygen quenchers and deuterium-oxide solvent within the K562 cells were needed. Penetration of the singlet-oxygen quenchers into the cytoplasm would be expected to decrease the singlet-oxygen lifetime within this compartment. Penetration of deuteriumoxide solvent into the cytoplasm would be expected to increase the singlet-oxygen lifetime within this compartment. The average concentration of these agents within the cell was determined by first solubilizing the cell pellets in phosphate buffer made with deuterium-oxide solvent, pD 7.4 and containing $70 \mathrm{mM}$ sodium lauryl sulfate (SLS). The lifetime of singlet oxygen was then determined from serial dilutions of these solubilized cell pellets. The resulting values were then plotted according to the SternVolmer equation. Extrapolation of the data to $100 \%$ cell pellet concentration gave the average quenching rate within the cell. The results were very linear and are shown in Figure 7. 


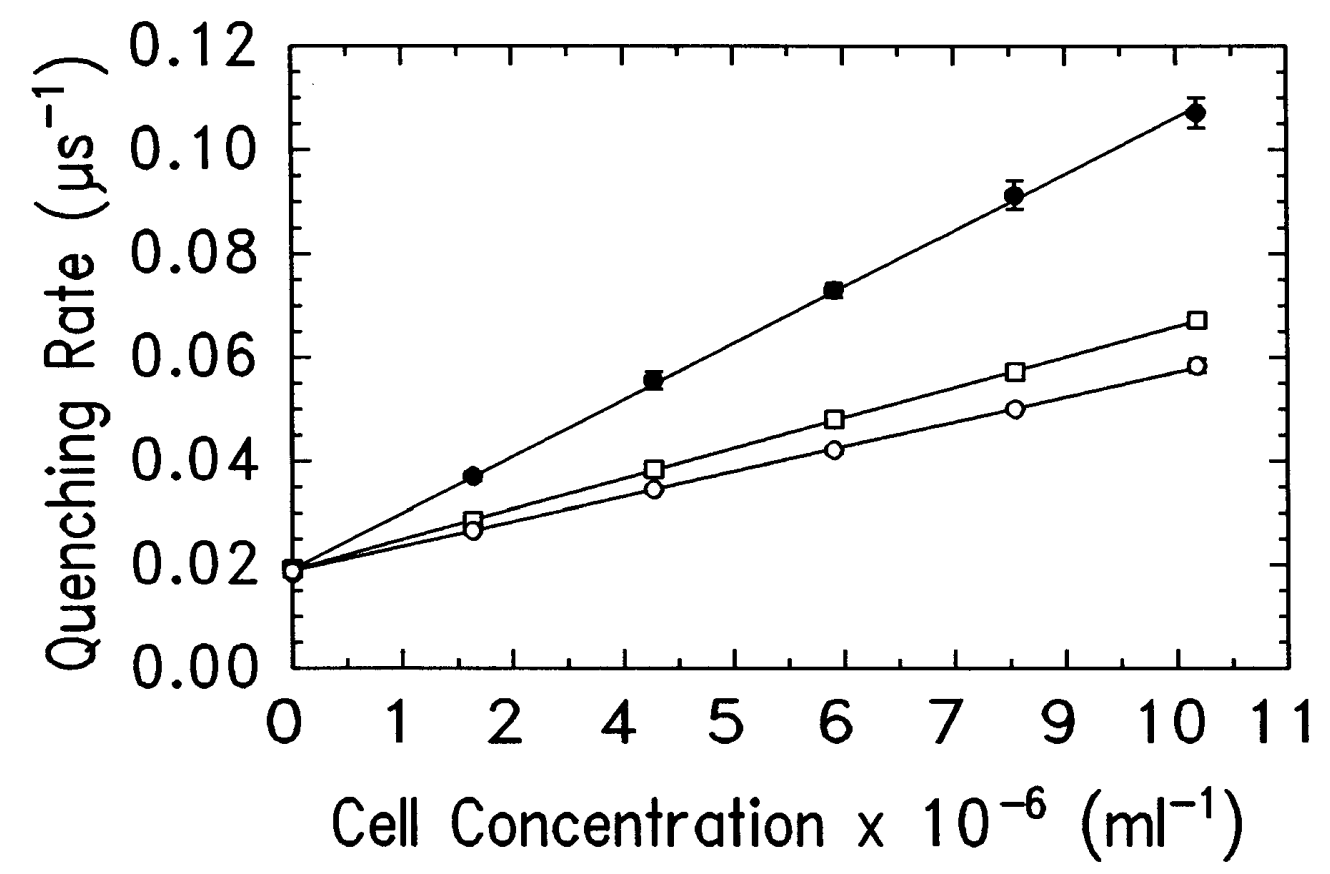

Figure 7. Typical Stern-Volmer Plots For Solubilized Cell Pellets. 
In Figure 7, the data for control cells $(O)$, cells incubated with $5.0 \mathrm{mM}$ sodium azide (๑), and cells incubated with $400 \mu \mathrm{M}$ Ni-chelate $2(\square)$ are listed. Each point was the average of 3 experiments \pm SEM. The cell pellets were diluted in $100 \mathrm{mM}$ phosphate buffer made from deuterium-oxide solvent, pD 7.4 and containing $70 \mathrm{mM}$ SLS. The photosensitizer used was $50 \mu \mathrm{M}$ TPPSO.

Table 3 summarizes the quenching data. As stated previously, the quenching rate of the control cell pellets was determined from extrapolation of the data to $100 \%$ cell pellet concentration. From the average weight of the cell pellets, the number of cells in the cell pellets and the density of the cells, $1.065 \mathrm{~g} / \mathrm{ml}(91)$, the volume of the cells was calculated. From this volume, the concentration of cells within the cell pellet was determined. At this $100 \%$ cell pellet concentration, it was assumed that the pellets were composed entirely of cells with no external buffer present.

The quenching rate of the control cell pellets was equal to the inverse of the singlet-oxygen lifetime. The apparent singlet-oxygen lifetime determined at $100 \%$ cell pellet concentration was equal to the inverse of the quenching rate. The change in the quenching rate with added quencher was equal to the difference between the quenching rate of the control cell pellets and the singlet-oxygen quencher-labeled cell pellets at $100 \%$ cell pellet concentration. The change in the quenching rate with added deuteriumoxide solvent was equal to the difference between the cell pellets incubated with water solvent and the cell pellets incubated with deuterium-oxide solvent. Replacement of the water solvent for deuterium-oxide solvent resulted in a negative value. The quencher or deuterium-oxide solvent concentrations within the cell pellets was determined by taking the product of the change in the quenching rate and the inverse of the quenching 
constant.

Therefore, when $5.0 \mathrm{mM}$ sodium azide was present in the external buffer, $5.2 \pm$ $0.30 \mathrm{mM}$ sodium azide was present within the K562 cells. When $400 \mu \mathrm{M}$ Ni-chelate 1 and $\mathrm{Ni}$-chelate 2 were present in the external buffer, only $170 \pm 10 \mu \mathrm{M}$ Ni-chelate 1 and $210 \pm 40 \mu \mathrm{M}$ Ni-chelate 2 was present within the K562 cells. The concentration of deuterium-oxide solvent present within the K562 cells was $21 \pm 8.0 \mathrm{M}$. Assuming that the concentration of water is $55 \mathrm{M}$, this suggests that only about $40 \%$ of the deuteriumoxide solvent penetrated the K562 cells. Perhaps, the presence of deuterium-oxide solvent in the buffer was uninviting for the cells. 
Table 3. Effect Of Singlet-Oxygen Quenchers And Of Deuterium-Oxide Solvent On Singlet-Oxygen Quenching By Cell Pellets.

\begin{tabular}{lllllll}
\hline Quencher & $\begin{array}{l}\text { Concentration } \\
\text { in external } \\
\text { buffer }\end{array}$ & Solvent & $\begin{array}{l}\text { Quenching rate } \\
\text { of control cell } \\
\text { pellets (no added } \\
\left.\text { quencher or } \mathrm{D}_{2} \mathrm{O}\right) \\
\times 10^{-6} \\
\left(\mathrm{~s}^{-1}\right)\end{array}$ & $\begin{array}{l}\text { Apparent }{ }^{1} \mathrm{O}_{2} \\
\text { lifetime in } \\
\text { control } \\
\text { cell pellets }\end{array}$ & $\begin{array}{l}\text { Change in } \\
\text { quenching rate } \\
\text { with added } \\
\text { quencher or with } \\
\mathrm{D}_{2} \mathrm{O} \text { solvent } \times 10^{-5} \\
(\mu \mathrm{s})\end{array}$ & $\begin{array}{l}\text { Quencher or } \\
\mathrm{D}_{2} \mathrm{O} \\
\text { concentration } \\
\text { in cell pellet }\end{array}$ \\
\hline azide & $5 \mathrm{mM}$ & $\mathrm{H}_{2} \mathrm{O}$ & $1.66 \pm 0.04$ & $0.60 \pm 0.02$ & $23 \pm 1$ & $5.2 \pm 0.3 \mathrm{mM}$ \\
Ni-chelate 1 & $400 \mu \mathrm{M}$ & $\mathrm{H}_{2} \mathrm{O}$ & $1.45 \pm 0.03$ & $0.69 \pm 0.02$ & $3.4 \pm 0.3$ & $170 \pm 10 \mu \mathrm{M}$ \\
Ni-chelate 2 & $400 \mu \mathrm{M}$ & $\mathrm{H}_{2} \mathrm{O}$ & $1.68 \pm 0.06$ & $0.60 \pm 0.02$ & $2.9 \pm 0.7$ & $210 \pm 40 \mu \mathrm{M}$ \\
& & $\mathrm{D}_{2} \mathrm{O}$ & $1.78 \pm 0.06$ & $0.56 \pm 0.02$ & $-1.2 \pm 0.4$ & $21 \pm 8 \mathrm{M}$
\end{tabular}

Quenching rate (QR) of control cell pellets $=\tau^{-1}$

Apparent ${ }^{1} \mathrm{O}_{2}$ lifetime in control cell pellets = quenching rate ${ }^{-1}$

Change in $\mathrm{QR}$ with added quencher $=\mathrm{QR}_{\text {quencher }}-\mathrm{QR}_{\text {control }}=\Delta$

Change in $\mathrm{QR}$ with $\mathrm{D}_{2} \mathrm{O}$ solvent $=\mathrm{QR}_{\mathrm{H} 2 \mathrm{O}}-\mathrm{QR}_{\mathrm{D} 2 \mathrm{O}}=\Delta$

Quencher or $\mathrm{D}_{2} \mathrm{O}$ concentration in cell pellet $=(\Delta){\text { (quenching constant })^{-1}}^{-1}$ 
Figures 8-11 show the comparison between the experimental ACE inactivation lifetime ratios and the ratios determined from the theoretical mathematical model. The experimental axis, on the left, is the ratio of the ACE inactivation lifetime without quencher to the ACE inactivation lifetime with quencher. The theoretical axis, on the right, is the ratio of the steady-state singlet-oxygen concentration to which the ACE molecules were exposed in the absence and presence of singlet-oxygen quencher. From the theoretical analysis, it was clear that singlet-oxygen quenchers with very large singletoxygen quenching constants were needed in order to obtain a significant inhibition of ACE inactivation on the K562 cell surface. For this reason, only azide anion, Ni-chelate 1 and $\mathrm{Ni}$-chelate 2 were studied.

In generating the theoretical curves shown in Figures 8-11, an assumption was made that the hydrophilic quenchers used as well as the deuterium-oxide solvent uniformly distributed themselves throughout the cytoplasmic compartment, but not the cell membrane. A further assumption was made that at equilibrium, the singlet-oxygen quencher concentration in the cytoplasm was proportional to the singlet-oxygen quencher concentration in the buffer. Thus, the concentrations of the quenchers and deuterium oxide in the cytoplasm were calculated using the quenching data given in Table 3 . For example, when $200 \mu \mathrm{M} \mathrm{Ni-chelate} 1$ was present in the external buffer instead of 400 $\mu \mathrm{M}$, an assumption was made that $85 \mu \mathrm{M}$ Ni-chelate 1 was present in the cytoplasmic compartment rather than $170 \mu \mathrm{M}$. Since the ratio of quencher concentration in the cytoplasm to quencher concentration in the buffer was different for each quencher and deuterium-oxide solvent, the theoretical curves given in Figures 8-11 are different.

The data were not sufficient to provide separate estimates for the singlet-oxygen 
lifetimes within the cell membrane and within the cytoplasm. To obtain separate estimates would have required a second target molecule for singlet oxygen located at the inner surface of the cell membrane or somewhat deeper within the cell cytoplasm. Thus, in obtaining fits of the theoretical curves to the experimental data, an assumption was made that the lifetime of singlet oxygen within the membrane and within the cytoplasm were equal. 


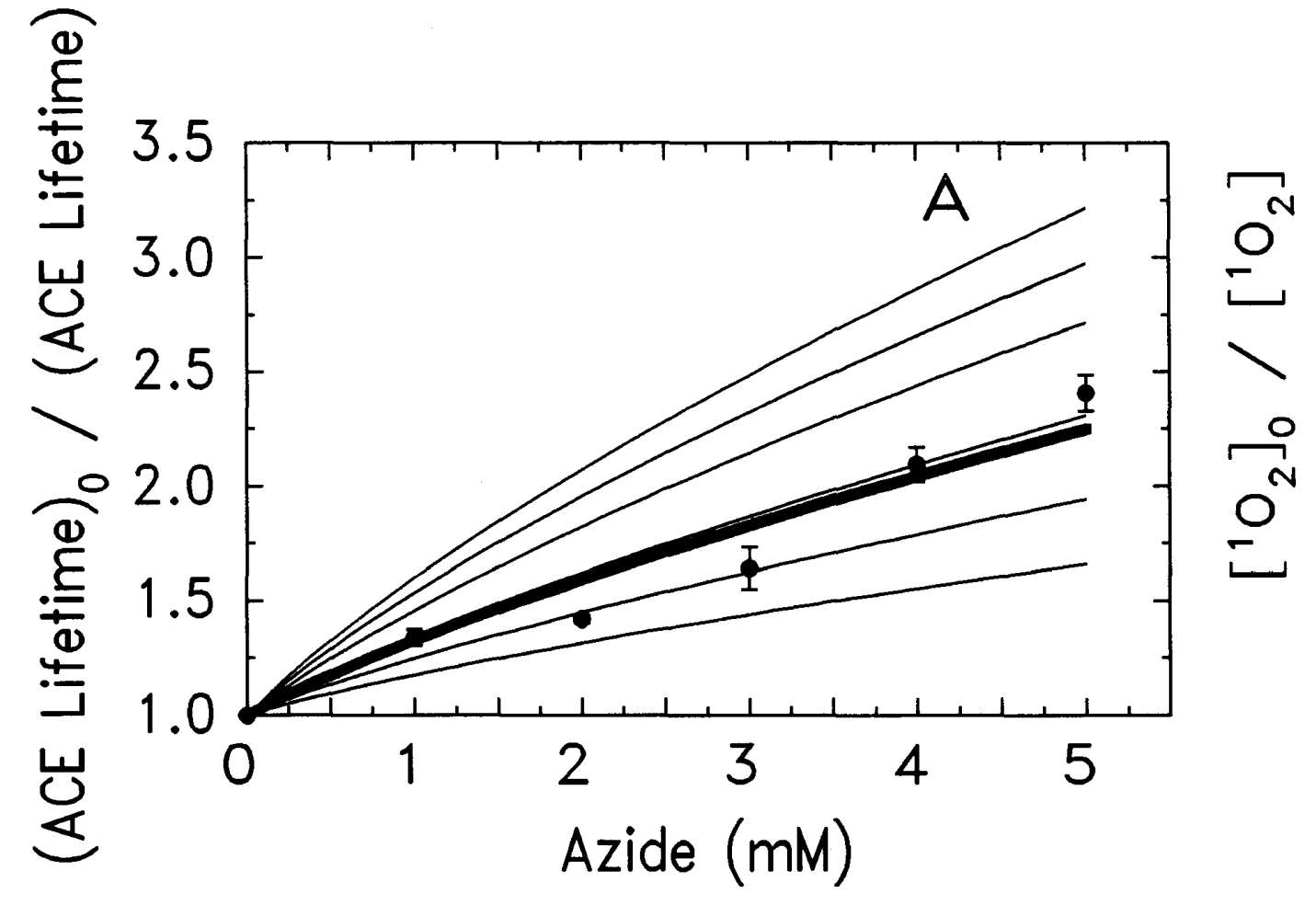

Figure 8. Comparison Between Theory And Experiment For The K562 Cells. The Singlet-Oxygen Quencher Is Sodium Azide. 


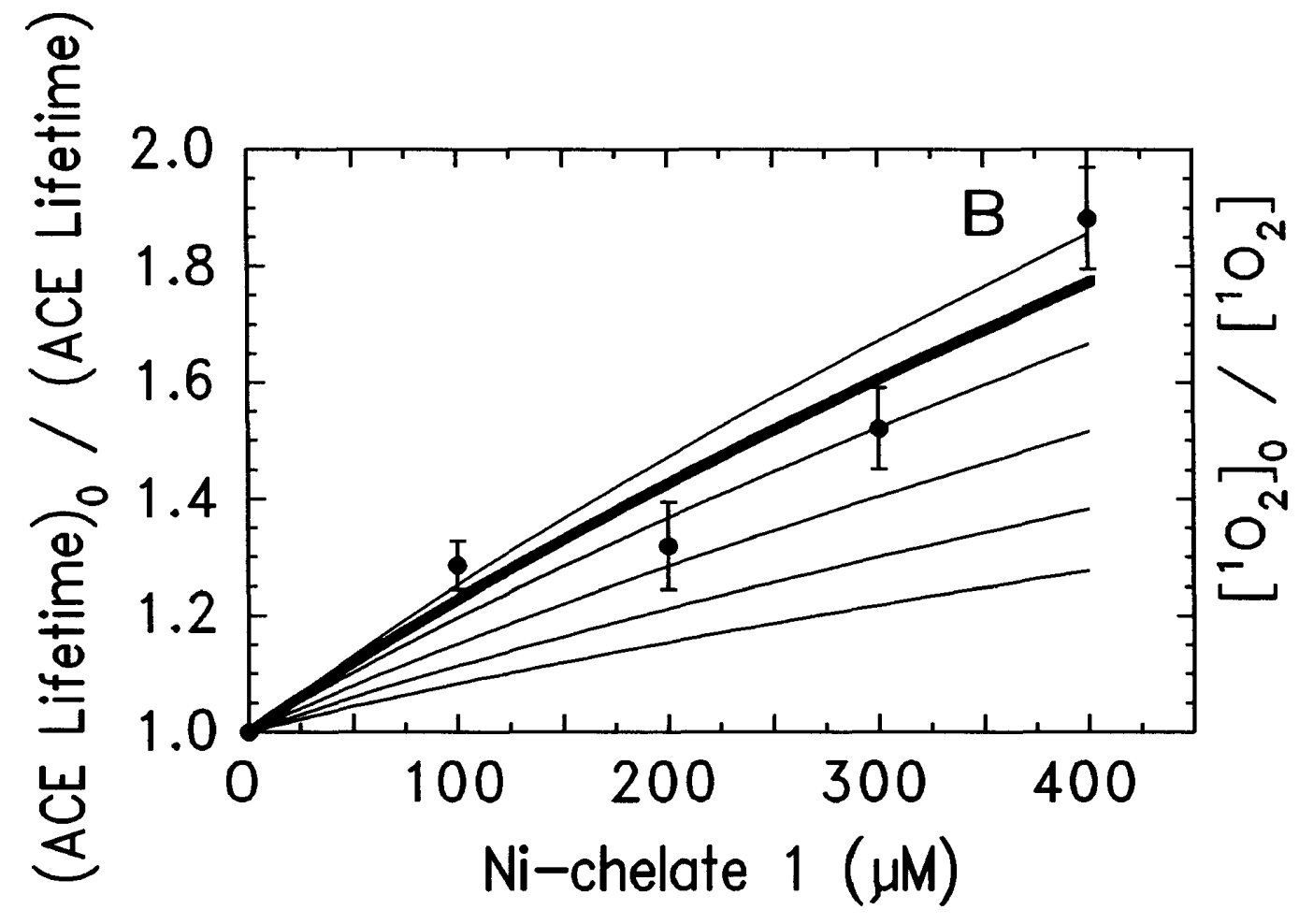

Figure 9. Comparison Between Theory And Experiment For The K562 Cells. The Singlet-Oxygen Quencher Is NiChelate 1. 


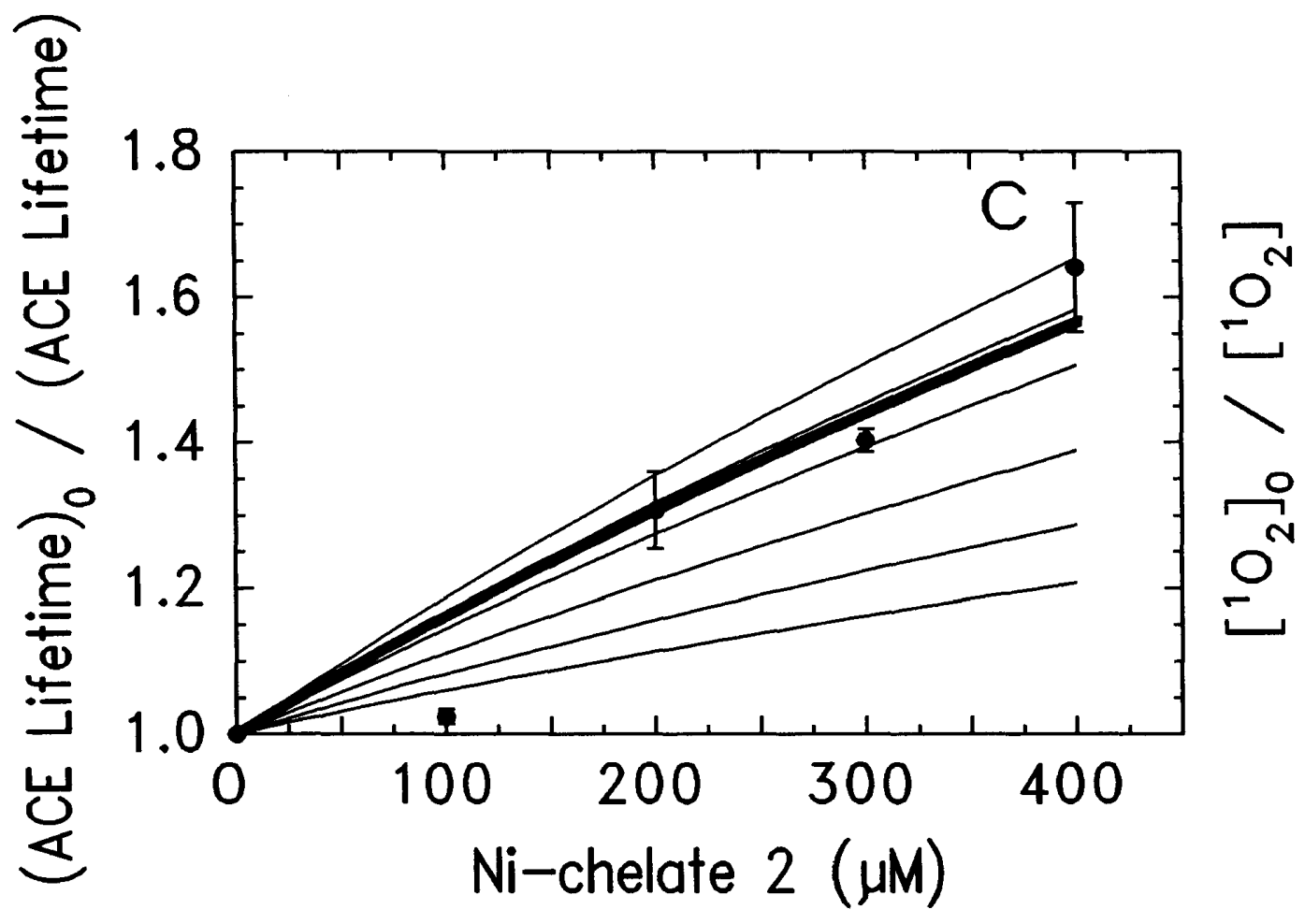

Figure 10. Comparison Between Theory And Experiment For The K562 Cells. The Singlet-Oxygen Quencher Is NiChelate 2. 


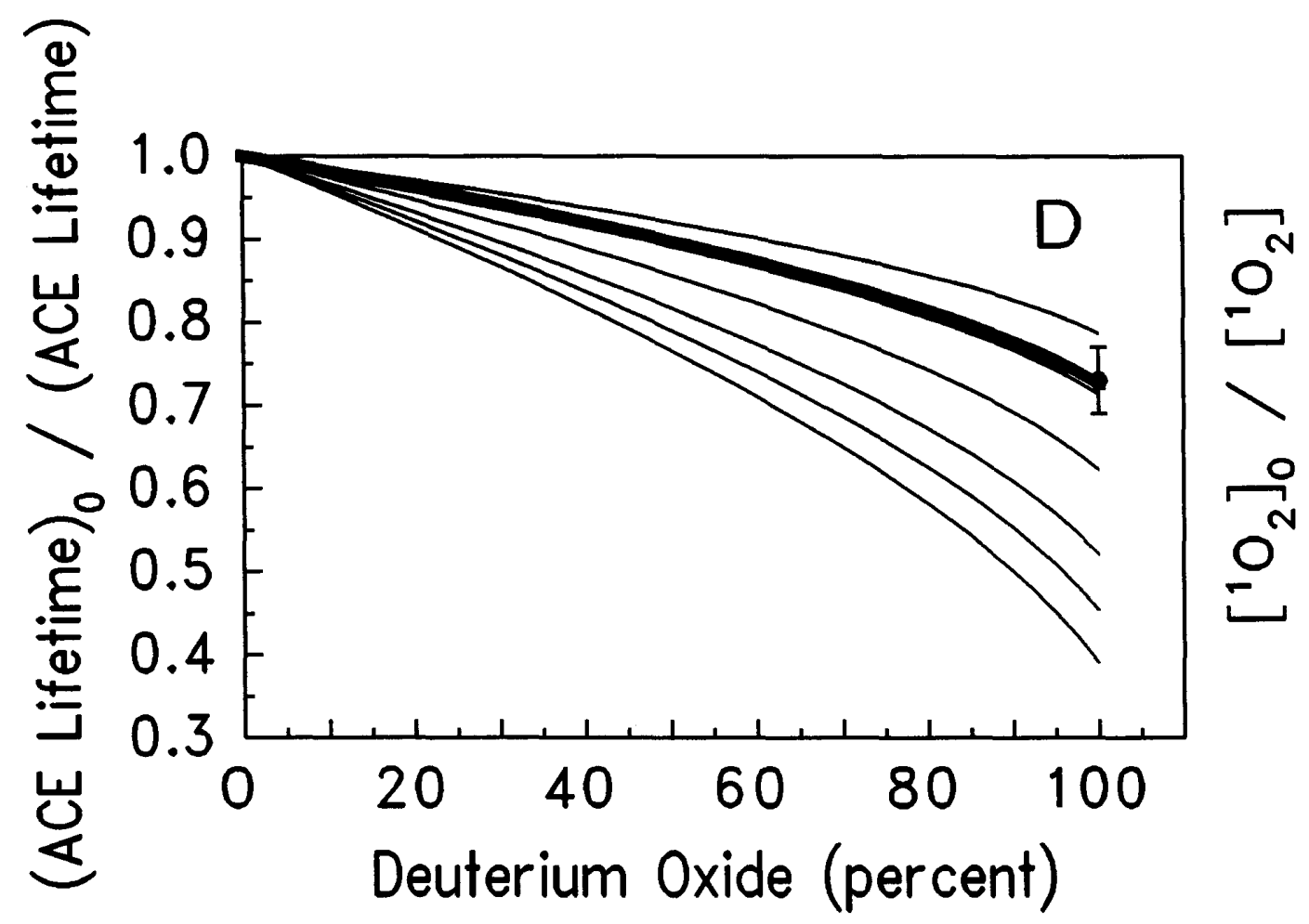

Figure 11. Comparison Between Theory And Experiment For The K562 Cells. Deuterium-Oxide Solvent. 
In Figures 8-11, the thin lines represented theoretical curves for various assumed cell singlet-oxygen lifetimes. The upper curves (lowest curve for Figure 11) were the theoretical upper limit for a cell that had no biological molecules present. In this case, the cytoplasmic lifetime was $3.1 \mu \mathrm{s}$ and the cell-membrane lifetime was $26 \mu \mathrm{s}$. In all other curves, the cytoplasmic and cell-membrane lifetimes were assumed to be the same and were $3.1,2.0,1.0,0.5$, and $0.25 \mu \mathrm{s}$ from top to bottom (bottom to top in Figure 11). The thick line in each panel was the result of a non-linear least-squares fit to the experimental data. Each point was the average of 3 experiments \pm SEM. In Figure 9, the thick line covered the $3.1 \mu \mathrm{s}$ thin line. These curves described the effect upon the steady-state concentration of singlet oxygen integrated over the region occupied by ACE when singlet-oxygen quenchers or deuterium-oxide solvent were added to the external buffer. The curves, plotted using the Stern-Volmer convention, displayed significant curvature in contrast to the linear relationship expected for a homogeneous system. The effects of quenchers and deuterium oxide upon the steady-state concentration of singlet oxygen was much less than the effects in dilute aqueous solution. Again, the curves in Figures 8-11 differed because they assumed different percentages of penetration of the quenchers and deuterium-oxide solvent into the cell cytoplasm.

Using sodium azide as a singlet-oxygen quencher, Figure 8, the theoretical model predicted a singlet-oxygen lifetime in the cytoplasm and in the membrane of $0.90 \pm 0.20$ $\mu \mathrm{s}$. This was in reasonable agreement with values reported in the literature. Using the nickel chelates as singlet-oxygen quenchers, Figures 9 and 10, the predicted singletoxygen lifetimes were anomalously large. The singlet-oxygen lifetimes were $3.2 \pm 1.1$ $\mu$ s for Ni-chelate 1 and $2.8 \pm 1.1 \mu \mathrm{s}$ for Ni-chelate 2 . The structure of these nickel 
chelates is shown in Figure 12. A property of polyaromatic compounds having at least two negative charges, the negative charges are on the sulfur groups of the nickel chelates, is that these compounds enter the cell by endocytosis rather than by diffusion and have a granular distribution throughout the cytoplasm (92). Perhaps, this uneven distribution of the nickel chelates throughout the cytoplasm with a higher concentration near the inner and outer cell membrane resulted in the larger than expected singletoxygen lifetimes. Using deuterium-oxide solvent, Figure 11, the theoretical model predicted a singlet-oxygen lifetime in the cytoplasm and in the membrane of $0.45 \pm 0.15$ $\mu \mathrm{s}$. This was in reasonable agreement with values reported in the literature. In Figure 11 , the theoretical curves decrease because deuterium-oxide solvent increases the singletoxygen lifetime. 
Figure 12. Nickel Chelate Structures.

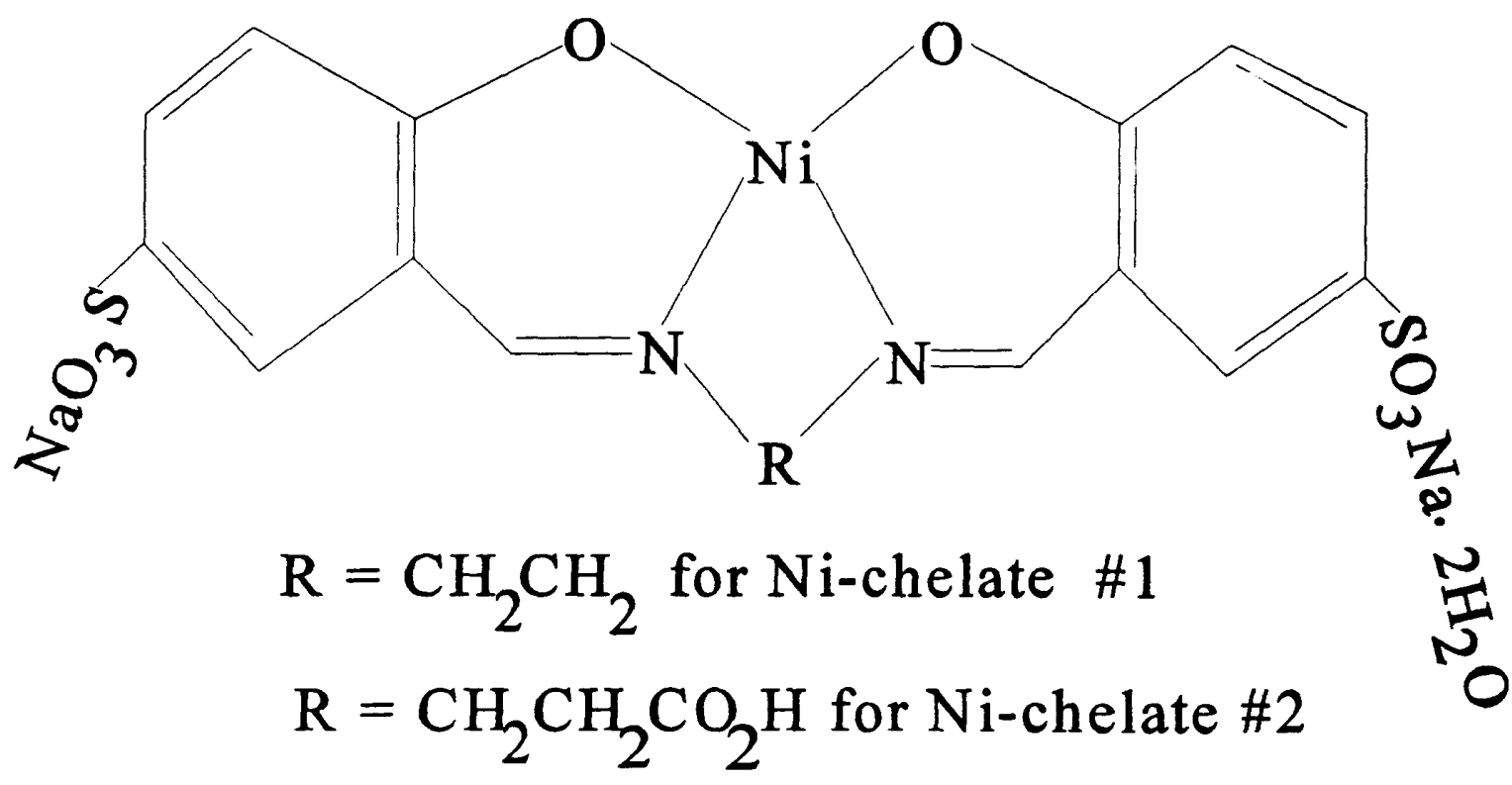


As stated above, most of the curves shown in Figures 8-11 assumed that the singlet-oxygen lifetimes in the cytoplasm and the cell membrane were equal. Figures 13 and 14 illustrated the effects on the theoretical model caused by independently varying the singlet-oxygen lifetimes in the cytoplasm and in the cell membrane. The singletoxygen quencher used was sodium azide. 


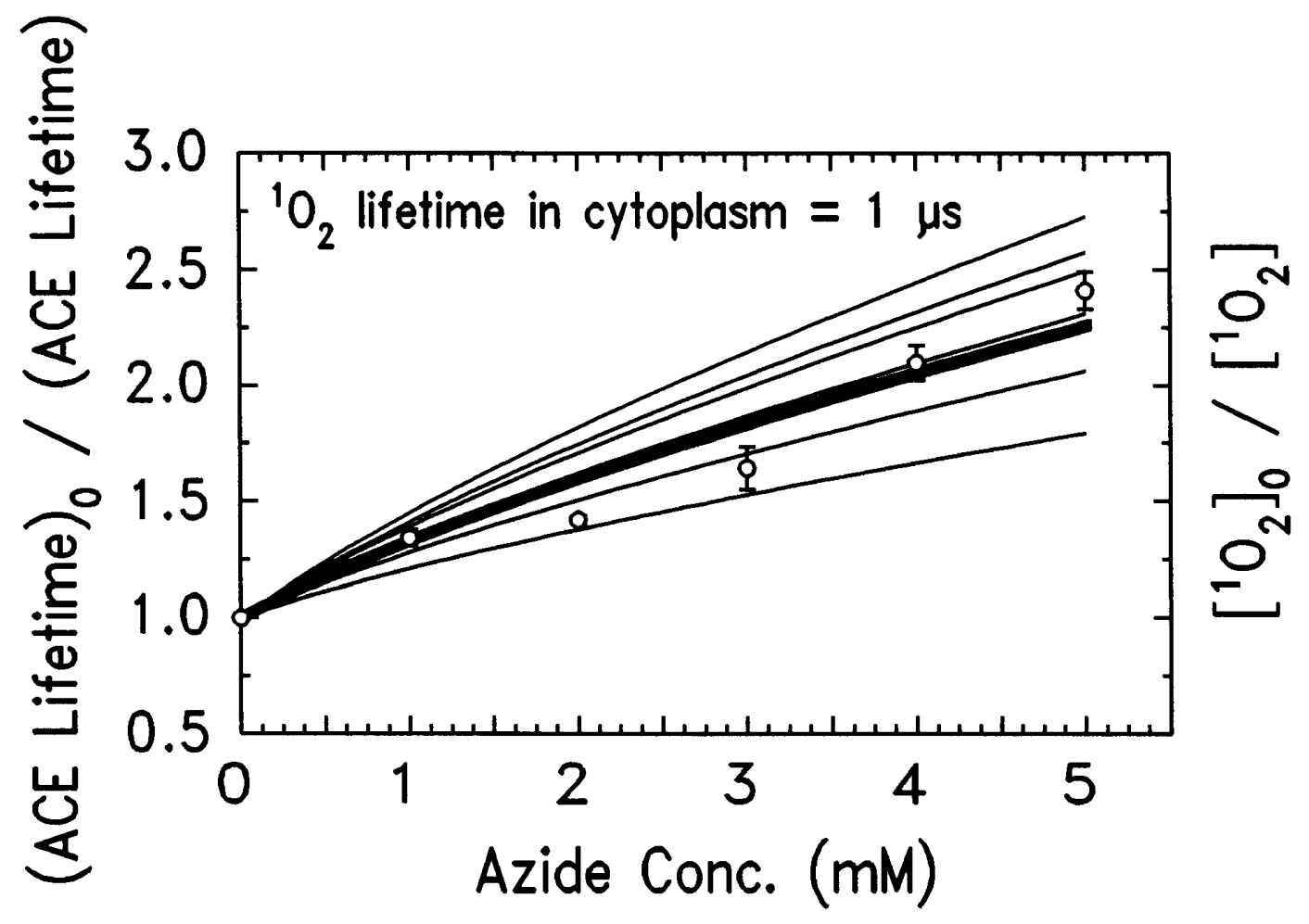

Figure 13. Comparison Between Theory And Experiment. Singlet-Oxygen Lifetime In The Cytoplasm Is Held Constant At $1 \mu \mathrm{s}$. 


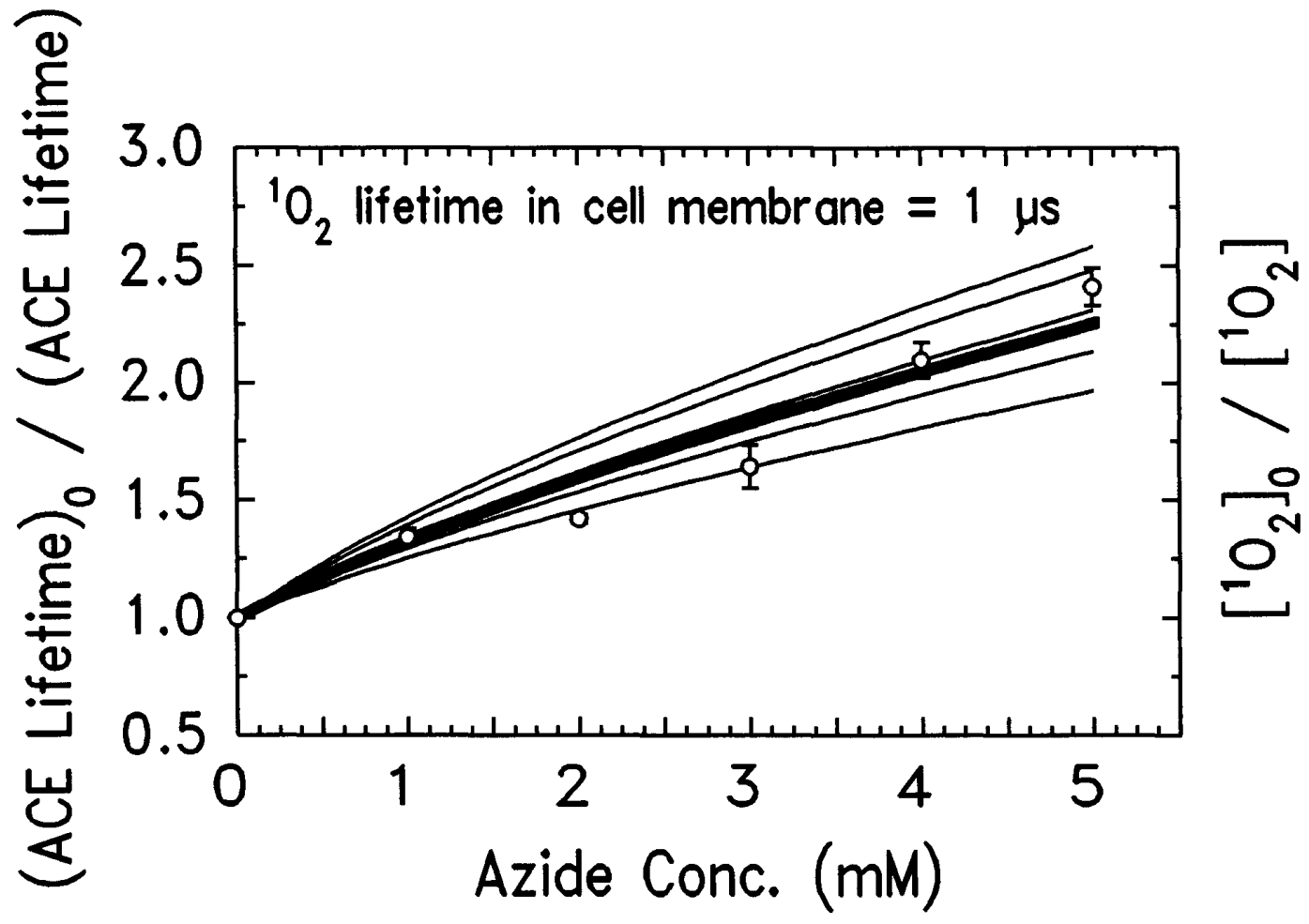

Figure 14. Comparison Between Theory And Experiment. Singlet-Oxygen Lifetime In The Cell Membrane Is Held Constant At $1 \mu \mathrm{s}$. 
In Figures 13 and 14, the thin lines represented varying singlet-oxygen lifetimes in the cell membrane and the cytoplasm, respectively. Again, the upper curves are the theoretical upper limit for a cell that has no biological molecules present. From top to bottom, the cell-membrane lifetimes were assumed to be $26,3.1,2.0,1.0,0.50$, and $0.25 \mu \mathrm{s}$. Holding the singlet-oxygen lifetime in the cytoplasm constant at $1.0 \mu \mathrm{s}$, Figure 13 , the non-linear least squares fit to the experimental data equaled a singlet-oxygen lifetime in the membrane of $0.85 \mu \mathrm{s}$. Holding the singlet-oxygen lifetime in the membrane constant at $1.0 \mu \mathrm{s}$, Figure 14, the non-linear least squares fit to the experimental data equaled a singlet-oxygen lifetime in the cytoplasm of $0.80 \mu \mathrm{s}$. Thus, increasing the lifetime in either the cytoplasm or the membrane caused a comparable decrease in the other compartment.

Table 4 illustrated how changes in various parameters affected the predictions of the theoretical model. The very last column of Table 4 is the theoretical ratio of the steady-state singlet-oxygen concentration to which the ACE molecules were exposed in the absence and in the presence of $5.0 \mathrm{mM}$ sodium azide. The effect of doubling or halving each parameter was shown on subsequent lines of the table. A factor of two change in any single parameter caused less than a factor of two change in the predictions of the model. For example, changing some parameters, such as the membrane thickness, the ACE radius or the cytoplasmic and membrane diffusion coefficients, caused only very small changes in the predictions of the model. Thus, the predictions of the theoretical model do not depend upon extremely accurate values for all the parameters. 
Table 4. Theoretical Effect Of Various Parameters Upon The Singlet-Oxygen Exposure To ACE On The K562 Cell Surface. Quenchers Added To The External Buffer.

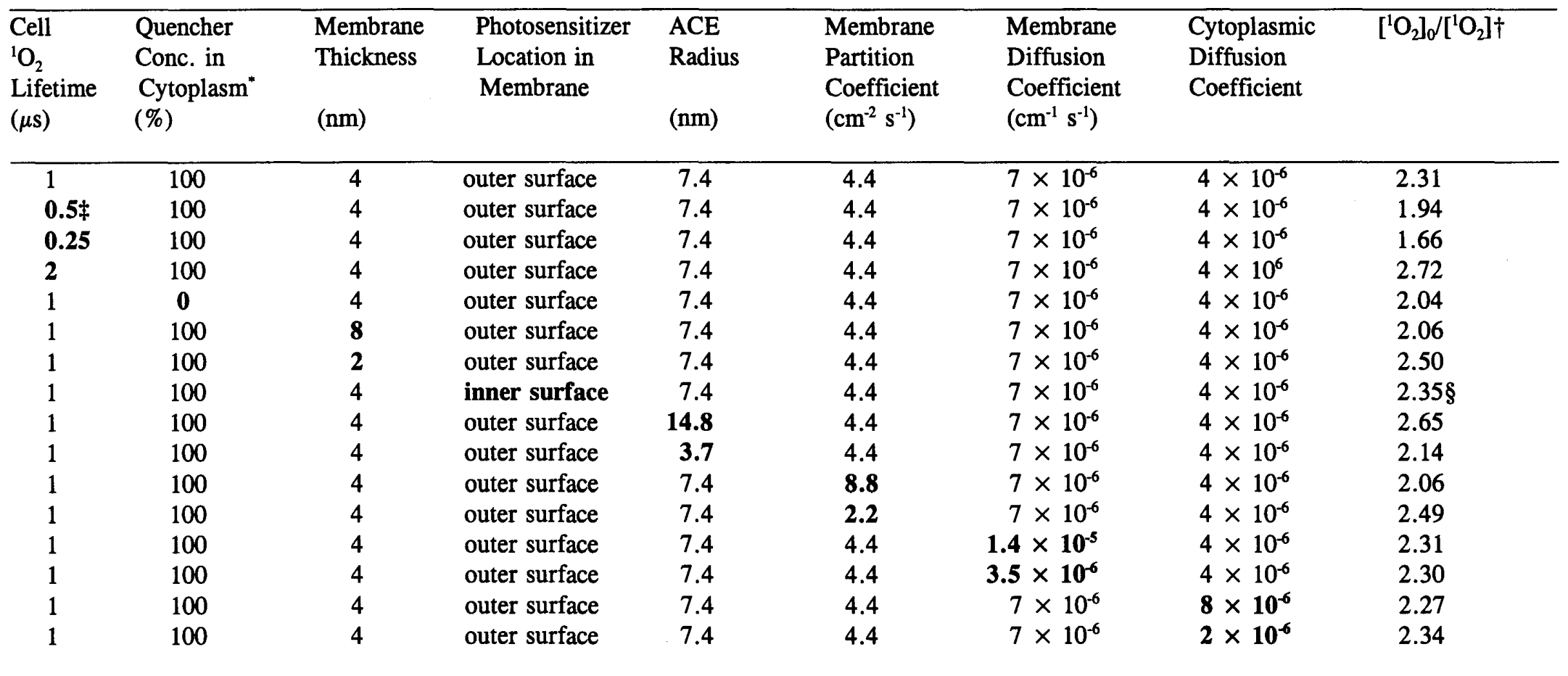

"Quencher concentration in cytoplasm as a percentage of the quencher concentration in the buffer.

†Ratio of steady-state singlet-oxygen concentration integrated over the position of the ACE molecule in the absence of added quenchers (singlet-oxygen lifetime in external buffer of $3.1 \mu \mathrm{s}$ ) to the integrated singlet-oxygen concentration in the presence of $5 \mathrm{mM}$ sodium azide (singlet-oxygen lifetime in external buffer of $0.396 \mu \mathrm{s}$ ). The ratios are calculated from the mathematical model described in the text.

$\ddagger$ Parameters in bold differ from those on the first line of the table.

$\S$ Calculated using a modified mathematical model in which all of the singlet oxygen is assumed to be generated at the interface between the cytoplasm and the cell membrane. 


\section{Studies With K562 Erythroleukemia Cells}

In the studies with the K562 cells, a number of controls were performed. As stated earlier, E-16, the lipophilic anionic photosensitizer used to incubate the K562 cells, binds to the outer cell membrane surface. The majority of the E-16 stays at the outer cell membrane surface however, some of the E-16 can diffuse into the buffer. In order to make sure that any diffusion of E-16 into the buffer was not responsible for the inactivation of the ACE molecules on the K562 cell surface, these cells were incubated with a different photosensitizer, eosin bound to high molecular-weight dextran. This water soluble photosensitizer essentially stayed in the buffer. As a result, the generation of singlet oxygen from this photosensitizer would become quenched by the buffer and would not be expected to have a great effect on the rate of ACE inactivation. As shown in Table 5, compared to E-16, eosin bound to high molecular-weight dextran caused very little inactivation of ACE in either water or deuterium-oxide buffer after a 30 minute irradiation time. Thus, these controls demonstrated that any diffusion of E-16 into the buffer was not responsible for the inactivation of the ACE molecules on the K562 cell surfaces. 
Table 5. Comparison Of Photochemical Inactivation Of ACE On K562 Leukemia Cells Caused By E-16 And Eosin Bound To Dextran.*

\section{Photosensitizer}

\section{(Activity / Activity $)_{0} \dagger$}

\section{Water solvent Deuterium-oxide solvent}

\begin{tabular}{lll}
\hline none & $0.97 \pm 0.01$ & $0.97 \pm 0.01$ \\
E16 & $0.35 \pm 0.01$ & $0.26 \pm 0.01$ \\
eosin bound to dextran & $0.92 \pm 0.01$ & $0.96 \pm 0.02$
\end{tabular}

"The concentrations of E16 and of eosin bound to dextran added to the buffer were each $1.0 \mu \mathrm{M}$. $\dagger$ Ratio of ACE activity after $30 \mathrm{~min}$. irradiation to pre-irradiation activity. 
Another explanation for the decrease in the ACE activity over time could be that the ACE molecules were being cleaved during the irradiation. If the ACE molecules were being cleaved from the cell surface during increasing irradiation times, a decrease in the activity of the enzyme over time would be expected. In order to control for this, the supernatant from irradiated cells was measured for ACE activity. The percentage of $\mathrm{ACE}$ activity found in the supernatant after a 30 minute irradiation time was $2.0 \pm 2.0 \%$ ( $n=3 \pm$ SEM) of the ACE activity initially present on the K562 cells. Thus, it was concluded that the ACE molecules on the surface of the K562 cells remained intact during irradiation.

Another concern was that the presence of deuterium-oxide solvent or singletoxygen quenchers in the buffer might change the amount of E-16 that partitioned into the K562 cell membranes. This potential artifact was evaluated by measuring the amount of E-16 in the cell pellets. The relative concentrations of E-16 were $1.00 \pm 0.02,1.00$ $\pm 0.02,0.99 \pm 0.01$, and $1.01 \pm 0.04(\mathrm{n}=3 \pm$ SEM) for cells incubated without an added singlet-oxygen quencher, with $5.0 \mathrm{mM}$ sodium azide, with $400 \mu \mathrm{M}$ Ni-chelate 1 and with $400 \mu \mathrm{M}$ Ni-chelate 2 , respectively. For cells incubated in deuterium-oxide buffer, the relative E-16 concentration was $1.01 \pm 0.03(n=3 \pm$ SEM). Therefore, it was concluded that the amount of E-16 that partitioned into the $\mathrm{K} 562$ cell membranes was not changed by the presence of deuterium-oxide solvent or singlet-oxygen quenchers in the buffer.

A fourth concern was that the photosensitization might lyse the cells, resulting in the release of significant amounts of the cell contents into the buffer. After a 30 minute irradiation time, the K562 cells were found to have lost $69 \pm 1.0 \%(\mathrm{n}=3 \pm \mathrm{SEM})$ of 
their ability to exclude the DNA staining dye, TO-PRO-3 iodide. After this was discovered, the lifetime of singlet oxygen in the cell supernatants labeled with E-16 and irradiated in PBS made with deuterium-oxide solvent was measured. After a 30 minute irradiation time, the lifetime of singlet oxygen in the cell supernatants was still $57 \pm 1.0$ $\mu \mathrm{s}(\mathrm{n}=3 \pm \mathrm{SEM})$. This demonstrated that large amounts of biological molecules were not released into the buffer. If large amounts of these molecules were present in the buffer, quenching would have significantly lowered the singlet-oxygen lifetime. Therefore, it was concluded that photosensitization of the K562 cells did not release significant amounts of the cell contents into the buffer because the singlet-oxygen lifetime measured in the cell supernatants was not changed.

Figure 15 demonstrated that variations of the E-16 concentrations in the buffer also varied the E-16 concentrations in the cell membrane. As shown, the data were linear up to $1.0 \mu \mathrm{M}$ E-16 and the data curved at higher E-16 concentrations. The curvature of the data was probably due to some sort of saturation effect caused by the high concentration of photosensitizer molecules within the cell membrane. In Figure 15, net fluorescence was equal to the fluorescence of the dyed cells minus the fluorescence of the undyed cells. Each point was the average of 3 experiments \pm SEM. 


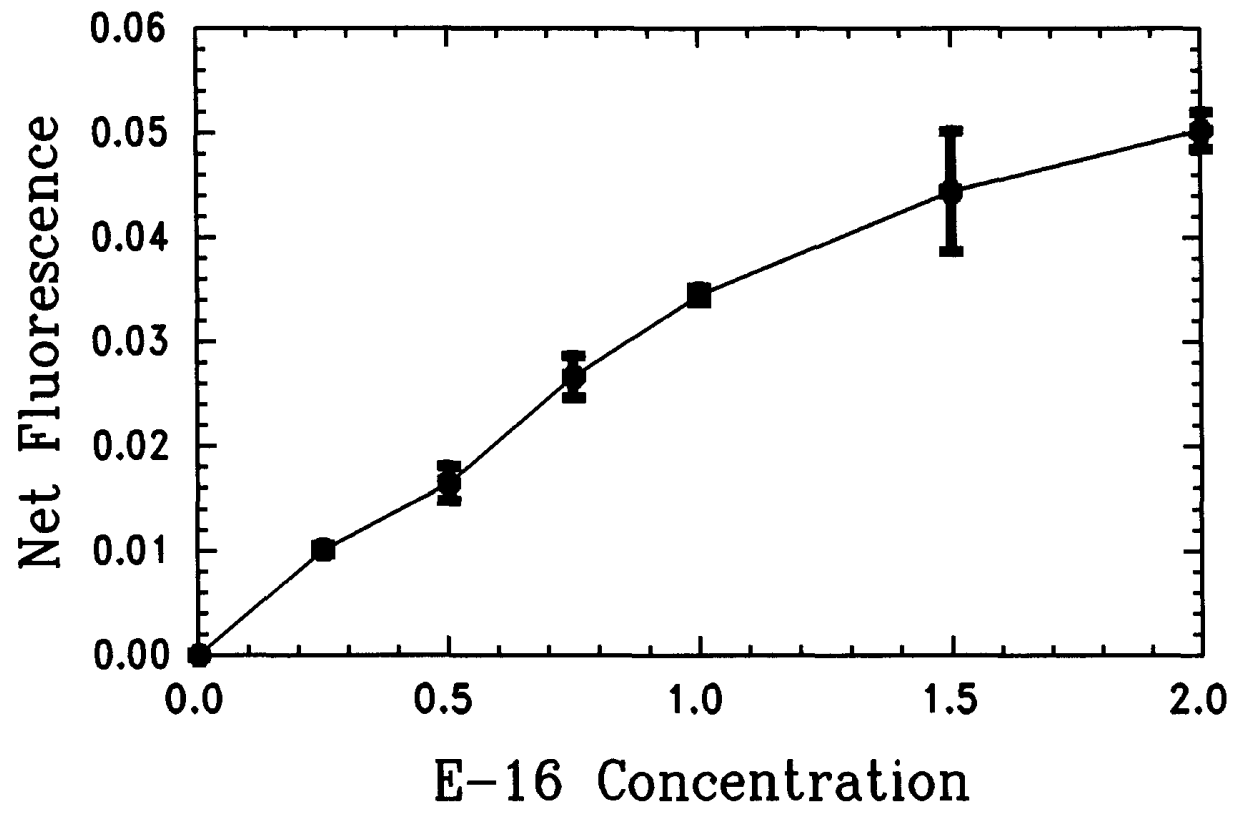

Figure 15. Net Fluorescence Intensity Versus Varying E-16 Concentration. The E-16 Concentrations Are 0, 0.25, $0.50,0.75,1.0,1.5$, And $2.0 \mu \mathrm{M}$, Respectively. 
Figure 16 illustrated the kinetics of ACE inactivation on the surface of the K562 cells. The data were well fit by a first order decay. The decrease in the activity of ACE over time was found to be proportional to the concentration of the active enzyme, [A]. Also, from the reciprocity experiments, Figure 2, the rate of ACE inactivation was found to be inversely proportional to the light intensity. Therefore, the results from these experiments obeyed a simple second-order rate expression, similar to the solution experiments.

As stated earlier, modest concentrations of singlet-oxygen quenchers should only have a minor effect on the rate of ACE inactivation. However, high concentrations of sodium azide, $(3.0 \mathrm{mM}$ and $5.0 \mathrm{mM})$, had a significant effect on the rate of ACE inactivation. The most likely reason for this effect was that at high singlet-oxygen quencher concentrations, the added singlet-oxygen quencher successfully competes with the biological molecules present within the cell. 


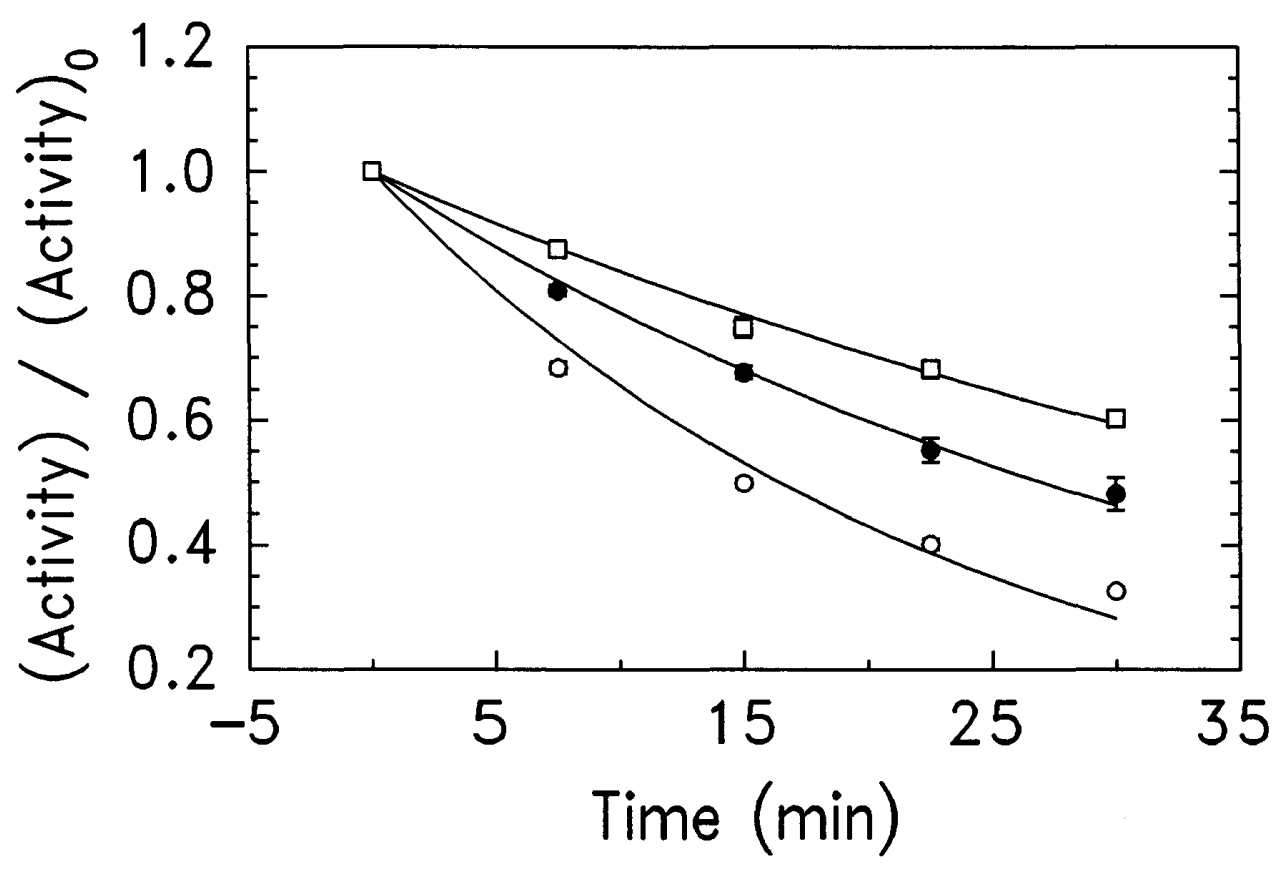

Figure 16. Effect Of Azide Anion Upon The Kinetics Of ACE Inactivation On The Surface Of The K562 Cells. 
In Figure 16, the conditions were $5 \times 10^{6}$ cells $/ \mathrm{ml}, 1.0 \mu \mathrm{M} \mathrm{E}-16,1.0 \mathrm{mg} / \mathrm{ml}$ glucose, PBS made with water solvent, $\mathrm{pH} 7.4$ and $600 \mu \mathrm{W} \mathrm{cm} \mathrm{cm}^{2}$ light fluence rate. The sodium azide concentrations used were $0 \mathrm{mM}(\bigcirc), 3.0 \mathrm{mM}(\odot)$, and $5.0 \mathrm{mM}(\square)$, respectively. The curves result from a non-linear least squares fit to an exponential decay. The correlation coefficients for the curves were $0.997,0.998$, and 0.994 from top to bottom, respectively. Each point was the average of 3 experiments \pm the SEM.

As stated earlier, determining the effects on cell membrane integrity can be another indicator of the cell membrane exposure to singlet oxygen. The results from these cell membrane integrity experiments using TO-PRO-3 iodide and sodium azide as a quencher, were illustrated in Figure 17. In this assay, intact cells exclude TO-PRO-3 iodide. However, this dye penetrates and binds to the nucleic acids of damaged cells, resulting in a large increase in the fluorescence intensity. In Figure 17, it was found that when the $\mathrm{K} 562$ cells were incubated with $5.0 \mathrm{mM}$ sodium azide, bottom curve, the protection of the cell membrane integrity was $1.94 \pm 0.06(n=3 \pm$ SEM) times that of the control cells, top curve. The protection factor was equal to the ratio of the irradiation times required to cause a loss of $50 \%$ cell membrane integrity. 


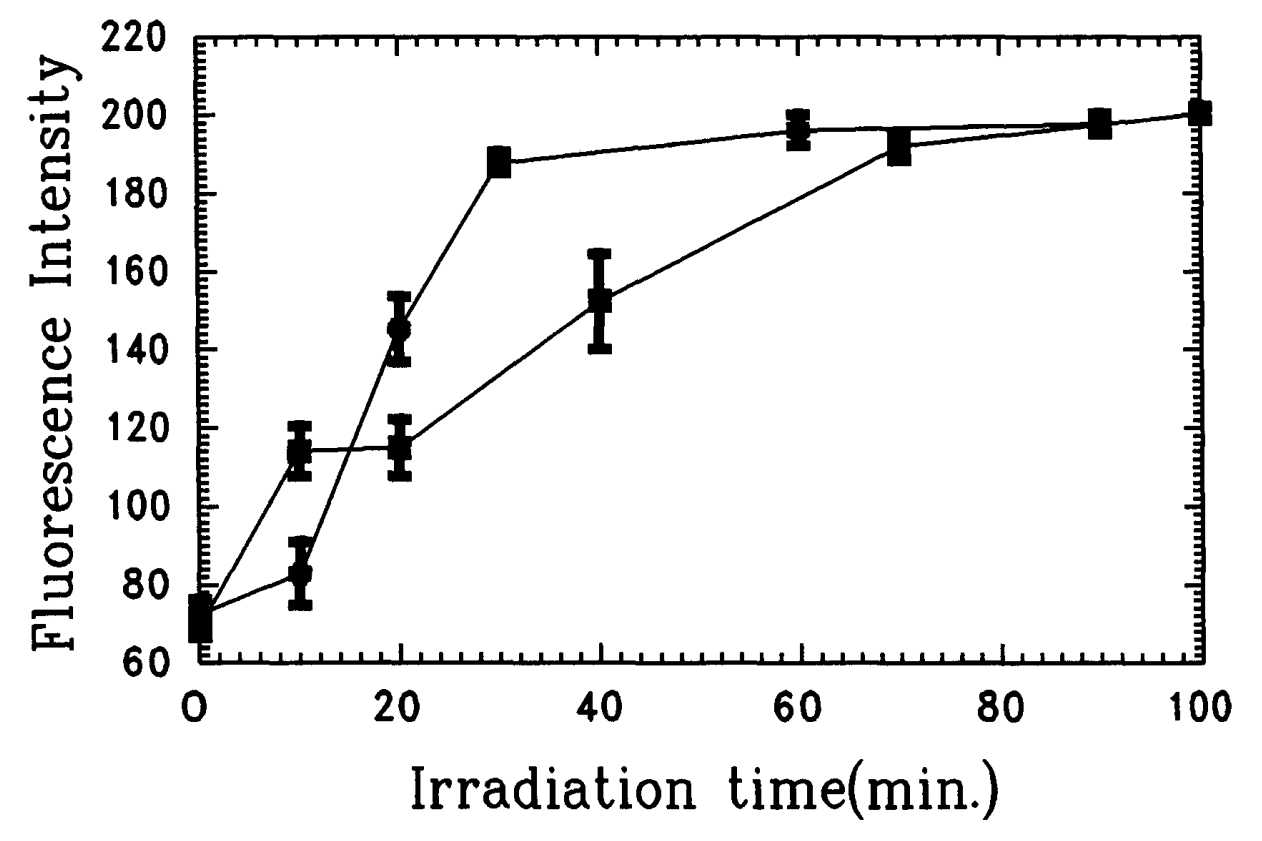

Figure 17. Protection Of Cell Membrane Integrity In The K562 Cells. Sodium Azide Is The Quencher. 
In Figure 17, the conditions were $5 \times 10^{6}$ cells $/ \mathrm{ml}, 1.0 \mu \mathrm{M} \mathrm{E}-16,1.0 \mathrm{mg} / \mathrm{ml}$ glucose, 2.0 $\mu \mathrm{M}$ TO-PRO-3 iodide in phosphate-buffered saline/glucose, $\mathrm{pH} 7.4$ and $600 \mu \mathrm{W} \mathrm{cm}$ light fluence rate. The sodium azide concentration used was $5.0 \mathrm{mM}$. The top curve contained the data for the control cells and the bottom curve contained the data for the cells incubated with $5.0 \mathrm{mM}$ sodium azide.

Finally, the protection of cell membrane integrity in the K562 cells by the singletoxygen quenchers: sodium azide, Ni-chelate 1 and $\mathrm{Ni}$-chelate 2 were summarized in Table 6. Again, the protection factor was equal to the ratio of the irradiation times required to cause a loss of $50 \%$ cell membrane integrity. The last column of Table 6 correlated these cell membrane integrity experiments with estimates of the singlet-oxygen lifetime within the $\mathrm{K} 562$ cells. Using $5.0 \mathrm{mM}$ sodium azide in the cell membrane integrity experiments, corresponded to a singlet-oxygen lifetime in the cytoplasm and the membrane of $0.90 \pm 0.10 \mu \mathrm{s}(\mathrm{n}=3 \pm \mathrm{SEM})$. This was in excellent agreement with the theoretical curves shown in Figure 8, which predicted a singlet-oxygen lifetime of $0.90 \pm 0.20 \mu \mathrm{s}$. Again, both nickel chelates gave anomalously large values for the singlet-oxygen lifetime in the cytoplasm and the membrane, $10 \pm 3.0 \mu \mathrm{s}$ for Ni-chelate 1 and $5.0 \pm 2.0 \mu$ s for Ni-chelate $2(n=3 \pm$ SEM). As stated previously, the nickel chelates probably had an uneven distribution throughout the cytoplasm with a higher concentration near the inner and outer cell membrane. This probably resulted in the larger than expected singlet-oxygen lifetime values. 
Table 6. Protection Of Cell Membrane Integrity On The K562 Cells Using Various Singlet-Oxygen Quenchers.

\begin{tabular}{llll}
\hline Quencher & Concentration & $\begin{array}{l}\text { *Protection of cell } \\
\text { membrane integrity }\end{array}$ & $\begin{array}{l}\text { Cell lifetime estimate } \\
\text { from theoretical model }\end{array}$ \\
\hline Azide & $5.0 \mathrm{mM}$ & $1.94 \pm .06$ & $0.90 \pm 0.10 \mu \mathrm{S}$ \\
Ni-chelate 1 & $400 \mu \mathrm{M}$ & $2.04 \pm .07$ & $10.0 \pm 3.0 \mu \mathrm{S}$ \\
Ni-chelate 2 & $400 \mu \mathrm{M}$ & $1.68 \pm .09$ & $5.0 \pm 2.0 \mu \mathrm{s}$
\end{tabular}

"For example, when the K562 cells were incubated with $5.0 \mathrm{mM}$ azide, the protection of the cell membrane integrity was $1.94 \pm .06$ times that of the control cells.

The results were reported as the average of 3 experiments \pm SEM. 


\section{CHAPTER 5}

\section{DISCUSSION}

Oxygen is very reactive when it is in the singlet state. In this state, singlet oxygen has $23 \mathrm{kcal} / \mathrm{mol}$ more energy than ground-state oxygen and has no unpaired electrons (1). Ground-state oxygen, on the other hand, has an unusual electronic structure consisting of two unpaired electrons (1). Any molecule that reacts with groundstate oxygen must have unpaired electrons. As a result, the kinetic reactivity of groundstate oxygen is severely restricted by the Wigner spin conservation rule (2). Singlet oxygen has been implicated in the biological damage caused by light and many photosensitizing agents, otherwise known as photodynamic therapy (3-5). As shown in Equation 2, singlet oxygen is generated by a Type II mechanism. While many other electronically excited states of oxygen exist, there has been no evidence that they are involved in photodynamic action (1). Since the half-life of singlet oxygen ranges from 1.0 to $0.10 \mu \mathrm{s}$, it can diffuse mean radial distances of at least $100 \mathrm{~nm}$ in the biological environment (26). Thus, singlet oxygen can react at loci remote from the site of generation and cause damage to many important constituents of cells including, amino acids, cholesterol, and bases of nucleic acids (3-5).

The detection of singlet-oxygen generation has been directly measured in some photosensitizer-labeled cells using highly specific assays for singlet oxygen. These assays 
include the detection of $1270 \mathrm{~nm}$ singlet-oxygen emission and the detection of the singletoxygen specific products, $5 \alpha$ and $6 \beta$ cholesterol hydroperoxides $(21,22,27-29)$. Singletoxygen reactions can also be inferred by the use of deuterated solvents and certain singlet-oxygen quenchers (5). The killing of photosensitizer-labeled cells is enhanced by deuterium-oxide solvent, because it increases the lifetime of singlet oxygen. The use of certain singlet-oxygen quenchers, such as sodium azide and nickel chelates, decrease the killing of photosensitizer-labeled cells because they reduce the steady-state concentration of singlet oxygen.

As stated earlier in this dissertation, much of the evidence that supports singletoxygen-mediated cell death is based on simple chemical and biochemical model systems rather than from studies of living cells. In these simple model systems, the generation of singlet oxygen is usually easy to measure because the lifetime of singlet oxygen is relatively long (10). Living cells are very complex and it is not clear whether the results from these simple model systems apply directly to intact cells. The measurement of singlet-oxygen generation within intact cells has proven to be difficult because of the short singlet-oxygen lifetime, between 1.0 and $0.10 \mu \mathrm{s}$ (13). Since the singlet-oxygen lifetime within cells is very short, the effects of deuterium-oxide solvent and modest concentrations of singlet-oxygen quenchers should be very small. This is because a reasonable assumption was made that most of the singlet oxygen generated will react with the high concentration of biological molecules present within the cell and become quenched. Very little of the singlet oxygen will become quenched by the water solvent in the buffer so, replacing the water with deuterium-oxide solvent (which is much less effective in quenching singlet oxygen) should only have a minor effect. In similar 
fashion, a very large concentration of singlet-oxygen quencher needs to be added to the cell in order to effectively compete with the large concentration of biological molecules present within the cell. However, for some cell lines and photosensitizers, the effects of deuterium-oxide solvent and certain singlet-oxygen quenchers are much larger than expected (14).

In the literature, many authors have found that acetylcholinesterase (ACE) is inactivated by singlet oxygen (17-20). The inhibition of ACE in erythrocyte membranes has been studied in many intensity and wavelength-dependent photosensitization experiments because it is a relatively simple and biologically relevant endpoint (46). Other evidence suggests that ACE is relatively insensitive to other reactive intermediates that may be produced in photosensitization reactions, such as hydroxyl radical and superoxide ion $(19,20)$. Therefore, under appropriately selected conditions, ACE can be used as a probe of singlet-oxygen-mediated membrane damage. In addition, determining the effects on cell membrane integrity can be another indicator of the cell membrane exposure to singlet oxygen (17).

The purpose of this dissertation was to perform a series of experiments that looked at the effects of deuterium-oxide solvent and various singlet-oxygen quenchers upon singlet-oxygen-mediated ACE inactivation and singlet-oxygen-mediated cell damage. A comparison was made between the inactivation of ACE in aqueous solution (an example of a simple model system) and the inactivation of ACE bound to the surface of K562 erythroleukemia cells. These experiments were performed in order to test the hypothesis that the inactivation of ACE on the surface of the K562 cells can be predicted by mathematical equations that model singlet-oxygen diffusion rates and lifetimes. 
Analysis of the data using this theoretical mathematical model was expected to provide an estimate of the lifetime of singlet oxygen close to the surface of the cell. John G. Parker carried out a similar analysis of the effects of deuterium-oxide solvent on photosensitized cytotoxicity (private communication).

\section{Studies With Purified Acetylcholinesterase (ACE)}

In order to show that the inactivation of $\mathrm{ACE}$ was a good indicator of the cell membrane exposure to singlet oxygen, the inactivation of this enzyme was first studied in solution. From these studies, it was determined if the inactivation of ACE was a reliable, quantitative measure of the steady-state singlet-oxygen concentration. The ACE inactivation lifetimes were determined from a plot of the normalized ACE activity versus time. These lifetimes were then evaluated to see if they were related to the steady-state concentration of singlet oxygen in the irradiated system. In Figure 1, bottom curve, the control was found to decay according to first-order kinetics. In other words, the decrease in the enzyme activity over time was found to be proportional to the concentration of the active enzyme, $[\mathrm{A}]$. Also, the presence of sodium azide, a singletoxygen quencher with a high singlet-oxygen quenching constant, in this system resulted in the first-order decay of ACE. Very long irradiation times were needed for these experiments because increasing concentrations of sodium azide increased the rate of ACE inactivation and water solvent has a short singlet-oxygen lifetime, $3.1 \mu \mathrm{s}$.

Next, experiments were performed in order to determine whether variations in the light intensity also caused variations in the rate of ACE inactivation. These 
experiments tested for reciprocity. For example, if the light intensity was decreased by a factor of 2, it should then take twice as long to inactivate ACE. As shown in Figure 2 , the rate of singlet-oxygen-mediated ACE inactivation was proportional to the inverse of the light intensity. The results from Figures 1 and 2 combined showed that the rate of ACE inactivation in solution was proportional to the concentration of the active enzyme, [A], and the steady-state singlet-oxygen concentration, $\left[{ }^{1} \mathrm{O}_{2}\right]$. Thus, these results obeyed a simple second-order rate expression as shown in Equation 10.

It was then necessary to select several singlet-oxygen quenchers that inhibited the activation of ACE by lowering the steady-state concentration of singlet oxygen and not by other mechanisms. Methionine, sodium azide, $\mathrm{Ni}$-chelate 1 and $\mathrm{Ni}$-chelate 2 were the singlet-oxygen quenchers used for these experiments. These quenchers were chosen because they were water-soluble, had large singlet-oxygen quenching constants, and they had a low reactivity with the excited triplet-state of the photosensitizer, E-16 $(21,56,70,93)$. These quenchers also represented two different classes of quenching: physical and chemical $(56,70,93)$. The data for these experiments were plotted according to the Stern-Volmer equation shown in Equation 11 and are presented in Figures 3 and 4. All of the data points were close to the theoretical results expected for an ideal singlet-oxygen quencher having no other effect on the system in both water and deuterium-oxide solvent. As a control, the addition of glycine, an amino acid that has a small singlet-oxygen quenching constant, to this system had no effect on the rate of ACE inactivation. Therefore, it was concluded that the actions of these singlet-oxygen quenchers could be explained quantitatively by assuming that their only mechanism of action was to quench singlet oxygen. 
In order to estimate the singlet-oxygen quenching constant for each quencher from the ACE inactivation experiments, the lifetime of singlet oxygen in the buffer solutions used was calculated. These values for the singlet-oxygen lifetimes were then plugged into the Stern-Volmer equation and solved for $\mathbf{k}$, the singlet-oxygen quenching constant. As shown in Table 1, the singlet-oxygen quenching constants calculated from Equation 11 were in excellent agreement with the singlet-oxygen quenching constants measured in this study using the decay of 1270-nm emission and singlet-oxygen quenching constants obtained from the literature $(3,26,56,62-72)$. For example, the singlet-oxygen quenching constant determined from the ACE experiments using the singlet-oxygen quencher $\mathrm{Ni}$-chelate 1 in water and in deuterium-oxide solvent was 2.1 $\pm 0.1 \times 10^{9} \mathrm{M}^{-1} \mathrm{~s}^{-1}$. Using the decay of singlet-oxygen emission at $1270 \mathrm{~nm}$, the singletoxygen quenching constant was determined to be $2.0 \pm 0.1 \times 10^{9} \mathrm{M}^{-1} \mathrm{~s}^{-1}$. The singletoxygen quenching constant reported in the literature was $1.6 \times 10^{9} \mathrm{M}^{-1} \mathrm{~s}^{-1}$. All of these values were in excellent agreement with one another.

Next, experiments were performed in order to determine the ratio for the ACE inactivation lifetime in water solvent and in deuterium-oxide solvent. The experimental ratio was determined by dividing the $\mathrm{ACE}$ inactivation lifetime in deuterium-oxide solvent by the ACE inactivation lifetime in water solvent. This ratio was $6.5 \pm 0.30$ at $\mathrm{pD}$ and $\mathrm{pH}$ 7.4. The theoretical ratio was determined by dividing the measured singletoxygen lifetime in the deuterium-oxide system ( $44 \mu \mathrm{s})$ by the measured singlet-oxygen lifetime in water $(3.1 \mu \mathrm{s})$. Thus, the theoretical ratio was 14 .

The difference between the theoretical and experimental ratios suggested the presence of some type of isotope effect. This hypothesis was confirmed by comparing 
the inactivation lifetime of ACE in deuterium-oxide buffer containing $700 \mu \mathrm{M}$ azide ion with the inactivation lifetime in water buffer. The presence of $700 \mu \mathrm{M}$ azide ion reduced the lifetime of singlet oxygen in the deuterium-oxide buffer to $3.1 \mu \mathrm{s}$, identical to the lifetime in water buffer. The ratio expected without an isotope effect would be 1.0 , because the singlet-oxygen lifetimes would have been the same in water and deuteriumoxide buffer. However, the lifetime of ACE inactivation in deuterium-oxide buffer with $700 \mu \mathrm{M}$ sodium azide was $2.2 \pm 0.10$ times the lifetime of inactivation in water buffer. This confirmed the presence of an isotope effect.

As stated in the results section, one type of isotope effect is a primary isotope effect at the site of enzyme inactivation (73). In deuterium-oxide solvent, some of the hydrogen atoms on ACE may exchange with some of the deuterium atoms from the solvent. For example, exchange of a hydrogen for a deuterium at the $\mathrm{OH}$ bond on a tyrosine ring can cause a primary kinetic deuterium isotope effect as large as a factor of 11.5 (73). Perhaps, this is the reason for the discrepancy between the experimental and the theoretical ratios.

A second type of isotope effect is a secondary solvent isotope effect (73). The ionized forms of deuterium oxide, $\mathrm{D}_{3} \mathrm{O}^{+}$and $\mathrm{OD}^{-}$, are less stable compared to neutral deuterium oxide, than the corresponding ionized forms of water. Similarly, the bond energy for ionizable deuterium atoms is greater than for ionizable hydrogen atoms on biological molecules, such as histidine. As a result, at equal $\mathrm{pH}$ and $\mathrm{pD}$, there are likely different amounts of ionization of various functional groups on ACE. The quenching constant for histidine is known to have a strong pD dependence between pD 7 and 8 (3). As a result, changing the solvent from deuterium oxide to water may change the 
quenching constant for histidine significantly. To assess this hypothesis, the inactivation of $\mathrm{ACE}$ at $\mathrm{pH}$ and $\mathrm{pD} 8.4$ was studied. The lifetime of photoinactivation of $\mathrm{ACE}$ at $\mathrm{pH}$ and $\mathrm{pD} 8.4$ was not significantly different from $\mathrm{pH}$ and $\mathrm{pD}$ 7.4. Furthermore, the ratio of inactivation lifetimes at $\mathrm{pH} 8.4$ and $\mathrm{pD} 8.4$ was $6.7 \pm 0.4$, essentially the same as the ratio at lower $\mathrm{pH}$. This suggested that the $\mathrm{pH}$ dependence of the histidine quenching constant cannot explain the anomalous ratio, but does not rule out other possible secondary solvent isotope effects. Perhaps, the $\mathrm{pH}$ dependence of the quenching constants of other amino acids in the active site of ACE, serine, glutamic acid or tryptophan, are responsible for the discrepancy between the experimental and the theoretical ratios.

\section{Theoretical Mathematical Model Of Singlet-Oxygen Quenching And Diffusion}

Having established that ACE inactivation was a reliable measure of the steadystate singlet-oxygen concentration in solution, a more complex system was investigated, the K562 cell line. Figure 5 depicted the geometry of the model system for the K562 cells. This cell line was selected because it contained significant amounts of the membrane-bound ACE and the cells grew as a suspension $(74,75)$. The photosensitizer, E-16, was selected for the K562 cell experiments because it was an lipophilic anionic eosin derivative that bound selectively to the outer cell surface of the K562 cells and had a large singlet-oxygen yield $(76,77)$. Since singlet oxygen was being generated directly on the cell surface and ACE was located on the outer cell surface, extending about 15 $\mathrm{nm}$ into the buffer, this enzyme would make an ideal probe for the singlet-oxygen 
concentration near the cell surface. Since the singlet-oxygen lifetime in the cytoplasm and the cell membrane is very short, between 1.0 and $0.10 \mu \mathrm{s}(4,60,78)$, the effects of deuterium-oxide solvent and modest concentrations of singlet-oxygen quenchers should only have a minor effect on the rate of ACE inactivation. This is because it was assumed that the majority of the singlet oxygen generated will be quenched by the high concentration of biological molecules present within the cell.

Much of the literature that supports singlet-oxygen-mediated cell damage is based on simple model systems and it is not clear whether the results from these simple model systems apply directly to intact cells. One approach to the analysis of singlet-oxygenmediated cytotoxicity is to use a mathematical model that accounts for singlet-oxygen quenching and diffusion in various cell compartments. The mathematical model used for the K562 cells was a modification of a published mathematical model of singlet-oxygen quenching and diffusion in the cell $(13,22,79-81)$. In order to use this theoretical model, a number of parameters were needed including the singlet-oxygen lifetimes and singletoxygen transport parameters for each phase. These parameters were obtained from the literature $(75,83-88)$ and are given in Table 2.

In this model, a one-dimensional linear coordinate system was used rather than a spherical coordinate system because the 15 to $20 \mu \mathrm{m}$ diameter of the cell (89) was sufficiently large so that diffusion in a one-dimensional linear coordinate system was an excellent approximation to a spherical coordinate system $(79,80)$. The one dimensional $\mathrm{X}$ axis was divided into three regions: the cytoplasm, the membrane and the external buffer. Each region of the $\mathrm{x}$ axis was described by a Fick equation that accounted for singlet-oxygen diffusion with an additional term added to account for singlet-oxygen 
quenching. Each region was assumed to have homogeneous properties with respect to singlet-oxygen diffusion and quenching. For these experiments, time-independent equations were applied because constant intensity irradiation was utilized. Using these conditions, a steady-state singlet-oxygen concentration was quickly reached (90). The mathematical model and the boundary conditions were illustrated in Equations 12-18. The steady-state singlet-oxygen concentration to which the ACE molecules were exposed was obtained by integrating the singlet-oxygen concentration in a narrow band of buffer just outside the surface of the membrane as shown in Equation 22. By integrating the singlet-oxygen concentration over the membrane and the cytoplasm, Equation 25 illustrates the amount of singlet oxygen quenched by the cell. By using this model, the inhibition of ACE inactivation on the K562 cell surface by singlet-oxygen quenchers can be used to calculate the lifetime of singlet oxygen in the cell membrane and in the cytoplasm close to the membrane.

The predictions of the theoretical model are depicted in a more readily understood manner in Figure 6. As stated in the results section, singlet oxygen is being generated directly on the outer cell membrane surface so, it is concentrated within the membrane. The diffusion of singlet oxygen within the membrane is very efficient because the membrane is so thin. As a consequence, the concentration gradient of singlet oxygen within this compartment is very small. The diffusion of singlet oxygen into the cytoplasm from the inner membrane is shorter compared to the diffusion of singlet oxygen from the outer membrane into the buffer because it was assumed that the singlet oxygen will become quenched by the high concentration of biological molecules present in the cytoplasm. The diffusion of singlet oxygen into the buffer from the outer 
membrane is longer than the previous scenario because the buffer is basically composed of water solvent. As a result, the singlet-oxygen lifetime in water solvent is longer when compared to the singlet-oxygen lifetime in the cytoplasm. In order to determine the steady-state singlet-oxygen concentration to which the ACE molecules were exposed, an integration was made from the membrane origin, 0 , to the diameter of the ACE molecules, $X_{A C E}$, as shown in Figure 5. This integration was performed in the absence and presence of singlet-oxygen quencher and generated theoretical ratios. From various assumed singlet-oxygen lifetimes in the different cell compartments, theoretical curves were generated. The data from the ACE inactivation experiments were then fitted to the theoretical model to see if any correlation existed. The best fit corresponded to an estimate of the singlet-oxygen lifetime in the membrane and in the cytoplasm close to the membrane.

In order to apply this mathematical model, the concentrations of the hydrophilic singlet-oxygen quenchers and deuterium-oxide solvent within the K562 cells were needed. Penetration of the singlet-oxygen quenchers into the cytoplasm would be expected to decrease the singlet-oxygen lifetime within this compartment. Penetration of deuteriumoxide solvent into the cytoplasm would be expected to increase the singlet-oxygen lifetime within this compartment. From serial dilutions of solubilized cell pellets, SternVolmer plots were generated. Extrapolation of the data to $100 \%$ cell pellet concentration gave the average quenching rate within the cell. The results were very linear and are shown in Figure 7.

Table 3 summarizes the quenching data. The quenching rate of the control cell pellets was equal to the inverse of the singlet-oxygen lifetime. The apparent singlet- 
oxygen lifetime determined at $100 \%$ cell pellet concentration was equal to the inverse of the quenching rate. The change in the quenching rate with added quencher was equal to the difference between the quenching rate of the control cell pellets and the singletoxygen quencher-labeled cell pellets at $100 \%$ cell pellet concentration. The change in the quenching rate with added deuterium-oxide solvent was equal to the difference between the cell pellets incubated with water solvent and the cell pellets incubated with deuterium-oxide solvent. Replacement of the water solvent for deuterium-oxide solvent resulted in a negative value. The quencher or deuterium-oxide solvent concentrations within the cell pellets was determined by taking the product of the change in the quenching rate and the inverse of the quenching constant.

Therefore, when $5.0 \mathrm{mM}$ sodium azide was present in the external buffer, $5.2 \pm$ $0.30 \mathrm{mM}$ sodium azide was present within the K562 cells. When $400 \mu \mathrm{M}$ Ni-chelate 1 and Ni-chelate 2 were present in the external buffer, only $170 \pm 10 \mu \mathrm{M}$ Ni-chelate 1 and $210 \pm 40 \mu \mathrm{M}$ Ni-chelate 2 was present within the K562 cells. The nickel chelates probably had an uneven distribution within the cytoplasm with a higher concentration near the outer and inner cell membrane. The concentration of deuterium-oxide solvent present within the $\mathrm{K} 562$ cells was $21 \pm 8.0 \mathrm{M}$. Assuming that the concentration of water is $55 \mathrm{M}$, this suggests that only about $40 \%$ of the deuterium-oxide solvent penetrated the K562 cells. Perhaps, the presence of deuterium-oxide solvent in the buffer was uninviting for the cells.

Figures 8-11 show the comparison between the experimental ACE inactivation lifetime ratios and the ratios determined from the theoretical mathematical model. From the theoretical analysis, it was clear that singlet-oxygen quenchers with very large singlet- 
oxygen quenching constants were needed in order to obtain a significant inhibition of ACE inactivation on the K562 cell surface. For this reason, only azide anion, Ni-chelate 1 and Ni-chelate 2 were studied. In generating the theoretical curves shown in Figures 8-11, an assumption was made that the hydrophilic quenchers used as well as the deuterium-oxide solvent uniformly distributed themselves throughout the cytoplasmic compartment, but not the cell membrane. A further assumption was made that at equilibrium, the singlet-oxygen quencher concentration in the cytoplasm was proportional to the singlet-oxygen quencher concentration in the buffer. Thus, the concentrations of the quenchers and deuterium oxide in the cytoplasm were calculated using the quenching data given in Table 3. Since the ratio of quencher concentration in the cytoplasm to quencher concentration in the buffer was different for each quencher and deuterium-oxide solvent, the theoretical curves given in Figures 8-11 are different.

The data were not sufficient to provide separate estimates for the singlet-oxygen lifetimes within the cell membrane and within the cytoplasm. To obtain separate estimates would have required a second target molecule for singlet oxygen located at the inner surface of the cell membrane or somewhat deeper within the cell cytoplasm. Thus, in obtaining fits of the experimental data to the theoretical curves, an assumption was made that the lifetime of singlet oxygen within the membrane and within the cytoplasm were equal.

In Figures 8-11, the thin lines represented theoretical curves for various assumed cell singlet-oxygen lifetimes. These curves described the effect upon the steady-state concentration of singlet oxygen integrated over the region occupied by ACE when singlet-oxygen quenchers or deuterium-oxide solvent were added to the external buffer. 
Using sodium azide as a singlet-oxygen quencher, Figure 8, the theoretical model predicted a singlet-oxygen lifetime in the cytoplasm and in the membrane of $0.90 \pm 0.20$ $\mu \mathrm{s}$. This was in reasonable agreement with values reported in the literature. As shown in Figures 9 and 10, when the nickel chelates were used as singlet-oxygen quenchers, the predicted singlet-oxygen lifetimes were anomalously large. The theoretical singletoxygen lifetimes within the cell were $3.2 \pm 1.1 \mu \mathrm{s}$ for Ni-chelate 1 and $2.8 \pm 1.1 \mu \mathrm{s}$ for Ni-chelate 2. The structure of these nickel chelates is shown in Figure 12. A property of polyaromatic compounds having at least two negative charges (the negative charges are on the sulfur groups of the nickel chelates) is that these compounds enter the cell by endocytosis rather than by diffusion and have a granular distribution throughout the cytoplasm (92). This uneven distribution of the nickel chelates throughout the cytoplasm may have resulted in a higher concentration near the cell membrane and is one possible explanation for the larger than expected singlet-oxygen lifetimes. Perhaps, the synthesis of a nickel chelate containing only one negative charge will lead to an even distribution throughout the cytoplasm, resulting in reasonable values for the singletoxygen lifetimes. Using deuterium-oxide solvent (Figure 11), the theoretical model predicted a singlet-oxygen lifetime in the cytoplasm and in the membrane of $0.45 \pm 0.15$ $\mu \mathrm{s}$. This was in reasonable agreement with values reported in the literature. In Figure 11 , the theoretical curves decrease because deuterium-oxide solvent increases the singletoxygen lifetime.

In order to estimate the lifetime of singlet oxygen in the cell from the deuteriumoxide experiments, the observed isotope effect was taken into account. This was measured for ACE on the cell surface by comparing the inactivation lifetimes for ACE 
in deuterium-oxide buffer containing $700 \mu \mathrm{M}$ sodium azide with the inactivation rate in water buffer. As shown in Table 3, the penetration of deuterium-oxide buffer into the cytoplasm was incomplete. However, the model suggested that this would only cause a $1.2 \%$ change in the ACE inactivation lifetime. As in the purified enzyme system, ACE was inactivated more slowly in the presence of $700 \mu \mathrm{M}$ sodium azide in deuterium-oxide solvent. The ACE inactivation lifetime in deuterium-oxide buffer with $700 \mu \mathrm{M}$ sodium azide was $1.29 \pm 0.03$ of the lifetime in water. This ratio was smaller than that observed in the purified enzyme system, perhaps, the exchange of the hydrogen and the deuterium is partially blocked when ACE is bound to the cell surface. The ACE inactivation lifetime in deuterium-oxide buffer was $0.94 \pm 0.02$ of that in water buffer. Correcting for the isotope effect gave a ratio of $0.73 \pm 0.04$. As shown in Figure 11, the best fit with the model was for a singlet-oxygen lifetime of $0.45 \pm 0.15 \mu \mathrm{s}$. Thus, the singlet-oxygen lifetime from the deuterium-oxide experiments was in reasonable agreement with the sodium azide data and the quenching data from the cell pellets shown in Table 3.

Most of the curves shown in Figures 8-11 assumed that the singlet-oxygen lifetimes in the cytoplasm and the cell membrane were equal. Figures 13 and 14 illustrated the effects on the theoretical model caused by independently varying the singlet-oxygen lifetimes in the cytoplasm and in the cell membrane. The singlet-oxygen quencher used was sodium azide. In Figures 13 and 14, the thin lines represented varying singlet-oxygen lifetimes in the cell membrane and the cytoplasm, respectively. Holding the singlet-oxygen lifetime in the cytoplasm constant at $1.0 \mu \mathrm{s}$ in Figure 13, the non-linear least squares fit to the experimental data equaled a singlet-oxygen lifetime in 
the membrane of $0.85 \mu \mathrm{s}$. Holding the singlet-oxygen lifetime in the membrane constant at $1.0 \mu \mathrm{s}$ in Figure 14, the non-linear least squares fit to the experimental data equaled a singlet-oxygen lifetime in the cytoplasm of $0.80 \mu \mathrm{s}$. Thus, increasing the lifetime in either the cytoplasm or the membrane caused a comparable decrease in the other compartment.

Table 4 illustrated how changes in various parameters affected the predictions of the theoretical model. The very last column of Table 4 is the theoretical ratio of the steady-state singlet-oxygen concentration to which the ACE molecules were exposed in the absence and in the presence of $5.0 \mathrm{mM}$ sodium azide. A factor of two change in any single parameter caused less than a factor of two change in the predictions of the model. For example, changing some parameters, such as the membrane thickness, the ACE radius or the cytoplasmic and membrane diffusion coefficients, caused only very small changes in the predictions of the model. Thus, the predictions of the theoretical model do not depend upon extremely accurate values for all the parameters.

\section{Studies With K562 Erythroleukemia Cells}

In the studies with the K562 cells, a number of controls were performed. As stated earlier, E-16, the lipophilic anionic photosensitizer used to incubate the K562 cells, binds to the outer cell membrane surface. The majority of the E-16 stays at the outer cell membrane surface however, some of the E-16 can diffuse into the buffer. In order to make sure that any diffusion of E-16 into the buffer was not responsible for the inactivation of the ACE molecules on the K562 cell surface, these cells were incubated 
with a different photosensitizer, eosin bound to high molecular-weight dextran. This water soluble photosensitizer essentially stayed in the buffer. As a result, the generation of singlet oxygen from this photosensitizer would become quenched by the buffer and would not be expected to have a great effect on the rate of ACE inactivation. As shown in Table 5, compared to E-16, the water soluble photosensitizer caused very little inactivation of $\mathrm{ACE}$ in either water or deuterium-oxide buffer after a 30 minute irradiation time. Thus, these controls demonstrated that any diffusion of E-16 into the buffer was not responsible for the inactivation of the ACE molecules on the K562 cell surfaces.

Another explanation for the decrease in the ACE activity over time could be that the ACE molecules were being cleaved during the irradiation. If the ACE molecules were being cleaved from the cell surface during increasing irradiation times, a decrease in the activity of the enzyme over time would be expected. In order to control for this, the supernatant from irradiated cells was measured for ACE activity. The percentage of $\mathrm{ACE}$ activity found in the supernatant after a 30 minute irradiation time was $2.0 \pm 2.0 \%$ of the ACE activity initially present on the K562 cells. Thus, it was concluded that the ACE molecules on the surface of the K562 cells remained intact during irradiation.

Another concern was that the presence of deuterium-oxide solvent or singletoxygen quenchers in the buffer might change the amount of E-16 that partitioned into the K562 cell membranes. This potential artifact was evaluated by measuring the amount of E-16 in the cell pellets. The relative concentrations of E-16 were $1.00 \pm 0.02,1.00$ $\pm 0.02,0.99 \pm 0.01$, and $1.01 \pm 0.04$ for cells incubated without an added singletoxygen quencher, with $5.0 \mathrm{mM}$ sodium azide, with $400 \mu \mathrm{M}$ Ni-chelate 1 and with 400 
$\mu \mathrm{M}$ Ni-chelate 2 , respectively. For cells incubated in deuterium-oxide buffer, the relative E-16 concentration was $1.01 \pm 0.03$. Therefore, it was concluded that the amount of E-16 that partitioned into the K562 cell membranes was not changed by the presence of deuterium-oxide solvent or singlet-oxygen quenchers in the buffer.

A fourth concern was that photosensitization might lyse the cells, resulting in the release of significant amounts of the cell contents into the buffer. After a 30 minute irradiation time, the K562 cells were found to have lost $69 \pm 1.0 \%$ of their ability to exclude the DNA staining dye, TO-PRO-3 iodide. However, the lifetime of singlet oxygen in the cell supernatants was still $57 \pm 1.0 \mu \mathrm{s}$. This demonstrated that large amounts of biological molecules were not released into the buffer. If large amounts of these molecules were present in the buffer, quenching would have significantly lowered the singlet-oxygen lifetime. Therefore, it was concluded that photosensitization of the K562 cells did not release significant amounts of the cell contents into the buffer because the singlet-oxygen lifetime measured in the cell supernatants was not changed.

Figure 15 demonstrated that variations of the E-16 concentrations in the buffer also varied the E-16 concentrations in the cell membrane. The data were linear up to 1.0 $\mu \mathrm{M} \mathrm{E}-16$ and the data curved at higher E-16 concentrations. The curvature of the data was probably due to some sort of saturation effect caused by the high concentration of photosensitizer molecules within the cell membrane.

Figure 16 illustrated the kinetics of ACE inactivation on the surface of the K562 cells. The data were well fit by a first order decay. The decrease in the activity of ACE over time was found to be proportional to the concentration of the active enzyme, [A]. Also, from the reciprocity experiments, Figure 2, the rate of ACE inactivation was found 
to be inversely proportional to the light intensity. Therefore, the results from these experiments obeyed a simple second-order rate expression, similar to the solution experiments.

As stated in the results section, modest concentrations of singlet-oxygen quenchers should only have a minor effect on the rate of ACE inactivation. However, high concentrations of sodium azide, $(3.0 \mathrm{mM}$ and $5.0 \mathrm{mM})$, had a significant effect on the rate of ACE inactivation. The most likely reason for this effect was that at high singlet-oxygen quencher concentrations, the added singlet-oxygen quencher successfully competes with the biological molecules present within the cell.

Determining the effects on cell membrane integrity can be another indicator of the cell membrane exposure to singlet oxygen. The results from these cell membrane integrity experiments using TO-PRO-3 iodide and sodium azide as a quencher, were illustrated in Figure 17. Intact cells exclude TO-PRO-3 iodide. However, this dye penetrates and binds to the nucleic acids of damaged cells, resulting in a large increase in the fluorescence intensity. In Figure 17, it was found that when the K562 cells were incubated with $5.0 \mathrm{mM}$ sodium azide, bottom curve, the protection of the cell membrane integrity was $1.94 \pm 0.06$ times that of the control cells, top curve. The protection factor was equal to the ratio of the irradiation times required to cause a loss of $50 \%$ cell membrane integrity.

Finally, the protection of cell membrane integrity in the K562 cells by the singletoxygen quenchers: sodium azide, Ni-chelate 1 and $\mathrm{Ni}$-chelate 2 were summarized in Table 6. The last column of Table 6 correlated these cell membrane integrity experiments with estimates of the singlet-oxygen lifetime within the K562 cells. Using 
$5.0 \mathrm{mM}$ sodium azide in the cell membrane integrity experiments, corresponded to a singlet-oxygen lifetime in the cytoplasm and the membrane of $0.90 \pm 0.10 \mu \mathrm{s}$. This was in excellent agreement with the theoretical curves shown in Figure 8, which predicted a singlet-oxygen lifetime of $0.90 \pm 0.20 \mu \mathrm{s}$. Again, both nickel chelates gave anomalously large values for the singlet-oxygen lifetime in the cytoplasm and the membrane, $10 \pm 3.0 \mu \mathrm{s}$ for Ni-chelate 1 and $5.0 \pm 2.0 \mu \mathrm{s}$ for Ni-chelate 2 . As stated previously, the nickel chelates had an uneven distribution throughout the cytoplasm with possibly a higher concentration near the cell membrane. This is one possible explanation for the larger than expected singlet-oxygen lifetime values.

\section{Summary And Conclusions}

In summary, a mathematical model was used to estimate the lifetime of singlet oxygen close to the surface of the K562 cells. The lifetime of singlet oxygen was varied in the external buffer and the rate of ACE inactivation on the surface of the K562 cells was used as an indicator of the singlet-oxygen concentration at the cell surface. The major advantage of using ACE inactivation as a monitor of the singlet-oxygen concentration at the cell surface was that the ACE inactivation could be carefully studied in solution in order to verify the reliability of this assay.

One limitation of this approach was the relatively small changes in the singletoxygen concentration caused by the addition of quenchers or changing the solvent from water to deuterium-oxide solvent. In order to vary the singlet-oxygen concentration by a factor of two, quenchers with very large quenching constants were needed. 
Unfortunately, there are relatively few hydrophilic quenchers with the required large quenching constants. The most commonly used quencher is azide ion, quenching constant $10^{8} \mathrm{M}^{-1} \mathrm{~s}^{-1}$. The water-soluble nickel complexes used in this project, as described by Botsivali et al., have a quenching constant on the order of $10^{9} \mathrm{M}^{-1} \mathrm{~s}^{-1}$. These quenchers appeared to be ideal for this study because they behaved in an ideal manner in experiments inhibiting ACE inactivation in solution. However, the nickel chelates gave anomalous results for the experiments with the K562 cells, causing excessive inhibition of the inactivation of ACE. As stated earlier, a property of polyaromatic compounds containing at least two negative charges, such as the nickel chelates used in this project, is that these compounds have an uneven distribution in the cytoplasm, which possibly resulted in a higher concentration near the cell membrane. A way to test this hypothesis would be to synthesize compounds with only one negative charge. These compounds would be expected to have an even distribution throughout the cytoplasm and prevent the excessive inhibition of ACE inactivation in the K562 cell experiments.

The deuterium-oxide solvent effect is more difficult to use to estimate the lifetime within the cell than the effect of added quenchers because the deuterium-oxide data obtained needed to be corrected for any isotope effects present. When this correction was carried out, there was reasonable agreement between the cell singlet-oxygen lifetimes derived from the deuterium-oxide experiments, $0.45 \pm 0.15 \mu \mathrm{s}$, and from the azide experiments, $0.90 \pm 0.20 \mu \mathrm{s}$.

The estimates for the lifetime of singlet oxygen near the surface of the K562 leukemia cells were in reasonable agreement with prior estimates in the literature. Matheson et al. estimated the lifetime of singlet oxygen within cells to be less than 1.0 
$\mu$ s based on the concentration of amino acids within cells (4). Moan and Berg used the rate of diffusion of singlet oxygen between two photosensitizers to estimate the singletoxygen lifetime within the membrane-bound structures of NHIK cells to be between 0.01 and $0.04 \mu \mathrm{s}$ (78). Finally, Baker and Kanofsky measured the quenching rates caused by the contents of L1210 leukemia cells to estimate a lifetime between 0.17 and $0.32 \mu \mathrm{s}$ (60). The estimate of Moan and Berg was lower than the other estimates, but this may have been because these authors measured the lifetime within membrane-bound structures and not the average lifetime throughout the cell. The very short lifetime within the red cell ghost membrane, from 0.024 to $0.13 \mu \mathrm{s}$, also suggested a particularly short singletoxygen lifetime within some membrane-bound structures (13).

The data presented in this dissertation provided an estimate of the average singlet-oxygen lifetime within the cell close to the cell surface. The singlet-oxygen concentration at the cell surface was most influenced by biological molecules within the root-mean-square diffusion distance of singlet oxygen into the cell. Using the $(2 \mathrm{D} \tau)^{-1 / 2}$ to calculate the linear diffusion distance into the cytoplasm and assuming a singlet-oxygen lifetime of $1.0 \mu \mathrm{s}$, gave a value of $20 \mathrm{~nm}$. Thus, the singlet-oxygen lifetime measurements from this project reflected an average lifetime within a $20 \mathrm{~nm}$ band just below the cell surface. In conclusion, based on the results presented in this dissertation, the effects of deuterium-oxide solvent and various singlet-oxygen quenchers upon singletoxygen-mediated ACE inactivation and singlet-oxygen-mediated cell damage can be predicted by mathematical equations that model singlet-oxygen diffusion rates and lifetimes. 


\section{Photodynamic Therapy And Possible Mechanisms Of Action}

As stated earlier in the significance section of this dissertation, photosensitizerbased therapies have been under investigation for some time and several thousand patients have been treated under various protocols (47-54). In this final section, possible mechanisms by which photodynamic therapy initiates tumor eradication will be discussed. Also, the experimental results presented in this project will be used to gain some insight into the mechanisms of photosensitization.

Photodynamic treatment of tumors was pioneered in 1903 by von Tappenier and Jesionek (24). An unsuccessful attempt was made to treat skin cancers with topical and injected eosin dye, followed by exposure of the lesions to direct sunlight (24). These attempts became more successful, however, with the discovery of new photodynamic therapy (PDT) drugs and the development of strong artificial light sources (24). The first practical PDT drug was synthesized in 1959 by Lipson, based on suggestions by S. Schwartz (24). An aqueous solution of a porphyrin mixture, referred to as hematoporphyrin derivative (HPD), was found to localize in neoplastic tissues after intravenous administration (24). The uptake of HPD by tumors was identified by a characteristic red fluorescence and this HPD fluorescence has been used for tumor diagnosis and visualization since the 1960s (24). Hematoporphyrin derivative drugs, under the name "Photofrin" (PF) has been made available for research and clinical trials (24). Upon intravenous administration of PF, skin photosensitization develops and exposure to direct sunlight must be avoided for a variable period that averages about six 
weeks, but may extend for several months (24). The light treatment is carried out at 2448 hours post-injection and the treatment time depends on the light dose, drug dose, power output of the delivery fiber, tumor coloration and depth, and the method of light delivery (24). Typical treatment times vary from about one minute for a lesion on the order of a few millimeters in size to more than an hour for a large organ, such as the entire bladder wall (24). The observable tissue effects during or immediately after PDT include loss of coloration and ecchymosis (24). Necrosis and eschar formation progress over a two-three week period and tissue breakdown and healing require about six-eight weeks together (24).

As stated earlier in the significance section, the use of photosensitizers and bronchoscopic light delivery has produced long-term remissions in early-stage non-smallcell lung cancer (50). Photosensitizer-based treatment of some systemic t-cell lymphomas (Sezary syndrome) has now been approved in the United States (51). Recent studies with obstructing esophageal cancer has shown that photodynamic therapy produces more durable relief of esophageal obstruction and improved performance status of patients when compared to laser tissue ablation without the use of a photosensitizer (52). Also, protocols in a variety of other cancers and in the purging of bone marrow preparations of cancer cells prior to reinfusion in autologous bone marrow transplants are being evaluated $(53,54)$.

A high fraction of all tumors treated with PDT have shown at least a partial response (24). The statistics for long-term tumor eradication are highly variable. Various factors can limit the response to PDT, including heterogeneities in the light dose, drug distribution, and tumor photosensitivity (24). It may be possible to improve PDT 
efficacy by increasing the therapeutic ratio to enable a higher light dose (24). Experimental techniques directed to this objective include combined PDT and full-body or localized hyperthermia, protection of normal tissue with radioprotective agents, increasing the localized drug concentration by coupling to monoclonal antibodies, and increasing tumor oxygenation by light dose fractionation (24). The combination of porphyrin photosensitization with ultrasound is an interesting concept that has been found to increase lethality in cell cultures (94). This approach would have major implications for PDT, if it can be substantiated for photosensitizers localized in tumors, because the limitations on treatment depth imposed by light penetration would not apply (24). Another interesting observation is that the administration of glucose to mice immediately prior to drug administration and at subsequent intervals prior to light irradiation potentiated the tumor response (95). In this case, the reduction of intratumoral $\mathrm{pH}$ by hyperglycemia may be involved (24).

The mechanism by which PDT initiates tumor eradication has been the subject of intensive basic research and the current theories were developed by extrapolating information derived from photosensitization studies on photochemical systems, cell cultures, and animal tumor models (24). Indirect evidence indicates that the primary PDT reaction is a Type II photosensitization mediated by singlet oxygen (24). As stated earlier, light absorption excites a porphyrin molecule to the short-lived fluorescent state, which may relax by emission of fluorescence, radiationless decay, or internal conversion to the triplet state (24). Energy transfer from the triplet state to molecular oxygen generates singlet oxygen (24). A singlet-oxygen molecule can diffuse about $0.10 \mu \mathrm{m}$ during its lifetime in tissue, which limits the primary reactions to the initial localization 
sites (24). The putative mechanism of action of PDT involves initiation of lipid peroxidation in tumor tissue membranes (24). The cellular targets for lipophilic anionic dyes, such as the dye used in this project, include the plasma and intracellular membranes of cancer cells (24). The mitochondria and lysosomes have also been implicated as the major targets of PDT damage (97). Leakage of lactate dehydrogenase $(\mathrm{LDH})$, and the release of eicosanoids (prostaglandins and thromboxanes) and histamine are early cellular responses to PDT (24). These fast-acting vasoactive agents are implicated in the vascular damage component, which is accompanied by the induction of heat stress proteins (96).

Another possible mechanism by which PDT initiates tumor eradication is by apoptosis (98-100). Apoptosis or programmed cell death is a mode of physiological cell death characterized by the condensation of chromatin around the nuclear periphery and the cleavage of DNA into oligonucleosome-size fragments by an endogenous endonuclease (98). In addition to developmental processes, in which apoptosis appears to be a programmed event of tissue modeling, there are a large number of biological agents and cellular stresses that can cause apoptosis in susceptible cells (98). The induction of apoptosis by many agents is observed over time periods on the order of several hours to days and requires active transcription and translation, presumably to synthesize proteins needed for the control of apoptosis (98). It has been suggested that intracellular signaling pathways are involved in the initiation of apoptosis (98). Protein kinase $\mathrm{C}$ and cytosolic $\mathrm{Ca}^{2+}$ have been shown to be involved in the apoptotic death of thymocytes (98). However, at the time this paper was published, direct evidence for the participation of membrane phospholipases and their products, the second messenger 
molecules, had not yet been reported (98).

In contrast to most treatments inducing apoptosis, PDT of mouse L5178Y lymphoma cells with a phthalocyanine photosensitizer and visible light causes the rapid induction of apoptosis, with a $90 \%$ lethal dose producing extensive DNA fragmentation in as little as one hour (98). Moreover, there was no requirement for protein or RNA synthesis in PDT-induced apoptosis, indicating that the signals initiated by PDT activate an endogenous endonuclease in the absence of new gene expression (98). The study of the induction of apoptosis in previous studies by Agarwal et al. have now made it possible to show that the PDT treatment of mouse L5178Y lymphoma cells activates the membrane-localized enzymes phospholipase C (PLC) and phospholipase $A_{2}\left(P_{L} A_{2}\right)(98)$. The authors postulated that PDT activates PLC causing the release of $\mathrm{IP}_{3}$. This release of $\mathrm{IP}_{3}$ causes the release of intracellular $\mathrm{Ca}^{2+}$, which probably activates an endogenous endonuclease. This leads to the DNA fragmentation pattern that is characteristic of apoptosis. The release of intracellular $\mathrm{Ca}^{2+}$ can also activate $\mathrm{PLA}_{2}$, resulting in the release of arachidonic acid. The arachidonic acid would then enter the cyclooxygenasedependent pathway. The formation of oxidized lipids could then activate the endogenous endonuclease, leading to apoptosis. Interestingly, the authors found that the addition of PLC and PLA 2 inhibitors completely inhibited the apoptosis-associated DNA fragmentation. This evidence strongly suggests that activation of PLC and PLA are $_{2}$ involved in apoptosis of mouse lymphoma cells in vivo. Perhaps, the techniques employed by Agarwal et al. can be used to determine if photosensitization also activates PLC and PLA $\mathrm{P}_{2}$ in the K562 erythroleukemia cells.

As stated earlier, singlet oxygen is believed to be the major mediator of 
cytotoxicity in these photosensitizer-based therapies. Since cancer is the second leading cause of morbidity and mortality in the United States, an enhanced understanding of photosensitizer-based therapies should lead to improvements in these forms of cancer treatment and ultimately to better patient care. Perhaps, the use of a theoretical mathematical model derived from the known properties of singlet oxygen, as presented in this dissertation, can lead to unique insights into the mechanisms of photosensitization. Since this model was used with K562 erythroleukemia cells, other malignant cell lines can potentially be used in the same manner. If the theoretical mathematical model predicts a large singlet-oxygen lifetime in the cytoplasm and the cell membrane, the model can possibly be used to select conditions that optimize the selectivity of photosensitization reactions to kill malignant cells while sparing normal cells. 


\section{REFERENCES}

1. Kanofsky, J.R. Peroxidase-catalyzed generation of singlet oxygen and of free radicals. In: Peroxidases in Chemistry and Biology, edited by Everse J., Everse K. and Grisham M.B. Boca Raton, Florida: CRC Press, 1991, p. 219-237.

2. Kasha, M. Singlet oxygen electronic structure and energy transfer. In: Singlet $\mathrm{O}_{2}$, Vol 1, edited by Frimer A.A. Boca Raton, Florida: CRC Press, 1985, p. 1-11.

3. Matheson, I.B.C. and J. Lee. 1979. Chemical reaction rates of amino acids with singlet oxygen. Photochem. Photobiol. 29: 879-881.

4. Matheson, I.B.C., R.D. Etheridge, N.R. Kratowich and J. Lee. 1975. The quenching of singlet oxygen by amino acids and proteins. Photochem. Photobiol. 21: 165171.

5. Nilsson, R., P.B. Merkel and D.R. Kearns. 1972. Unambiguous evidence for the participation of singlet oxygen $\left({ }^{1} \Delta_{\mathrm{g}}\right)$ in photodynamic oxidation of amino acids. Photochem. Photobiol. 16: 117-124.

6. Kalyanaraman, B., J.B. Feix, F. Sieber, J.P. Thomas and A.W. Girotti. 1987. Photodynamic action of merocyanine 540 on artificial and natural cell membranes: 
Involvement of singlet molecular oxygen. Proc. Natl. Acad. Sci. USA. 84: 29993003.

7. Valenzeno, D.P., J. Trudgen, A. Hutzenbuhler and M. Milne. 1987. Singlet oxygen involvement in photohemolysis sensitized by merocyanine-540 and rose bengal. Photochem. Photobiol. 46: 985-990.

8. Merkel, P.B. and D.R. Kearns. 1972. Remarkable solvent effects on the lifetime of oxygen. J. Am. Chem. Soc. 94: 1029-1030.

9. Young, R.H., K. Wehrly and R.L. Martin. 1971. Solvent effects in dye-sensitized photooxidation reactions. J. Am. Chem. Soc. 93: 5774-5779.

10. Kanofsky, J.R., A. Baker and P. Sima. Singlet oxygen diffusion and quenching in studies of photooxidative damage to intact cells and to cell membranes. In: The Oxygen Paradox, edited by Davies K.J.A. and Ursini F. Padova, Italy: CLEUP University Press, 1995, p. 539-549.

11. Egorov, S.Y., V.F. Kamalov et al. 1989. Rise and decay kinetics of photosensitized singlet oxygen luminescence in water. Measurements with a nanosecond timecorrelated single photon counting technique. Chem. Phys. Lett. 163: 421-424.

12. Parker, J.G. and W.D. Stanbro. 1984. Optical determination of the rates of 
formation and decay of $\mathrm{O}_{2}\left({ }^{1} \Delta_{\mathrm{g}}\right)$ in $\mathrm{H}_{2} \mathrm{O}, \mathrm{D}_{2} \mathrm{O}$ and other solvents. J. Photochem. 25: $545-547$.

13. Kanofsky, J.R. 1991. Quenching of singlet oxygen by human red cell ghosts. Photochem. Photobiol. 53: 93-99.

14. Ito, T. 1978. Cellular and subcellular mechanisms of photodynamic action: The ${ }^{1} \mathrm{O}_{2}$ hypothesis as a driving force in recent research. Photochem. Photobiol. 28: 493508.

15. Roberts, W.L., B.H. Kim and T.L. Rosenberry. 1987. Differences in the glycolipid membrane anchors of bovine and human erythrocyte acetylcholinesterase. Proc. Natl. Acad. Sci. USA. 84: 7817-7821.

16. Toutant, J.P., W.L. Roberts, N.R. Murray and T.L. Rosenberry. 1989. Conversion of human erythrocyte acetylcholinesterase from an amphophilic to a hydrophilic form by phosphatidylinositol-specific phospholipase $\mathrm{C}$ and serum phospholipase D. Eur. J. Biochem. 180: 503-508.

17. Kochevar, I.E., J. Bouvier, M. Lynch and C.W. Lin. 1994. Influence of dye and protein location on photosensitization of the plasma membrane. Biochim. Biophys. Acta. 1196: 172-180. 
18. Allen, M.T., M. Lynch, A. Lagos, R.W. Redmond and I.E. Kochevar. 1991. A wavelength dependent mechanism for rose bengal-sensitized photoinhibition of red cell acetylcholinesterase. Biochim. Biophys. Acta. 1075: 42-49.

19. Bachowski, G.J., T.J. Pintar and A.W. Girotti. 1991. Photosensitized lipid peroxidation and enzyme inactivation by membrane-bound merocyanine 540 : Reaction mechanisms in the absence and presence of ascorbate. Photochem. Photobiol. 53: 481-491.

20. Lambert, C.R., H. Stiel, D. Leupold, M.C. Lynch and I.E. Kochevar. 1996. Intensity-dependent enzyme photosensitization using $532 \mathrm{~nm}$ nanosecond laser pulses. Photochem. Photobiol. 63: 154-160.

21. Baker, A. and J.R. Kanofsky. 1991. Direct observation of singlet oxygen phosphorescence at $1270 \mathrm{~nm}$ from L1210 leukemia cells exposed to polyporphyrin and light. Arch. Biochem. Biophys. 286: 70-75.

22. Baker, A. and J.R. Kanofsky. 1993. Time-resolved studies of singlet oxygen emission from L1210 leukemia cells labeled with 5-(N-hexadecanoyl)aminoeosin. A comparison with a one-dimensional model of singlet oxygen diffusion and quenching. Photochem. Photobiol. 57: 720-727.

23. Foote, C. 1968. Mechanisms of photosensitized oxidation. Science. 162: 963-970. 
24. Grossweiner, L.I. Photosensitization. In: The Science of Phototherapy, Boca Raton, Florida: CRC Press, 1994, p. 41-49.

25. Monroe, B.M. Singlet oxygen in solution: Lifetimes and reaction rate constants. In: Singlet $\mathrm{O}_{2}$, Vol 1, edited by Frimer A.A. Boca Raton, Florida: CRC Press, 1985 , p. $177-224$.

26. Lindig, B.A. and M.A.J. Rodgers. 1981. Rate parameters for the quenching of singlet oxygen by water-soluble and lipid-soluble substrates in aqueous and micellar systems. Photochem. Photobiol. 33: 627-634.

27. Korytowski, W., G.J. Bachowski and A.W. Girotti. 1993. Analysis of cholesterol and phospholipid hydroperoxides by high performance liquid chromatography with mercury drop electrochemical detection. Anal. Biochem. 213: 1-9.

28. Khan, A.U. and M. Kasha. 1979. Direct spectroscopic observation of singlet oxygen emission at $1268 \mathrm{~nm}$ excited by sensitizing dyes of biological interest in liquid solution. J. Am. Chem. Soc. 76: 6047-6049.

29. Rodgers, M.A.J. 1983. Time-resolved studies of $1.27 \mu \mathrm{m}$ luminescence from singlet oxygen generated in homogeneous and microheterogeneous fluids. Photochem. Photobiol. 37: 99-103. 
30. Krasnovsky, A.A., Jr. 1979. Photoluminescence of singlet oxygen in pigment solutions. Photochem. Photobiol. 29: 29-36.

31. Velan, B., H. Grosfeld, C. Kronman, M. Leitner et al. 1991. The effect of elimination of intersubunit disulfide bonds on the activity, assembly, and secretion of recombinant human acetylcholinesterase. J. Biol. Chem. 266: 23977-23984.

32. Massoulie, J. and S. Bon. 1982. The molecular forms of cholinesterase and acetylcholinesterase in vertebrates. Ann. Rev. Neurosci. 5: 57-106.

33. Chatonnet, A. and O. Lockridge. 1989. Comparison of butyrylcholinesterase and acetylcholinesterase. Biochem. J. 260: 625-634.

34. Silman, I. and A. Futerman. 1987. Modes of attachment of acetylcholinesterase to the surface membrane. Eur. J. Biochem. 170: 11-22.

35. Ott, P. 1985. Membrane acetylcholinesterases: Purification, molecular properties and interactions with amphiphilic environments. Biochimica et Biophysica Acta. 822: $375-392$.

36. Nachmansohn, D. and E. Neumann. In: Chemical and Molecular Basis of Nerve Activity, New York: Academic Press, 1975. 
37. Rosenberry, T. Acetylcholinesterase. In: Advances in Enzymology, edited by Meister A., New York: John Wiley and Sons, 1975, p. 103-218.

38. Quigley-MacPhee, K., P. Taylor and S. Taylor. 1985. Primary structures of the catalytic subunits from two molecular forms of acetylcholinesterase. J. Biol. Chem. 260: 12185-12189.

39. Sussman, J.L., M. Harel, F. Frolow, C. Oefner et al. 1991. Atomic structure of acetylcholinesterase from Torpedo californica: A prototypic acetylcholine-binding protein. Science. 253: 872-878.

40. Massoulie, J., J. Sussman, S. Bon and I. Silman. 1993. Structure and functions of acetylcholinesterase and butyryl cholinesterase. Progress in Brain Research. 98: 139-146.

41. Shinitzky, M., Y. Dudai and I. Silman. 1973. Spectral evidence for the presence of tryptophan in the binding site of acetylcholinesterase. Febs Letters. 30: 125-127.

42. Weise, C., H.J. Kreienkamp, R. Raba, A. Pedak et al. 1990. Anionic subsites of the acetylcholinesterase from Torpedo californica. EMBO J. 9: 3885-3888.

43. Shafferman, A., C. Kronman, Y. Flashner, M. Leitner et al. 1992. Mutagenesis of human acetylcholinesterase. J. Biol. Chem. 267: 17640-17648. 
44. Soreq, H., R. Ben-Aziz, C.A. Prody, S. Seidman et al. 1990. Molecular cloning and construction of the coding region for human acetylcholinesterase reveals a $\mathrm{G}+$ C-rich attenuating structure. Proc. Natl. Acad. Sci. USA. 87: 9688-9692.

45. Barak, D., N. Ariel, B. Velan and A. Shafferman. In: Multidisciplinary Approaches to Cholinesterase Function, edited by Shafferman A. and Velan B., Plenum, London, 1992. In Press.

46. Fluhler, E.N., J.K. Hurley and I.E. Kochevar. 1989. Laser intensity and wavelength dependence of rose-bengal-photosensitized inhibition of red blood cell acetylcholinesterase. Biochimica et Biophysica Acta. 990: 269-275.

47. Dougherty, T.J. 1993. Photodynamic therapy. Photochem. Photobiol. 58: 895-900.

48. Rosenthal, D.I. and E. Glatstein. 1994. Clinical applications of photodynamic therapy. Ann Med. 26: 405-409.

49. Pass, H.I. 1993. Photodynamic therapy in oncology: Mechanisms and clinical use. J. Natl. Cancer Inst. 85: 443-455.

50. Imamura, S., Y. Kusunaki, N. Takifuji et al. 1994. Photodynamic therapy and/or external beam radiation therapy for roentgenologically occult lung cancer: Cancer. 73: $1609-1614$. 
51. Edelson, R.I., C.I. Berger, F. Gasparro et al. 1987. Treatment of cutaneous T cell lymphoma by extracorporeal photochemotherapy: Preliminary results. $N$. Eng. J. Med. 316: 297-303.

52. Heier, S.K., K.A. Rothman, L.M. Heier and W.S. Rosenthal. 1995. Photodynamic therapy for obstructing esophageal cancer: Light dosimetry and randomized comparison with Nd:YAG laser therapy. Gastroenterol. 109: 63-72.

53. Sieber, F., J.L. Spivak and A.M. Sutcliffe. 1984. Selective killing of leukemia cells by merocyanine 540-mediated photosensitization. Proc. Natl. Acad. Sci. USA. 81: $7584-7587$.

54. Mulroney, C.M., S. Gluck and A.D. Ho. 1994. The use of photodynamic therapy in bone marrow purging. Sem. Oncol. 21(Suppl 6): 24-27.

55. Salomaa, P., L.L. Schaleger and F.A. Long. 1964. Solvent deuterium isotope effects on acid-base equilibria. J. Am. Chem. Soc. 86: 1-7.

56. Botsivali, M., D.F. Evans, P.H. Missen and M.W. Upton. 1985. Studies on singlet oxygen in aqueous solution. Part 2 . Water-soluble square planar nickel complexes as quenchers. J. Chem. Soc. Dalton Trans. 1147-1149.

57. Ellman, G.L., K.D. Courtney, V. Andres, Jr., and R.M. Featherstone. 1961. A new 
and rapid colorimetric determination of acetylcholinesterase activity. Biochem. Pharmacol. 7: 88-95.

58. Kanofsky, J.K. 1988. Singlet oxygen production from the peroxidase-catalyzed oxidation of indole-3-acetic acid. J. Biol. Chem. 263: 14171-14175.

59. Kanofsky, J.K. 1990. Quenching of singlet oxygen by human plasma. Photochem. Photobiol. 51: 299-303.

60. Baker, A. and J.K. Kanofsky. 1992. Quenching of singlet oxygen by biomolecules from L1210 leukemia cells. Photochem. Photobiol. 55: 523-528.

61. Tanielian, C., L. Golder and C. Wolff. 1984. Production and quenching of singlet oxygen by the sensitizer in dye-sensitized photo-oxygenations. J. Photochem. 25: $117-125$.

62. Schmidt, H. and P. Rosenkranz. 1976. On the mechanism of the acridine orange sensitized photodynamic inactivation of lysozyme. I. Basic kinetics. $Z$. Naturforsch. C:Biosci. 31C: 29-39.

63. Seely, G.R. 1977. Mechanisms of the photosensitized oxidation of tyramine. Photochem. Photobiol. 26: 115-123. 
64. Gupta, A.K. and K.K. Rohatgi-Murherjee. 1978. Solvent effect on photosensitized oxidation of iodide ion by anthracene sulphonates. Photochem. Photobiol. 27: 539-543.

65. Usui, Y., M. Tsukada and H. Nakamura. 1978. Kinetic studies of photosensitized oxygenation by singlet oxygen in aqueous micellar solutions. Bull. Chem. Soc. Jpn. 51: $379-384$.

66. Harbour, J.R., S.L. Issler and M.L. Hair. 1980. Singlet oxygen and spin trapping with nitrones. J. Am. Chem. Soc. 102: 7778-7779.

67. Haag, W.R. and T. Mill. 1987. Rate constants for interaction of ${ }^{1} \mathrm{O}_{2}\left({ }^{1} \Delta_{\mathrm{g}}\right)$ with azide ion in water. Photochem. Photobiol. 45: 317-321.

68. Wessels, J.M. and M.A.J. Rodgers. 1995. Detection of the $\mathrm{O}_{2}\left({ }^{1} \Delta_{\mathrm{g}}\right) \rightarrow \mathrm{O}_{2}\left({ }^{3} \mathrm{\Sigma} \mathrm{g}\right)$ transition in aqueous environments: A Fourier-transform near-infrared luminescence study. J. Phys. Chem. 99: 15725-15727.

69. Hall, R.D. and C.F. Chignell. 1987. Steady-state near-infrared detection of singlet molecular oxygen: A Stern-Volmer quenching experiment with sodium azide. Photochem. Photobiol. 45: 459-464.

70. Devasagayam, T.P.A., A.R. Sundquist, P. DiMascio, S. Kaiser and H. Sies. 1991. 
Activity of thiols as singlet molecular oxygen quenchers. J. Photochem. Photobiol. B. Biol. 9: 105-116.

71. Rougee, M., R.V. Bensasson, E.J. Land and R. Pariente. 1988. Deactivation of singlet molecular oxygen by thiols and related compounds, possible protectors against skin photosensitivity. Photochem. Photobiol. 47: 485-489.

72. Michaeli, A. and J. Feitelson. 1994. Reactivity of singlet oxygen toward amino acids and peptides. Photochem. Photobiol. 59: 284-289.

73. Hine J. Physical Organic Chemistry, Second Ed., New York: McGraw-Hill Book Co., 1962, p. 71-73 and 120-121.

74. Barr R.D., M. Koekebakker and A.A. Lawson. 1988. Acetylcholinesterase in the human erythron. II. Biochemical assay. Am. J. Hematol. 28: 260-5.

75. Rosenberry, T.I. and D.M. Scoggin. 1984. Structure of human erythrocyte acetylcholinesterase. Characterization of intersubunit disulfide bonding and detergent interaction. J. Biol. Chem. 259: 5643-5652.

76. Dragsten P.R., R. Blumenthal and J.S. Handler. 1981. Membrane asymmetry in epithelia: Is the tight junction a barrier to diffusion in the plasma membrane? Nature. 294: 718-722. 
77. Pooler J.P. 1989. Photooxidation of cell membranes using eosin derivatives that locate in lipid or protein to study the role of diffusible intermediates. Photochem. Photobiol. 50: 55-68.

78. Moan J. and K. Berg. 1991. The photodegradation of porphyrins in cells can be used to estimate the lifetime of singlet oxygen. Photochem. Photobiol. 53: 549-553.

79. Fu, Y., and J.R. Kanofsky. 1995. Singlet-oxygen generation from liposomes: A comparison of time-resolved $1270 \mathrm{~nm}$ emission with singlet-oxygen kinetics calculated from a one dimensional model of single-oxygen diffusion and quenching. Photochem. Photobiol. 62: 692-702.

80. Fu, Y., P.D. Sima and J.R. Kanofsky. 1996. Singlet-oxygen generation from liposomes: A comparison of $6 \beta$-cholesterol hydroperoxide formation with predictions from a one-dimensional model of singlet-oxygen diffusion and quenching. Photochem. Photobiol. 63: 468-476.

81. Kanofsky, J.R. and P.D. Sima. 1994. Singlet oxygen chemiluminescence at gasliquid interfaces: Theoretical analysis with a one-dimensional model of singlet oxygen quenching and diffusion. Arch. Biochem. Biophys. 312: 244-253.

82. Ogilby, P.R., and C.S. Foote. 1982. Chemistry of singlet oxygen. 36. Singlet molecular oxygen $\left({ }^{1} \Delta_{g}\right)$ luminescence in solution following pulsed laser 
excitation. Solvent deuterium isotope effects on the lifetime of singlet oxygen. J. Am. Chem. Soc. 104: 2069-2070.

83. St-Denis, C.E., and C.J.D. Fell. 1971. Diffusivity of oxygen in water. Can. J. Chem. Eng. 49: 885.

84. Fischkoff, S. and J.M. Vanderkoii. 1975. Oxygen diffusion in biological and artificial membranes determined by the fluorochrome pyrene. J. Gen. Physiol. 65: 663-676.

85. O'Loughlin, M.A., D.W. Whillans and J.W. Hunt. 1980. A fluorescence approach to testing the diffusion of oxygen into mammalian cells. Radiat. Res. 84: 477495.

86. Bougnoux, P., N. Salem, C. Lyons and T. Hoffman. 1985. Alteration in the membrane fatty acid composition of human lymphocytes and cultured transformed cells induced by interferon. Molec. Immunol. 22: 1107-1113.

87. Cornell, B.A. and F. Separovic. 1983. Membrane thickness and acyl chain length. Biochim. Biophys. Acta 733: 189-193.

88. Subczynski, W.K., J.S. Hyde and A. Kusumi. 1989. Oxygen permeability of phosphatidylcholine-cholesterol membranes. Proc. Natl. Acad. Sci. USA. 86: 
4474-4478.

89. Klein E., H. Ben-Bassat, H. Neumann, P. Ralph, et al. 1976. Properties of the K562 cell line, derived from a patient with chronic myeloid leukemia. Int. J. Cancer. 18: $421-431$.

90. Crank J. The Mathematics of Diffusion, Oxford: Oxford University Press, 1975.

91. Silvestro, L., I. Viano, G. Compagnoni, M.L. Soffiantino et al. 1988. Drug sensitivity tests after cell separation on density gradients. Anticancer Res. 8: 119124.

92. Boyle, R.W. and D. Dolphin. 1996. Structure and biodistribution relationships of photodynamic sensitizers. Photochem. Photobiol. 64: 469-485.

93. Foote, C.S., T.T. Fujimoto and Y.C. Chang. 1972. Chemistry of singlet oxygen $\mathrm{XV}$. Irrelevance of azide trapping to mechanism of the ene reaction. Tetrahedron Lett. 45.

94. Kessel, D., R. Jeffers and C. Cain. 1992. Promotion of porphyrin cytotoxicity by ultrasound. SPIE-Int. Soc. Opt. Eng. 1645: 82.

95. Nelson, J.S., S. Kime, L. Brown and M.W. Berns. 1992. Glucose administration 
combined with photodynamic therapy of cancer improves therapeutic efficacy. Lasers Surg. Med. 12: 153.

96. Gomer, C.J., A. Ferrario and N. Rucker. Examination of in vitro and in vivo photodamage induced by photodynamic therapy. In: Photodynamic Therapy of Neoplastic Disease, Vol. I, edited by Kessel D., Florida: CRC Press, 1990, chap. 11.

97. Hilf, R., R.S. Murrant, U. Narayanan and S.L. Gibson. 1986. Relationship of mitochondrial fraction of cellular adenosine triphosphate levels to hematoporphyrin derivative-induced photosensitization in R3230AC mammary tumors. Cancer Res. 46: 211-217.

98. Agarwal, M.L., H.E. Larkin, S.I.A. Zaidi, H. Mukhtar and N.L. Oleinick. 1993. Phospholipase activation triggers apoptosis in photosensitized mouse lymphoma cells. Cancer Res. 53: 5897-5902.

99. Luo, Y., C.K. Chang and D. Kessel. 1996. Rapid initiation of apoptosis by photodynamic therapy. Photochem. Photobiol. 63: 528-534.

100. Agarwal, R., N.J. Korman, R.R. Mohan, D.K. Feyes, S. Jawed, M.T. Zaim and H. Mukhtar. 1996. Apoptosis is an early event during phthalocyanine photodynamic therapy-induced ablation of chemically induced squamous 
papillomas in mouse skin. Photochem. Photobiol. 63: 547-552. 


\section{VITA}

The author, Gail Denise Deadwyler, was born in Chicago, Illinois on August $18,1969$.

In August, 1987, Ms. Deadwyler entered Southern Illinois University at Carbondale, receiving the degree of Bachelor of Arts in Chemistry in May 1992.

In August, 1992, Ms. Deadwyler entered the Department of Molecular and Cellular Biochemistry at Loyola University of Chicago, enabling her to complete the Doctorate of Philosophy in January, 1997.

In August, 1997, Ms. Deadwyler will attend the University of Iowa College of Medicine, Class of 2001. 


\section{APPROVAL SHEET}

The dissertation submitted by Gail D. Deadwyler has been read and approved by the following committee:

Jeffrey Kanofsky, M.D., Ph.D., Director

Professor, Medicine and Molecular and Cellular Biochemistry

Loyola University Chicago

Richard Schultz, Ph.D.

Professor, Molecular and Cellular Biochemistry

Loyola University Chicago

Allen Frankfater, Ph.D.

Professor, Molecular and Cellular Biochemistry

Loyola University Chicago

Robert Wurster, Ph.D.

Professor, Physiology

Loyola University Chicago

Ronald Belusko, M.D., Ph.D.

Associate Professor, Anesthesiology

Loyola University Chicago

The final copies have been examined by the director of the dissertation and the signature which appears below verifies the fact that any necessary changes have been incorporated and that the dissertation is now given final approval by the committee with reference to content and form.

The dissertation is, therefore, accepted in partial fulfillment of the requirements for the degree of Ph.D.

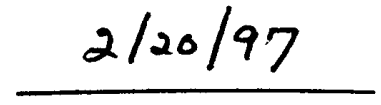

Date

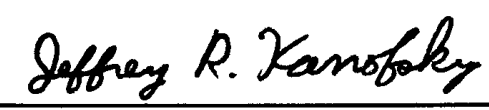

Director's Signature 